Annuaire suisse de politique de développement

16 | 1997

Environnement et développement, 5 ans après Rio

\title{
2. Négociations internationales
}

\section{(2) OpenEdition}

1 Journals

Édition électronique

URL : http://journals.openedition.org/aspd/788

DOI : 10.4000/aspd.788

ISSN : 1663-9669

Éditeur

Institut de hautes études internationales et du développement

\section{Édition imprimée}

Date de publication : 1 mars 1997

Pagination : 13-92

ISSN : 1660-5934

\section{Référence électronique}

«2. Négociations internationales », Annuaire suisse de politique de développement [En ligne], 16 | 1997, mis en ligne le 07 août 2012, consulté le 08 septembre 2020. URL : http://journals.openedition.org/ aspd/788 ; DOl : https://doi.org/10.4000/aspd.788 


\section{NÉGOCIATIONS INTERNATIONALES}

\section{RELATIONS FINANCIÈRES INTERNATIONALES}

\subsection{FLUX FINANCIERS VERS LES PAYS EN DÉVELOPPEMENT}

Les flux de capitaux à destination des pays en développement - comprenant des apports de fonds privés et publics - ont globalement augmenté de façon régulière ces dernières années. L'aide publique au développement plafonne depuis 1990 à environ 60 milliards de dollars, tandis que les afflux du secteur privé ont marqué ces deux dernières années une forte croissance pour arriver à un total de 170 milliards de dollars en 1995. Cependant, le volume de ces apports varie dans des proportions appréciables selon les définitions et les méthodes statistiques adoptées par les sources d'informations. Il y a différentes manières de mesurer les flux financiers Nord-Sud. Les principales institutions concernées sont l'OCDE, le FMI et la Banque mondiale, ainsi que la Banque des règlements internatio$\operatorname{naux}(B R I)$.

Ces quatre institutions collectent leurs données en fonction d'un mandat spécifique et des relations qu' elles entretiennent avec leurs membres.

- L'OCDE' se fonde sur le point de vue "pays donateur". Ses statistiques sont basées sur les données fournies par les pays membres dans le cadre des systèmes de notification du CAD ${ }^{2}$, dont le système de notification des pays créanciers (SNPC) fait partie. L'OCDE s'appuie également sur les rapports d'activité de la Banque des règlements internationaux pour déterminer les flux financiers du secteur privé.

- La Banque mondiale adopte la perspective des "pays bénéficiaires », et reprend les flux financiers que lui indiquent les rapports présentés par ces pays (système de notification des pays débiteurs - SNPD). Elle dresse une statistique de l'endettement par pays, exposée dans ses World Debt Tables.

$\checkmark$ Les statistiques du FMI se basent sur les données relatives à la balance des paiements de ses membres. Banque mondiale et FMI constituent une organisation vraiment planétaire, qui regroupe 181 pays.

$\checkmark$ La BRI dresse une statistique bancaire détaillée des pays qui lui soumettent des comptes rendus à ce sujet, et la commente régulièrement dans son Rapport annuel. Les membres et actionnaires de la BRI sont les banques centrales de 41 pays. En 1996, neuf nouveaux membres ont été admis en son sein : Russie, Chine, Hongkong, Singapour, Inde, Corée du Sud, Arabie saoudite, Mexique, Brésil. Cette extension d'une institution traditionnellement centrée sur l'Europe ouvre celle-ci vers les pays nouvellement industrialisés d'Asie et d'Amérique latine. La Banque suit ainsi la globalisation des marchés financiers.

Ces dernières années, les différents systèmes de notification en vigueur ont été étendus aux pays d'Europe orientale et de l'ex-Union soviétique - ce qui n'est pas fait pour réduire les disparités et les incertitudes statistiques.

I En 1996, l'OCDE comprenait l'Union européenne et 26 pays, dont 21 font partie de son Comité d'aide au développement (CAD).

2 Le CAD compte 22 membres au total, soit 21 Etats et l'Union européenne. 
L'OCDE et la Banque mondiale présentent des divergences statistiques notamment dans les domaines suivants :

- Les entités géographiques auxquelles se réfèrent les deux institutions ne coïncident pas (l'OCDE couvre une étendue plus vaste que la Banque mondiale).

$\checkmark$ L'OCDE enregistre les prêts bancaires à court terme ainsi que les fonds destinés à l'assistance technique sous forme de dons, deux éléments non retenus par la Banque mondiale. Celle-ci fait valoir que les dons de l'assistance technique n'entrent pas dans la balance des paiements, et n'apparaissent donc pas dans les flux financiers. De son côté, l'OCDE inclut ces fonds dans son total des flux financiers en observant que cet argent représente une source de financement pour le pays bénéficiaire.

$\checkmark$ Données sur les investissements directs : la Banque mondiale reprend tels quels les investissements indiqués par le pays bénéficiaire dans sa balance des paiements ; ces chiffres englobent donc les investissements directs entre pays en développement. Ceux de l'OCDE comprennent exclusivement les investissements directs des pays membres de cette organisation.

OCDE, Banque mondiale, FMI et BRI ont constitué un groupe de travail commun chargé d'effectuer des consultations régulières sur les différentes manières de concevoir la statistique des flux financiers. Ces quatre institutions exposent, dans une publication commune, les modèles statistiques qu'elles ont adoptés pour collecter les données relatives à la balance des paiements, à l'endettement et aux flux financiers. ${ }^{3}$ Ce groupe étudie aussi la question de savoir comment mieux saisir à l'avenir les investissements directs et de portefeuille étrangers. En 1995, ces deux catégories d'investissements représentaient ensemble plus de deux tiers des flux financiers nets vers les pays en développement.

Le tableau 5 reproduit les données de l'OCDE concernant la composition des apports financiers aux pays en développement.

\section{$\square$ Plafonnement du financement public}

Les flux de capitaux d'origine publique servent essentiellement à financer le développement des pays à faibles revenus, où les capitaux privés ne s'aventurent guère. L'aide publique au développement a peu progressé ces dernières années ; elle atteignait environ 60 milliards de francs en 1995. Avec les autres modes de financement public, le flux global des fonds publics destinés au développement plafonne à 70 milliards de dollars depuis 1990. En 1995, cet apport global est même retombé à la moyenne la plus basse de 0,27\% du PIB (OCDE) enregistrée en 1970. Cette année-là, les membres de l'ONU avaient convenu de se donner pour objectif de consacrer $0,7 \%$ de leur PIB à des dépenses publiques en faveur du développement.

Il y a régression de la part relative de PNB consacrée à l'aide publique aux pays les moins avancés (PMA). En 1994, cette part ne représentait pas plus de 0,07\% du PNB des pays du CAD alors qu'elle était encore de 0,09\% en 1990 ; elle était ainsi tombée au-dessous de la moitié des 0,15\% qui avaient été fixés en 1990 à la Conférence de Paris sur les PMA. La Banque mondiale appelle les pays donateurs à renverser cette tendance fatale aux pays les plus pauvres.

${ }^{3}$ Encours de la dette, flux et balance des paiements : OCDE/Banque mondiale/FMI/BRI, OCDE, 1994. 
Tableau $n^{\circ} 5$

Flux de capitaux nets à destination des pays en développement, 1992-1995, OCDE (en milliards de dollars courants)

\begin{tabular}{lrrr}
\hline & $\mathbf{1 9 9 3}$ & $\mathbf{1 9 9 4}$ & $\mathbf{1 9 9 5}$ \\
\hline I. Financement public du développement (FPD) & $\mathbf{7 0 . 1}$ & $\mathbf{7 1 . 6}$ & $\mathbf{6 9 . 4}$ \\
\hline 1. Aide publique au développement (APD) & 56.4 & 60.5 & 60.1 \\
dont : Versements bilatéraux & 39.6 & 41.3 & 40.6 \\
$\quad$ Versements multilatéraux & 16.8 & 19.2 & 19.5 \\
\hline 2. Autres FPD & 13.7 & 11. & 9.3 \\
dont : Versements bilatéraux & 6.4 & 7.5 & 5.0 \\
$\quad$ Versements multilatéraux & 7.3 & 3.6 & 4.3 \\
\hline II. Total des crédits à l'exportation & $\mathbf{- 0 . 6}$ & $\mathbf{9 . 3}$ & $\mathbf{1 1 . 0}$ \\
\hline III. Apports privés & $\mathbf{8 6 . 4}$ & $\mathbf{1 3 4 . 1}$ & $\mathbf{1 5 8 . 9}$ \\
\hline 1. Investissements directs (OCDE) & 38.6 & 48.5 & $\mathbf{5 3 . 6}$ \\
2. Prêts bancaires internationaux (b) & 9.0 & 42.6 & $\mathbf{7 0 . 0}$ \\
3. Total des prêts obligataires & 29.0 & 29.0 & 19.3 \\
4. Autres apports privés & 4.0 & 8,0 & 10.0 \\
5. Dons ONG & 5.8 & 6.0 & 6.2 \\
\hline Total des apports nets de ressources & $\mathbf{1 5 5 . 9}$ & $\mathbf{2 1 5 . 0}$ & $\mathbf{2 3 9 . 3}$ \\
\hline a. A l'exclusion des prêts obligataires consentis par les banques, qui figurent à la rubrique \\
III.3, et les crédits financiers garantis, qui sont inclus dans la rubrique II. & \\
\hline
\end{tabular}

Source : OCDE, Rapport du CAD 1996.

L'aide publique au développement se répartit, selon les données de la Banque mondiale, de la manière suivante : $36 \%$ vers l'Afrique noire, $16 \%$ vers l'Europe et l'Asie centrale, $13 \%$ vers l'Asie du Sud, $13 \%$ vers l'Asie orientale, $13 \%$ vers l'Afrique du Nord et le Proche-Orient, $8 \%$ vers l'Amérique latine. ${ }^{4}$

Cette diminution des fonds publics affectés au développement s'explique par la récession persistante - assortie de lourds déficits budgétaires - dans les pays industrialisés. On évoque également une lassitude générale (aid fatigue) et du désenchantement face à la médiocre efficacité de l'aide. ${ }^{5}$ Les Etats-Unis - autrefois premier bailleur de fonds publics en chiffres absolus - ont réduit leur aide de $25 \%$, ce qui la ramène à 7,3 milliards de dollars pour 1995. C'est le Japon qui est devenu la plus importante source de financement : 14,5 milliards de dollars en 1995. La France et l'Allemagne ont également dépassé les USA, avec, respectivement, 8,4 et 7,5 milliards de dollars. En 1995, la Suisse a dépensé pour la coopération au développement 1,084 milliard de dollars en valeur nominale (925 millions à prix constants), alors que le montant déboursé en 1994 était de 982 millions de dollars. Cela représente, selon l'OCDE, un important recul de $6 \%$ en valeur réelle.

\footnotetext{
${ }^{4}$ Cf. Rapport annuel 1996 de la Banque mondiale.

Commentaire sur les chiffres provisoires de l'OCDE pour 1995, Neue Zürcher Zeitung du 18. Juni 1996.
} 


\section{$\square$ Boom des flux financiers du secteur privé}

Les flux financiers privés comprennent les investissements directs, les crédits bancaires internationaux, les emprunts internationaux, ainsi que d'autres prestations d'aide et le travail de développement des organisations privées d'entraide. Ces flux de capitaux privés ont atteint un nouveau record qui se chiffre à 159 milliards de dollars et représente deux tiers du total des apports financiers à destination des pays en développement. Cette dynamique procède d'une expansion de nombreuses entreprises des pays industrialisés qui investissent à l'étranger dans le but d'améliorer leur compétitivité internationale.

Les mouvements de capitaux privés se concentrent sur les marchés intéressants des pays en développement dont l'économie est en train de décoller. Les douze principaux pays destinataires absorbent quatre cinquièmes de ces flux financiers.

Les investissements directs, les crédits bancaires et les emprunts internationaux subissent des fluctuations cycliques de grande amplitude, en fonction de la conjoncture qui règne dans le pays considéré. L'accroissement des investissements directs - la Banque mondiale chiffre ceux-ci, pour l'année 1995, à 90 milliards de dollars (avec les investissements à l'étranger des pays en développement), et l'OCDE, à 54 milliards (investissements de ses membres uniquement) - constitue un nouveau record. Les crédits bancaires, à court terme surtout, ont aussi marqué une forte progression ces deux dernières années, pour atteindre le montant record de 70 milliards de dollars.

L'aide privée au développement se maintient depuis quelques années à un niveau constant d'environ 6 milliards de dollars.

\section{$\square$ La crise mexicaine}

Une crise financière aiguë a frappé le Mexique à la fin de 1994. Le haut niveau de la demande de biens de consommation et d'investissement, en dépit de taux d'intérêt élevés, faisait contraste avec la baisse des salaires et l'accroissement du chômage. Les investisseurs ont perdu confiance, d'où une hémorragie de capitaux, mexicains, notamment - qui, combinée au lourd endettement du pays, a déclenché une crise de trésorerie et le début d'une phase de récession. Un soutien massif de la part des Etats-Unis et du FMI a aidé le Mexique à maîtriser relativement vite cette crise aiguë. D'importants mouvements de capitaux internationaux ont repris dès le second semestre 1995 le chemin du Mexique et d'autres pays latino-américains, surtout le Brésil et le Chili, mais aussi l'Argentine et la Colombie. La BRI y voit le signe d'une confiance retrouvée des investisseurs dans la politique de stabilisation menée par ces pays. La BRI constate dans son rapport annuel que la crise mexicaine n'a que brièvement freiné la dynamique des flux financiers privés.

Une politique financière rigoureuse et des taux d'intérêt élevés dans les pays en développement dynamiques d'une part, la conjoncture et les taux d'intérêt médiocres qui prévalaient dans les pays industrialisés d'autre part, sont à l'origine des importants flux financiers, y compris d'importants retours de capitaux, à destination des pays en développement, selon l'analyse de la BRI. ${ }^{6}$

${ }^{6}$ Banque des règlements internationaux, 66 Rapport annuel, Bâle : BRI juin 1996, chapitre VII. 
Pour l' Europe orientale et la CEI, les investissements directs d'origine étrangère se concentrent sur la Hongrie (13,3 milliards de dollars à fin 1995), la Pologne $(6,8)$ et la République tchèque $(5,9)$; ensuite seulement vient la Russie avec 3,9 milliards de dollars d'investissements directs en 1995 (indications fournies par le Wiener Institut für Internationale Wirtschaftsvergleiche).

Alors que les chiffres varient d'une institution à l'autre quant au volume indiqué pour les investissements directs, ceux-ci marquent une nette tendance à la hausse depuis le début des années 1990. Face à la globalisation des activités de production et à la libéralisation des mouvements de capitaux qui l'accompagne, les établissements financiers prévoient que ces investissements directs vont encore augmenter dans les années à venir. Eléments à l'appui de cette thèse : globalisation rapide de la production, intégration croissante des pays en développement dans le commerce mondial, améliorations de la politique économique des pays en développement en faveur du secteur privé. Il convient toutefois de relativiser une vision trop globalement euphorique de la situation : les apports de capitaux privés, et en particulier les investissements directs, continuent de se focaliser sur un nombre restreint de pays. Quatre cinquièmes de ces investissements se sont concentrés sur douze pays (Chine, Mexique, Brésil, Corée, Malaysia, Argentine, Indonésie, Thaïlande, Russie, Inde, Turquie, Hongrie). Rien que la Chine en a absorbé plus de deux cinquièmes, soit 38 milliards de dollars d'investissements étrangers.

\section{$\square$ Rapport sur les investissements dans le monde}

La CNUCED publie chaque année un rapport sur l'évolution des investissements (World Investment Report). Selon ce document, le flux des investissements internationaux totalisait en valeurs nominales 208 milliards de dollars en 1993, 226 milliards en 1994 et 315 milliards en 1995. Les pays en développement ont absorbé 37\% de ces investissements en 1994, part qui a progressé à $40 \%$ en 1995 - ce qui représente un montant de 100 milliards de dollars.

Tableau $n^{\circ} 6$

Investissements internationaux de 1993 à 1995

\begin{tabular}{lccr}
\hline (en milliards de dollars) & $\mathbf{1 9 9 3}$ & $\mathbf{1 9 9 4}$ & $\mathbf{1 9 9 5}$ \\
\hline Pays industrialisés & & & \\
\hline - entrées & 129.3 & 132.8 & 203.2 \\
- sorties & 192.4 & 190.9 & 270.5 \\
\hline Pays en développement & & & \\
\hline - entrées & 73.1 & 87.0 & 99.7 \\
- sorties & 33.0 & 38.6 & 47.0 \\
\hline Europe de l'Est & & & \\
\hline - entrées & 5.59 & 5.89 & 12.08 \\
- sorties & 0.20 & 0.55 & 0.30 \\
\hline Tous les pays & & & \\
\hline - entrées & $\mathbf{2 0 7 . 9}$ & $\mathbf{2 2 5 . 7}$ & $\mathbf{3 1 4 . 9}$ \\
- sorties & $\mathbf{2 2 5 . 5}$ & $\mathbf{2 3 0 . 0}$ & $\mathbf{3 1 7 . 8}$ \\
\hline
\end{tabular}

Source : CNUCED, Rapport 1996 sur les investissements dans le monde. 
Le rapport de 1995 analyse le rôle joué par les sociétés transnationales et par la concurrence pour les investissements. La CNUCED évalue le total des transnationales dans le monde à $40^{\prime} 000$ sociétés-mères et $250^{\prime} 000$ filiales étrangères. Ce sont les Etats-Unis qui investissent le plus à l'étranger (23\% en 1994); la Chine est le pays en développement qui attire le plus d'investissements (40\% en 1994). L'Afrique reste dans l'ensemble peu intéressante pour les investisseurs, qui n'ont injecté que 3 milliards de dollars dans ce continent. Les pays subsahariens ont attiré à peine 1,8 milliard de dollars en 1994, à égalité avec la Nouvelle-Zélande. Les investissements ont totalisé 1,3 milliard de dollars en Afrique du Nord, comme au Portugal. La CNUCED relève l'existence d'un potentiel inexploité sur le continent africain : selon cette organisation, des enquêtes auprès de filiales américaines en Afrique indiqueraient une rentabilité supérieure à celle de sociétés travaillant dans d'autres régions en développement.

Le Rapport de 1996 sur les investissements dans le monde analyse le rapport entre commerce et investissements. Ces deux aspects sont étroitement liés : les investissements se dirigent sur les marchés où le commerce est dynamique, et inversement. La globalisation des relations ne concerne pas l'ensemble des pays du monde, mais se concentre sur les régions dont l'économie bouge. Les pays les moins avancés restent exclus de cette "globalisation", laquelle confirme ainsi leur marginalité.

Les quelque 100 milliards de dollars que totalisent les investissements directs étrangers (tableau 6) sont devenus la plus forte composante des apports de capitaux privés dans les pays en développement (54\%).

Les entreprises helvétiques comptent parmi les acteurs économiques de l'OCDE qui investissent le plus à l'étranger ; la Suisse détient en effet la palme pour ce qui est du niveau d'investissements à l'étranger par habitant. Cumulé de 1983 à 1994, le total des investissements suisses à l'étranger atteint 64 milliards de dollars - dont plus de $80 \%$ sont allés vers les pays de l'OCDE, 13,9\% vers l'Amérique latine, et $4,2 \%$ à destination de l'Asie.

Le besoin de protéger les investissements privés a suscité un réseau dense de plus de 900 accords bilatéraux entre 150 pays, surtout entre nations industrialisées et pays en développement. La Suisse a conclu plus de 70 accords de ce genre, lesquels se sont brusquement multipliés au cours des années 1990. Pas moins de 299 accords de protection des investissements ont été conclus dans le monde entre janvier 1994 et juin 1995. Le temps semble être venu où la communauté internationale doit se donner des règles multilatérales dans le domaine des investissements, comme elle l'a fait pour celui du commerce.

Des efforts ont été entrepris au sein de l'OCDE en vue d'élaborer un accord multilatéral sur les investissements. Les travaux préparatoires donnent lieu à une consultation de pays non membres, en particulier des « économies dynamiques » qui attirent le plus d'investissements. L'adoption d'un accord multilatéral sur la protection des investissements est prévue pour 1997 ; des pays non membres de l'OCDE pourront y adhérer. 


\subsection{ENDETTEMENT EXTÉRIEUR}

Selon les indications fournies par la Banque mondiale, la dette extérieure des pays en développement totalisait 2068 milliards de dollars en 1995, ce qui représente une augmentation de $8 \%$ par rapport à l'année précédente. Le tableau 7 en donne la composition et l'évolution depuis 1992.

\section{Tableau $\mathbf{n}^{\circ} 7$}

\begin{tabular}{lcccr}
\hline \multicolumn{4}{l}{. Endettement extérieur ${ }^{1}$ des pays en développement (en milliards de dollars) } \\
\hline Endettement à long terme & $\mathbf{1 9 9 2}$ & $\mathbf{1 9 9 3}$ & $\mathbf{1 9 9 4}$ & $\mathbf{1 9 9 5}^{1}$ \\
\hline - de source publique & 1305 & 1391 & 1523 & 1622 \\
\hline \multicolumn{1}{c}{ (bilatéral et multilatéral) } & 674 & 726 & 791 & 837 \\
\hline- de source privée & 631 & 665 & 731 & 786 \\
\hline Endettement à court terme & 323 & 345 & 335 & 385 \\
\hline Crédits du FMI & 38 & 40 & 44 & 61 \\
\hline Endettement cumulé & $\mathbf{1 6 6 7}$ & $\mathbf{1 7 7 6}$ & $\mathbf{1 9 2 1}$ & $\mathbf{2 0 6 8}$ \\
\hline
\end{tabular}

\begin{tabular}{lcrrr}
\hline II. Endettement (en pour-cent) & \multicolumn{3}{c}{} \\
\hline & \multicolumn{2}{c}{$\begin{array}{l}\text { Dette/ Recettes } \\
\text { d'exportation }\end{array}$} & \multicolumn{2}{c}{$\begin{array}{c}\text { Service de la dette/ } \\
\text { Recettes d'exportation }\end{array}$} \\
\hline Pays en développement : & $\mathbf{1 9 9 4}$ & $\mathbf{1 9 9 5}^{2}$ & $\mathbf{1 9 9 4}$ & $\mathbf{1 9 9 5}^{\mathbf{2}}$ \\
\hline - très endettés & 162.8 & 150.0 & 16.6 & 16.3 \\
\hline - moyennement endettés & 332.2 & 323.2 & 26.5 & 29.2 \\
\hline - autres & 209.3 & 199.1 & 24.4 & 24.4 \\
\hline
\end{tabular}

\begin{tabular}{lrrrr}
\hline III. Endettement par régions (en pour-cent) & & & \\
\hline Sud-Sahara, Afrique & 265.7 & 269.8 & 14.0 & 14.7 \\
\hline Asie de l'Est et Pacifique & 93.3 & 83.3 & 12.0 & 10.7 \\
\hline Asie du Sud & 271.6 & 245.7 & 25.6 & 24.9 \\
\hline Europe et Asie centrale & 153.7 & 144.6 & 14.6 & 15.4 \\
\hline Amérique latine et Caraïbes & 258.6 & 254.2 & 27.5 & 30.3 \\
\hline Moyen-Orient et Afrique du Nord & 148.5 & 136.9 & 15.4 & 13.7 \\
\hline Régions pauvres fortement endettées & 531.8 & 561.3 & 18.2 & 23.8 \\
\hline
\end{tabular}

1) La Banque mondiale indique dans les World Debt Tables l'endettement des pays sur base de leurs rapports à la Banque.

2) Chiffres provisoires.

Source : Banque mondiale, World Debt Tables 94-95, 1996. 
Une caractéristique importante du niveau d'endettement extérieur est le ratio d'endettement, c'est-à-dire le rapport entre la dette et les recettes d'exportation. Sa moyenne s'est améliorée, passant de $163 \%$ en 1994 à $150 \%$ pour l'année sous revue. Cette valeur globale doit, elle aussi, être relativisée selon les catégories de pays. C'est la région économiquement dynamique de l'Asie orientale qui présente les meilleurs ratios.

FMI et Banque mondiale évaluent le ratio supportable à 200, ou au maximum $250 \%$. Les pays dont le ratio d'endettement dépasse $200 \%$ doivent être considérés comme des "pays à problèmes » et bénéficier d'allégements spéciaux.

Un autre indicateur est le ratio service de la dette/recettes d'exportation. La CNUCED considère un ratio de $20 \%$ comme " économiquement acceptable ", tandis que le FMI et la Banque mondiale estiment que ce ratio peut aller jusqu'à $25 \%$. L'économie de certains pays appartenant notamment à la catégorie des PMA présente un ratio bien plus élevé, donc « économiquement inacceptable ».

\section{$\square$ Initiative en faveur des pays pauvres très endettés (PPTE)}

La Banque mondiale et le FMI ont lancé une initiative en faveur des PPTE, (en anglais HIPC - heavily indebted poor countries). Ne devraient en bénéficier que les pays les plus démunis (relevant exclusivement de l'AID), dont les problèmes d'endettement seraient insurmontables si l'on s'en tenait aux mécanismes ordinaires.

Cette initiative se fonde sur les considérations suivantes :

- l'analyse effectuée en vue d'un allégement des dettes prend en compte la situation globale du pays et sa dette extérieure (debt sustainability) ; on maintient le principe du cas par cas - chaque pays étant examiné individuellement ;

- le pays considéré doit avoir adopté jusque-là, en tant que débiteur, un comportement de nature à prouver que de nouveaux allégements seront mis à profit (good use) ;

- les nouvelles mesures doivent autant que possible rester dans la ligne de celles qui ont déjà été prises ;

- les mesures doivent se répartir si possible sur l'ensemble des créanciers (participation équitable) ;

- les créanciers multilatéraux conservent leur statut de créanciers prioritaires ;

- les nouveaux apports de fonds à ces pays devraient être octroyés à des conditions de faveur.

Ces pays n'auront les moyens de faire valoir leur potentiel économique qu'avec un allégement substantiel de l'endettement qui les paralyse. Des appels ont été lancés à plusieurs reprises lors des conférences internationales pour améliorer la situation à cet égard. Le sommet mondial de mars 1995 pour le développement social a donné lieu à la "déclaration de Copenhague ", selon laquelle des allégements de dettes sont un préalable au développement durable en Afrique et dans les pays les moins avancés d'autres continents.

Beaucoup de pays créanciers, dont la Suisse, ont renoncé à leurs créances publiques bilatérales envers des pays en développement pauvres et surendettés. Ces remises de dettes ont atteint 2,6 milliards de dollars en 1994, ce qui ne représente pas un allégement substantiel par rapport aux 212 milliards de dollars que totalisent les créances bilatérales envers les pays en question. 
Les chefs d'Etats des sept premières puissances économiques (G7) ont rédigé, lors de leur sommet de l'été 1996 à Lyon, une déclaration relative à un nouveau partenariat avec les pays en développement. Le principe qui sous-tend ce manifeste est qu'il incombe aux pays en développement eux-mêmes de promouvoir leur propre économie. Les puissances industrielles entendent, de leur côté, rendre leur travail de coopération plus efficace, et le concentrer sur les pays les plus pauvres. Il a été décidé à Lyon de prévoir des mesures d'allégement accrues, adoptées dans le « menu » de gestion de l'endettement sous le nom de conditions de Lyon : la remise maximale des dettes bilatérales des pays les plus pauvres devrait passer désormais de 67 à $90 \%$ (cette limite a ensuite été ramenée à $80 \%$ lors de la session annuelle 1996 du FMI et de la Banque mondiale). Banque mondiale et FMI doivent donner leur appui financier à ce processus. Selon la proposition discutée par ces deux organisations durant la session de printemps 1996, cet allégement de dettes coûterait 7 à 8 milliards de dollars. La Banque mondiale devrait mettre à disposition 2 milliards (les bénéfices éventuels ou bien des réserves), et le FMI élargirait sa FASR de manière à pouvoir accorder des crédits encore plus avantageux aux pays pauvres et surendettés qui sont censés bénéficier de l'initiative PPTE. Ces mesures d'allégement concernent entre huit et vingt pays pauvres - africains pour la plupart - dont le ratio d'endettement dépasse $200 \%$. Le choix d'un pays se fait de cas en cas.

Banque mondiale et FMI discutent aujourd'hui ensemble les modalités de nouveaux allégements de dettes. On s'est rendu compte que seule une stratégie portant sur l'endettement global (dettes bilatérales et multilatérales) et incluant tous les créanciers d'un pays surendetté peut réussir. La session d'avril 1996 du FMI et de la Banque mondiale, ainsi que le sommet économique du G7 à Lyon, en juillet 1996, ont en outre entériné le principe selon lequel les dettes multilatérales doivent faire l'objet d'une stratégie globale.

\section{Gestion de la dette}

Le FMI fournit une contribution importante à la gestion de la dette. Ses prescriptions d'ajustement structurel, visant à stabiliser la situation macro-économique des pays en développement, exercent une influence décisive sur la politique économique et financière de ces pays. Le pays qui souhaite négocier ses dettes dans le cadre du Club de Paris est censé avoir préalablement passé un accord avec le FMI. Mais il y a également d'autres « managers » pour défendre les intérêts des créanciers. Fondé en 1983, l'Institut de finance international (Institute of International Finance, IIF) a servi de porte-parole et de représentant des banques entraînées dans la crise de l'endettement latino-américain qui avait éclaté en 1982 au Mexique. Cinq banques suisses font partie de cette " organisation à but non lucratif » qui compte actuellement quelque 200 établissements. L'IIF consacre aujourd'hui une bonne partie de ses activités à l'analyse du marché des investissements et des produits dérivés.

La CNUCED se fait l'avocat des pays pauvres dans les négociations relatives à l'endettement. Elle a commencé dès 1983 à fournir systématiquement aux pays en développement des conseils et une assistance informatique concernant les 
aspects techniques de la dette. ${ }^{7}$ Très concrètement, la CNUCED prépare les pays en développement à négocier leurs dettes publiques bilatérales avec le Club de Paris, en leur fournissant un programme informatique qui établit les chiffres caractéristiques de leur dette. A l'origine, c'était le PNUD qui en assumait les frais. Plusieurs pays, dont la Suisse, ont également participé au financement de ce programme.

\subsection{FONDS MONÉTAIRE INTERNATIONAL}

L'exercice 1995/96 du Fonds monétaire international a vu ses promesses de crédit atteindre le montant record de 26 milliards de dollars, dont 18 milliards ont été effectivement versés. Le Mexique et la Russie se placent en tête pour les montants absorbés. L'ampleur des crédits alloués ces dernières années amène le FMI à renforcer ses ressources financières. La Suisse n'est pas d'accord que le FMI vende de l'or pour financer des mesures visant à éponger des dettes multilatérales.

Le FMI revêt la fonction d'une « grande banque de développement mondiale » qui octroie des crédits à ses membres - donc à presque tous les pays de la planète. L'adhésion du Brunei et de la Bosnie-Herzégovine au cours de l'année sous revue porte le nombre de ses membres à 181 pays.

\section{$\square$ Crédits du FMI : niveau record}

Au cours de l'exercice clos au 30 avril 1996, le FMI a secouru le Mexique sous la forme de crédits exceptionnels totalisant 3,5 milliards de DTS (5,1 milliards de dollars), et alloué à la Russie pas moins de 3,8 milliards de DTS (5,5 milliards de dollars). Ces deux pays déterminent le haut niveau des crédits du FMI absorbés par l'Europe et l'Amérique latine. L'exercice a également été marqué par de fortes demandes d'autres pays, les principaux étant l'Argentine $(0,8$ milliards de DTS), la Zambie $(0,7)$, l'Ukraine $(0,5)$ et l'Algérie $(0,4)$.

L'exercice se solde cependant par un transfert de ressources net de 5,2 milliards de DTS (avec 12,3 milliards de DTS versés, et 7,1 milliards remboursés) - donc inférieur au montant correspondant de l'exercice précédent, qui atteignait 7 milliards de DTS. Le tableau 8 résume les mouvements de capitaux enregistrés sur les comptes du FMI.

On constate ainsi que le FMI accorde la très grande majorité de ses prêts sous la forme classique des crédits de disponibilité. La facilité d'aide à la transition systémique a servi d'instrument temporaire, destiné aux pays qui passaient d'une économie planifiée à l'économie de marché ; son importance va en diminuant.

\section{Renforcement des fonds propres}

Ayant une forte demande à satisfaire, le FMI voit ses fonds diminuer, ce qui l'amène à envisager de nouvelles ressources. La dotation en trésorerie du FMI

${ }^{7}$ Ce programme informatique s'intitule SYGADE (Système de gestion et d'analyse de la dette). Au-delà des questions d'endettement, il constitue un outil d'analyse et de conseil en matière d'administration et de politique économique et financière. La mise en place du programme SYGADE dans les pays concernés leur donne accès aux informations dont ils ont besoin pour participer activement à la gestion de la dette. Les dettes des 30 pays qui utilisent ce programme totalisent à peu près 400 milliards de dollars, soit un quart de la dette globale. (Source : Bulletin CNUCED, $\mathrm{n}^{\circ} 34$, novembre-décembre 1995). 
s'effectue normalement sous forme d'une augmentation des quotes-parts. Une nouvelle augmentation est en discussion depuis longtemps, mais se heurte à des résistances, de la part des Etats-Unis notamment. La direction du FMI serait plutôt favorable à l'allocation de nouveaux DTS, mais le consensus fait défaut entre les pays membres sur cette question aussi. La discussion est en revanche plus avancée en ce qui concerne le doublement des Accords généraux d'emprunt du Club des Dix (avec l'Arabie saoudite en tant que membre associé). Le FMI verrait cette opération lui procurer 50 milliards de dollars, lesquels seraient toutefois réservés pour des difficultés de trésorerie exceptionnelles - par exemple la crise financière aiguë d'un pays membre comme ce fut le cas au Mexique. Il est prévu de passer un accord parallèle à cet effet (nouvel accord d'emprunt ou new arrangement to borrow - NAB).

\section{Tableau $n^{\circ} 8$}

Crédits du FMI 1993-1996 (en milliards de DTS, clôture au 30 avril)

\begin{tabular}{lrrrr}
\hline & $\mathbf{1 9 9 3}$ & $\mathbf{1 9 9 4}$ & $\mathbf{1 9 9 5}$ & $\mathbf{1 9 9 6}$ \\
\hline Versements & 5.9 & 5.9 & 11.2 & 12.3 \\
\hline - Afrique & 0.4 & 1.2 & 1.0 & 2.3 \\
\hline - Asie & 1.8 & 0.7 & 0.4 & 0.4 \\
\hline - Europe & 1.3 & 3.3 & 2.9 & 5.0 \\
\hline - Proche-Orient & & & 0,1 & 0,1 \\
\hline - Amérique latine & 2.3 & 0.8 & 6.8 & 4.4 \\
\hline Remboursements & 4.1 & 4.5 & 4.2 & 7.1 \\
\hline Transferts nets & 1.8 & 1.4 & 7.0 & 5.2 \\
\hline Crédits non remboursés & 28.2 & 29.2 & 36.8 & 42.0 \\
\hline Obligations non honorées à l'échéance & 3.0 & 2.9 & 3.0 & 2.2 \\
\hline Nombre de pays bénéficiaires de crédits & 90 & 93 & 99 & 97 \\
\hline
\end{tabular}

Les montants octroyés se répartissent sur les différentes formes de crédit comme suit :

\begin{tabular}{lrr}
\hline & $\mathbf{1 9 9 5 / 9 6}$ & $\mathbf{1 9 9 4 / 9 5}$ \\
\hline - Crédits de disponibilité & 9.1 & 7.6 \\
\hline - Facilité élargie du fonds (FEF) & 1.6 & 1.6 \\
\hline - Facilité d'aide à la transition systémique (STF) & 0.1 & 1.1 \\
\hline - Crédits d'ajustement structurel à des conditions de faveur & & 0.6 \\
(crédits FAS et FASR) & 1.5 & \\
\hline
\end{tabular}

Source : Rapport annuel 1996 du FMI.

\section{$\square$ Prévention des crises}

Les répercussions de la crise mexicaine ont incité le FMI à prendre une série de mesures en vue de prévenir des situations analogues, ou tout au moins de les gérer. La politique économique est globalement soumise à une surveillance renforcée, et l'on vouera désormais une attention particulière aux mouvements de capitaux. Les pays qui ont accès au marché des capitaux soumettront la publication de leurs données économiques et financières à des règles rigoureuses (special data dissemination standards), de manière à permettre un meilleur contrôle. 


\section{$\square$ Facilité d'ajustement structurel renforcée}

La Facilité d'ajustement structurel renforcée (FASR) permet au FMI d'accorder aux pays les plus pauvres des crédits particulièrement avantageux (taux d'intérêt de $0,5 \%$ ), avec de longs délais de remboursement. Ce sont là des crédits transitoires, destinés à financer des mesures d'ajustement structurel. Ils sont soumis aux conditions habituelles du FMI, comprenant en particulier la mise en œuvre d'un programme d'ajustement structurel. La FASR est financée par des contributions de certains pays et par les remboursements d'anciens crédits du FMI. Un débat s'est engagé sur la question de savoir si le FMI devrait vendre de son or. Il sera nécessaire de procéder à un renouvellement de la FASR à partir de 1998. Celle-ci devrait être financièrement autonome à partir de l'an 2005, au moment où d'importants crédits seront remboursables. Le FMI entend apporter sa contribution à l'initiative PPTE en donnant une ampleur accrue au moyen de financement avantageux que constitue la FASR.

\section{$\square$ Vente d'or par le FMI}

Les Etats-Unis et la Grande-Bretagne proposent que le FMI vende 5\% de ses réserves d'or afin de pouvoir consacrer 2 milliards de dollars supplémentaires à des mesures d'allégement en faveur des plus pauvres parmi les pays surendettés. Ce plan est rejeté notamment par l'Allemagne, l'Italie, le Japon, certains pays nordiques et la Suisse. La décision de vendre de l'or du FMI requiert une majorité de $85 \%$ des voix ; les pays opposés à cette opération forment une minorité suffisante pour la bloquer.

\section{$\square$ Position de la Suisse au sein du FMI}

La Suisse conduit auprès du FMI un groupe de pays comprenant la Pologne et cinq Etats d'Asie centrale (Azerbaïdjan, Kirghizistan, Tadjikistan, Turkménistan et Ouzbékistan). Ces pays détiennent ensemble 2,77\% des voix au Conseil exécutif du FMI. Comme d'autres pays européens, la Suisse (Conseil fédéral et Banque nationale) fait partie des adversaires de la vente d'or par le FMI. La Communauté de travail des organisations d'entraide suisses y est par contre favorable.

\subsection{GROUPE DE LA BANQUE MONDIALE}

Au cours de l'exercice fiscal clos au 30 juin 1996, la Banque mondiale et l'Association internationale de développement (AID) ont fait des promesses de crédit pour un montant de 21,4 milliards de dollars (22,5 milliards l'année précédente). Les plus importants "clients" de la Banque mondiale ont de nouveau été la Chine et l'Inde, dont les emprunts ont totalisé ensemble 5 milliards de dollars. Un vaste débat s'est engagé durant l'année sous revue à la suite des propositions émises par un groupe de travail de la Banque mondiale, tendant à instaurer une stratégie globale qui inclurait les dettes multilatérales; mais aucune décision n'a encore été prise à ce sujet. A côté de sa fonction d'établissement de crédit, la Banque mondiale publie des analyses et des études importantes concernant la problématique générale du développement.

Des promesses de crédit susmentionnées, 14,5 milliards de dollars relèvent de la Banque mondiale proprement dite, et 6,9 milliards de dollars, de l'AID. Le tableau 
9 indique les mouvements de capitaux sur les comptes de la Banque mondiale de 1993 à 1996, et le tableau 10, les dix principaux bénéficiaires de ces crédits.

Tableau $n^{\circ} 9$

Flux de ressources de la Banque mondiale 1992-1995

(en milliards de dollars)

\begin{tabular}{lrrrr}
\hline & $\mathbf{1 9 9 2}$ & $\mathbf{1 9 9 3}$ & $\mathbf{1 9 9 4}$ & $\mathbf{1 9 9 5}$ \\
\hline Banque mondiale & & & & \\
\hline Engagements & 15.2 & 16.9 & 14.2 & 16.9 \\
\hline Versements & 11.7 & 12.9 & 10.4 & 12.7 \\
\hline Versements nets' $^{\prime}$ & 1.8 & 2.4 & -0.7 & $\mathbf{0 . 9}$ \\
\hline Engagements totaux & 100.8 & 104.5 & 109.3 & 123.5 \\
\hline Crédits non utilisés & 67.4 & 78.7 & 79.7 & 75.3 \\
\hline AID & & & & \\
\hline Engagements & 6.6 & 6.8 & 6.6 & 5.7 \\
\hline Versements $^{\text {Versements nets }}{ }^{1}$ & 4.8 & 4.9 & 5.5 & 5.7 \\
\hline
\end{tabular}

1) Versements moins remboursements.

Source : Rapport annuel de la Banque mondiale.

Tableau $n^{\circ} 10$

Les Principaux bénéficiaires de crédits de la Banque mondiale

\begin{tabular}{lrrrr}
\hline Principaux emprunteurs & \multicolumn{1}{l}{} & $\mathbf{1 9 9 5}$ & Principaux emprunteurs & $\mathbf{1 9 9 6}$ \\
\hline Pays & Millions de \$ $^{\text {Phine }}$ & 3000 & Pays & Millions de \$ \\
\hline Mexique & 2387 & Chine & 2970 \\
\hline Inde & 2064 & Inde & 2080 \\
\hline Russie & 1741 & Russie & 1820 \\
\hline Argentine & 1425 & Argentine & 1510 \\
\hline Indonésie & 1417 & Indonésie & 990 \\
\hline Pakistan & 706 & Viêt-nam & 502 \\
\hline Ukraine & 646 & & \\
\hline Brésil & 552 & & \\
\hline Thaillande & 513 & & \\
\hline
\end{tabular}

1) Crédits de la Banque mondiale alloués en 1994/95 et 1995/96.

Source : Rapport annuel de la Banque mondiale. 
Les promesses de crédit de la Banque mondiale se répartissent de la manière suivante :

$25 \%$ Asie orientale/Pacifique

$21 \%$ Amérique latine

14\% Asie méridionale

$20 \%$ Europe/Asie centrale

$13 \%$ Afrique subsaharienne

$7 \%$ Proche-Orient et Afrique du Nord

Les plus gros emprunteurs auprès de la Banque mondiale ont été la Chine $(2,97$ milliards de dollars), l'Inde (2,08), la Russie $(1,82)$, l'Argentine $(1,51)$ et l'Indonésie $(0,99)$. Le Viêt-nam a bénéficié pour la première fois de crédits importants (502 millions de dollars).

\section{Nouvelle stratégie globale de la dette}

La Banque mondiale a pris l'initiative de solutions inédites afin de réduire l'endettement des pays les plus pauvres (cf. initiative PPTE évoquée plus haut). Sa contribution à cette initiative comprend la création d'un "fonds fiduciaire PPTE », dont la dotation doit se chiffrer à 11 milliards de dollars. Il incombera à l'AID de gérer ce nouveau fonds, auquel les pays pauvres et surendettés pourront recourir durant 15 ans afin d'honorer le service de leur dette.

La création de cette facilité constituée de ressources bilatérales et multilatérales ne doit pas menacer la solvabilité de la Banque mondiale et du FMI. Un pays qui entend bénéficier de ce fonds fiduciaire devra remplir les conditions prévues par la Banque mondiale, à savoir mettre en œuvre des réformes économiques dont les objectifs centraux seront la lutte contre la pauvreté et la durabilité écologique.

Dans le contexte de cette nouvelle initiative en faveur des PPTE, la Bánque mondiale - puis le FMI - ont même parlé de remettre certaines créances multilatérales, ce qui constituait jusque-là un tabou absolu.

A la veille de la session de printemps 1996 où ces idées devaient être débattues, Oxfam International, Eurodad et d'autres organisations de développement privées ont lancé une campagne de soutien à la proposition de la Banque mondiale. Des ONG suisses l'ont également appuyée.

\section{Agence internationale pour le développement (AID)}

L'AID jouera un rôle important dans la réalisation de l'initiative PPTE. Une politique de crédit sélective et l'allocation de prêts supplémentaires devraient sortir les pays les plus pauvres de l'ornière et ramener leur dette à un niveau supportable.

\section{Rapport sur le développement dans le monde}

Le Rapport de 1996 sur le développement dans le monde ${ }^{8}$ tire un premier bilan après six ans de politique de réformes pratiquée par les pays de l'ancien bloc soviétique, ainsi que par la Chine et le Viêt-nam, qui sont devenus d'importants emprunteurs auprès de la Banque mondiale. Une comparaison entre la Chine et la Russie montre que la réussite dépend, outre la volonté de procéder à des réformes profondes, de conditions initiales favorables à une refonte générale des structures. En Russie, un quart de la production économique était liée au complexe militaire ; $90 \%$ des salariés travaillaient dans le secteur public, et $10 \%$ dans

8 From Plan to Market, World Development Report 1996, Oxford University Press, juin 1996. 
l'agriculture. L'Etat chinois, de son côté, n'occupait que 19\% de l'ensemble des travailleurs, et $71 \%$ gagnaient leur vie dans l'agriculture. La Russie subit une douloureuse restructuration de son lourd et pléthorique appareil d'Etat, alors qu'en Chine des entreprises dynamiques ont directement absorbé la maind'œuvre libérée par le redimensionnement du secteur agricole. Les problèmes étaient et restent énormes : la privatisation requiert des marchés efficaces et suppose la garantie du droit à la propriété ; ce processus implique une augmentation de la corruption et de la criminalité, la pauvreté croissante requiert une bonne politique sociale, etc. La Banque mondiale considère cependant que le bilan est jusqu'ici positif pour l'Europe orientale.

\section{Banque mondiale et environnement}

Après les critiques soulevées par les répercussions sociales et écologiques de nombreux grands projets qu'elle finançait en tout ou partie, la Banque mondiale a ouvert une division « environnement ». Elle exige des études d'impact sur l'environnement, et est devenue d'une manière générale plus consciente du facteur écologique. Elle a notamment exposé sa politique en la matière dans une étude intitulée Mainstreaming the Environment (septembre 1995). La Banque mondiale travaille à un système de classification verte (selon des critères écologiques). Le système en question répertorie les richesses écologiques et humaines dont dispose un pays donné, et ces critères conduisent à une nouvelle évaluation du niveau de prospérité. Selon la définition qu'en donne la Banque mondiale, un développement est écologiquement durable si les générations futures disposent d'un capital écologique et humain plus important que la génération actuelle. Cela nécessitera des investissements dans des projets environnementaux et dans la formation - des femmes notamment. ${ }^{9}$

En 1996, les milieux écologistes et des organisations de développement ont à nouveau critiqué la Banque mondiale pour son projet de financer une centrale thermique à charbon en Inde. L'exploitation des mines de charbon nécessiterait le déplacement de 11'000 personnes. Ce projet de migration intérieure ne procurerait ni terres, ni travail à la population déplacée, et contreviendrait aux principes de la Banque mondiale. Telle est l'argumentation présentée par la Déclaration de Berne ${ }^{10}$. La Banque mondiale est d'une manière générale exhortée à donner davantage de poids aux critères environnementaux dans sa politique de crédit, et notamment à encourager les formes alternatives d'énergie (solaire en particulier) dans les pays en développement.

\section{Réformes de la Banque mondiale}

La Banque mondiale doit améliorer par des réformes l'efficacité et la qualité de son travail ; telle est la conviction de son nouveau président James Wolfensohn, entré en fonction en juin 1995. Wolfensohn estime qu'il faut «briser les habitudes bureaucratiques et créer une culture d'entreprise axée sur l'efficacité, qui s'intéresse davantage aux besoins des pays en développement ${ }^{\prime \prime}$. Un premier pas

\footnotetext{
9 L'étude du système de classification verte a été présentée par Ismail Serageldin, sous-directeur responsable des questions environnementales, à l'occasion d'un séminaire organisé par l'Office fédéral des affaires économiques extérieures (cf. Neue Zürcher Zeitung, 11/12 novembre 1995).

${ }^{10}$ EvB-Magazin 2/96, EvB fordert Weltbank heraus.

${ }^{11}$ Wolfensohn cité par la NZZ du 8.12.1995, Reorganisation an der Weltbank-Spitze.
} 
dans ce sens est la création de deux nouveaux postes de directeurs qui en porte le nombre à cinq, lesquels auront des compétences plus claires.

\section{$\square$ Stratégie de développement}

La Banque mondiale élabore actuellement une stratégie de développement qui accorde un haut degré de priorité aux aspects sociaux, soit diminution de la pauvreté, participation de la société civile au travail de développement, contribution du secteur privé à un développement socialement et écologiquement durable. Par ailleurs, elle est en train de jeter les bases d'une stratégie pour le développement de l'Europe orientale et de l'Asie centrale.

\section{Position de la Suisse}

Le nouveau président James Wolfensohn a séjourné en Suisse durant le mois de mai 1996. Confédération et organisations privées ont eu l'occasion de lui exposer leurs préoccupations en matière de développement. La Suisse est représentée au Conseil exécutif ; elle appuie la Banque mondiale dans son initiative portant sur les dettes multilatérales et l'importance à donner aux critères écologiques dans l'octroi de crédits.

\subsection{SESSION ANNUELLE DU FMI ET DE LA BANQUE MONDIALE}

Le FMI et la Banque mondiale tiennent régulièrement leur session annuelle en automne à Washington, siège des deux organisations, pour y discuter et trancher des questions importantes qui les concernent l'une et l'autre. Le point le plus important de la 51e session, tenue du ler au 3 octobre 1996, était la décision à prendre concernant une nouvelle initiative commune sur la dette des PPTE.

Les deux organes de contrôle que sont le Comité intérimaire du FMI et le Comité de développement commun à la Banque mondiale et au FMI se réunissent avant la session annuelle pour passer en revue les points essentiels à débattre ; le Club des Dix (G10), le Groupe des vingt-quatre (G24) et le G7 font de même (cf. encadré).

ORGANES DU FMI ET DE LA BANQUE MONDIALE, PARTICIPATION DE LA SUISSE

Conseil d'administration : FMI et Banque mondiale ont l'un et l'autre un organe exécutif comprenant 24 sièges. Lors des négociations en vue de son adhésion, la Suisse y a mis la condition qu'elle puisse faire partie du Conseil d'administration. La quote-part de capital nécessaire a pu être réunie en constituant un groupe comprenant la Pologne et quatre pays d'Asie centrale sous la conduite de la Suisse. Notre pays est représenté au Conseil d'administration du FMI par Daniel Kaeser (DFF), et auprès de la Banque mondiale par Jean-Daniel Gerber (DFEP).

Comité intérimaire : organe dans lequel les pays membres sont représentés par leur ministre des finances ou le chef de la banque centrale, et qui conseille le FMI en matière de politique économique et monétaire. Ce comité a adopté une déclaration intitulée "partenariat pour une croissance globale durable », et approuvé l'initiative sur l'endettement. Le conseiller fédéral Kaspar Villiger et Hans Meyer, directeur de la Banque nationale, ont pris part pour la Suisse à la réunion qui précédait la session annuelle de 1996. 
Comité de développement: cet organe commun du FMI et de la Banque mondiale conseille les deux institutions dans le domaine de la politique de développement. La Suisse y est normalement représentée par le directeur de l'Office fédéral des affaires économiques extérieures (en 1996, par le secrétaire d'Etat Franz Blankart). C'est de ce comité qu'émane la nouvelle initiative concernant la dette des pays pauvres.

G10: le Club des Dix compte en fait les onze principaux pays industrialisés, dont la Suisse. Il procure au FMI des fonds destinés à surmonter des problèmes aigus de trésorerie, dans le cadre des Accords généraux d'emprunt (AGE).

G24 : ce groupe représente les intérêts des pays en développement auprès du FMI et de la Banque mondiale. En ce qui concerne l' initiative sur l'endettement, le G24 a défendu la revendication d'un allégement pouvant atteindre $90 \%$ de la dette grevant les pays en développement à la fois pauvres et surendettés (point de vue adopté par la Suisse également).

G7 : les ministres des finances et les chefs des banques centrales du G7 (Etats-Unis, Canada, France, Allemagne, Italie, Grande-Bretagne et Japon) se rencontrent régulièrement avant la session annuelle du FMI et de la Banque mondiale, pour en discuter l'ordre du jour.

Les 181 pays membres ont délégué des représentants à la session annuelle de 1996, dont l'objet important était la décision à prendre concernant la proposition d'alléger la dette des PPTE. D'autres sujets étaient le projet de doubler le montant des Accords généraux d'emprunt (AGE) entre le Club des Dix et le FMI, ainsi que l'harmonisation prochaine des priorités que se donnent les deux institutions de Bretton Woods. Celles-ci entendent unir leurs efforts pour mieux combattre la corruption et pour renforcer le secteur financier des pays en développement.

\section{$\square$ Initiative sur l'endettement}

Selon la décision prise lors de la session annuelle, les Etats créanciers occidentaux réunis au sein du Club de Paris réduiront à un niveau « supportable » - avec l'appui du G7, du FMI et de la Banque mondiale - l'endettement des pays pauvres très endettés (PPTE). Il sera désormais possible, dans le cadre du Club de Paris, d'effacer jusqu'à $80 \%$ (67\% jusqu'à présent) de la dette bilatérale qui grève ces pays. Le FMI et la Banque mondiale reprennent ainsi à leur compte les recommandations émises à Lyon par le G7 concernant 1'allégement des dettes qui pèsent sur les PPTE. Entre en considération une vingtaine de pays - notamment Ouganda, Mozambique, Zambie, Côte-d'Ivoire, Ethiopie, Tanzanie, Mali, Bolivie, Guyane, Nicaragua - dont la dette dépasse 200 à $250 \%$ (et les intérêts à honorer, 20 à $25 \%$ ) des recettes d'exportation. On s'en tiendra au principe de procéder de cas en cas. La répartition entre dettes bilatérales et multilatérales de ces pays se chiffre à 80 et $20 \%$ environ. Le coût estimé de l'opération varie beaucoup d'une source à l'autre. Selon les calculs de la Banque mondiale, le total pourrait atteindre 7,7 milliards de dollars.

Le FMI entend participer à cette initiative d'allégement de la dette par un montant de 1,3 milliard de DTS (environ 2 milliards de dollars) en donnant une ampleur accrue à la FASR, après que son Conseil d'administration avait rejeté, lors d'une séance tenue deux semaines avant la session annuelle, la proposition de vendre de l'or. La FASR constitue l'instrument qu'utilise le FMI pour octroyer 
des crédits avantageux ; elle devrait être financièrement autonome à partir de l'an 2005 , avec les gros remboursements de capitaux qui auront lieu alors. Son financement jusque-là doit encore être réglé. Dans un premier temps, des apports bilatéraux permettront d'octroyer de nouveaux crédits bon marché par le biais de la FASR. On envisage également la possibilité d'accorder des subsides (grants).

La Suisse prendra part à l'initiative sur l'endettement à la condition que son mode de financement soit défini de manière encore plus précise, et que les autres pays confirment leur participation. La quote-part helvétique étant de 2,4\%, sa contribution bilatérale se chiffre à 31 millions de DTS (soit 56 millions de francs à verser par la Confédération). A cela s'ajoute la remise de précédents apports au fonds de réserve, pour un montant d'environ 20 millions de francs (à la charge de la Banque nationale). Les contributions bilatérales de la Suisse requièrent un arrêté fédéral. Pour ce qui est des allégements de dette à consentir dans le cadre du Club de Paris, la Suisse a déjà annulé ses créances vis-à-vis du groupe de pays considéré. Elle s'était montrée favorable à une remise pouvant atteindre $90 \%$ de la dette existante, mais se satisfait du compromis provisoire de $80 \%$.

La Banque mondiale considère que la mise en œuvre de l'initiative commune en faveur du désendettement des PPTE est une des activités essentielles de son programme d'action en six points pour les années à venir. Il s'agira notamment d'accroître les crédits alloués par l'AID. La Banque mondiale a par ailleurs ouvert un fonds fiduciaire dont la dotation devrait atteindre 2 milliards de dollars ; une première tranche de 500 millions de dollars, tirée du bénéfice net, y a déjà été versée en 1996.

Les cinq autres points du plan d'action de la Banque mondiale sont : combattre la corruption, renforcer le secteur financier des pays en développement, surveiller de plus près les répercussions sociales des activités de la banque, redonner davantage d'importance à la lutte contre la pauvreté dans les régions rurales, accroître le rôle de la Banque mondiale dans le domaine technologique.

\section{Accord généraux d'emprunts (AGE)}

La session annuelle de 1996 a définitivement adopté le doublement du montantcadre des AGE, qui passe ainsi de 17 à 34 milliards de DTS (environ 50 milliards de dollars) et doit prendre effet cette année même. Les onze pays du Club des Dix fournissent $80 \%$ de ces nouveaux fonds, le reste étant apporté par d'autres pays européens et asiatiques. La part de la Suisse se chiffre à 4,6\%, ce qui représente 1,13 milliard de dollars.

\section{$\square$ Renforcement du secteur financier des pays en développement}

FMI et Banque mondiale veulent faire cause commune avec les banques de développement régionales afin de renforcer le secteur financier des pays en développement, entreprendre des efforts accrus en vue d'aiguiller davantage de capitaux privés vers les pays en développement démunis. Il s'agit d'accroître à cet effet les moyens dont disposent les deux institutions. L'afflux de capitaux privés à destination des pays en développement a énormément augmenté ces dernières années, mais il se concentre sur un petit nombre de pays qui jouissent d'un marché développé ou d'une économie à haut potentiel. Le FMI et la Banque mondiale utiliseront ensemble des moyens ciblés pour tenter de diriger à l'avenir des capitaux privés vers les pays pauvres. 


\subsection{RÉAMÉNAGEMENTS DE DETTES PAR LE CLUB DE PARIS}

Les conditions de rééchelonnement des dettes publiques bilatérales se négocient entre le pays débiteur et les gouvernements créanciers dans le cadre du Club de Paris. Cet organe informel se constitue en fonction de la dette à réaménager; la Suisse participe aux négociations lorsque les dettes qui la concernent atteignent au moins un million de francs. Les accords multilatéraux servent ensuite de référence pour les négociations bilatérales en vue de restructurer la dette.

Il appartient au pays débiteur de demander à négocier le réaménagement de sa dette. A la fin des négociations, les deux parties (créanciers et débiteur) signent un protocole (agreed minutes) qui constituera le cadre de référence aux négociations bilatérales. Beaucoup de pays en développement pauvres et surendettés (PPTE) ont une lourde charge de dettes publiques bilatérales. Environ $30 \%$ des intérêts qu'ils ont à verser se rapportent à des crédits publics accordés bilatéralement. Cette proportion est de $15 \%$ pour les pays lourdement endettés à revenus intermédiaires. Les négociations de rééchelonnement de la dette représentent un énorme travail. On estime que les gouvernements africains ont dû affronter entre 1980 et 1992 quelque 8000 négociations de ce genre avec leurs créanciers ! ${ }^{12}$ Ces tractations absorbent des ressources humaines et financières importantes, sans procurer des allégements significatifs.

En 1988, à l'initiative du président français François Mitterrand, le G7 avait résolu lors de son sommet économique à Toronto de procéder à des allégements de dettes. Ces conditions de Toronto prévoyaient la diminution d'un tiers au maximum d'échéances portant sur 1 à 3 ans, cela sous forme de remise, de bas taux d'intérêt ou de rééchelonnement des échéances en question. Vingt pays ont bénéficié de ces conditions jusqu'en 1991. Leur endettement n'en a été réduit que de 4\%. La décision a donc été prise en 1991 de porter la remise possible des échéances à $50 \%$ (conditions de Toronto élargies).

Fin 1994, l'instauration des conditions de Naples constituait un pas dans la direction d'une remise sur le stock de la dette : il devenait possible d'effacer jusqu'à deux tiers de la dette totale des pays les plus pauvres. Le Club de Paris conserve toutefois la possibilité, lors des négociations, de n'accorder qu'une remise de $50 \%$ ou de limiter celle-ci aux échéances. Parmi les onze pays qui ont négocié des réaménagements en 1995, seuls la Bolivie et l'Ouganda ont obtenu une remise touchant au montant de leur dette. Les conditions sont sévères : paiements ponctuels sous le régime des précédents accords de rééchelonnement, programme de réformes imposé par le FMI, garantie que les engagements résiduels après remise seront respectés.

La stratégie adoptée au sein du Club de Paris a ainsi introduit progressivement des éléments de concession auxquels on peut recourir de cas en cas. Une nouvelle étape a été franchie en 1996 avec les conditions de Lyon $^{13}$ : les pays à faible revenu peuvent bénéficier désormais d'une réduction de $80 \%$ de l'encours de la dette (au lieu de $67 \%$ ) ; cette réduction peut également porter, comme précédemment, sur le service de la dette pour une période de rééchelonnement d'un à trois ans.

\footnotetext{
${ }^{12}$ Alfred Gugler, «Öffentliche bilaterale Schulden die späten Einsichten der Regierungsgläubiger », in : mosquito, $\mathrm{Nr}$ 2/März 1996.

${ }^{13}$ L'Annuaire Suisse-Tiers Monde décrit régulièrement l'évolution des conditions de rééchelonnement de la dette et des remises accordées par le Club de Paris.
} 
Les deux options conditions de Toronto élargies et conditions de Naples sont applicables aux crédits publics et aux crédits d'exportation assortis d'une garantie publique. Les crédits de coopération publics ne donnent lieu à aucune remise, mais sont rééchelonnés sur une très longue période (30 à 40 ans).

\section{$\square$ Réaménagements multilatéraux en 1995}

En 1995, 18 nouveaux protocoles de réaménagement portant sur 20,7 milliards de dollars - dont 7,3 milliards concernaient l'Algérie, et 6,4 milliards, la Russie - ont été négociés avec le Club de Paris. Les conditions de Naples (allégement de dette allant jusqu'à $67 \%$ pour les pays les plus pauvres et les plus endettés) ont été accordées pour la première fois à 13 pays débiteurs. Les cinq autres pays ont négocié le réaménagement de leur dette aux conditions habituelles. La Suisse est concernée pour un montant global de 298 millions de francs répartis sur huit pays (dont trois bénéficient des conditions de Naples). L'Ouganda a été en 1995 le premier pays à bénéficier des conditions de Lyon. Le tableau 11 résume les réaménagements de la dette qui ont eu lieu en 1995 et 1996.

Tableau $n^{\circ} 11$

Accords multilatéraux de rééchelonnement des dettes

\begin{tabular}{lrlr}
\hline Pays & Montant (mio \$) & Pays & Montant (mio \$) \\
\hline Guinée & $\mathbf{1 9 9 5}$ & & $\mathbf{1 9 9 6}$ \\
\hline Cambodge & 156 & Zambie & 566 \\
\hline Ouganda & 249 & Honduras & 112 \\
\hline Guinée Bissau & 110 & Sierra Leone & 39 \\
\hline Togo & 195 & Ghana & 93 \\
\hline Tchad & 237 & Russie & $40^{\prime 2} 200$ \\
\hline Croatie & 24 & Mali & 33 \\
\hline Nicaragua & 861 & Guyanne & 793 \\
\hline Bolivie & 848 & Tchad & 12 \\
\hline Sénégal & 482 & Burkina Faso & 64 \\
\hline Haïti & 169 & Congo & $1{ }^{\prime} 758$ \\
\hline Russie & 117 & Pérou & $6 ’ 724$ \\
\hline Mauritanie & $6{ }^{\prime} 400$ & Yémen & 113 \\
\hline Algérie & 66 & Bénin & 209 \\
\hline Macédoine & $7 ’ 320$ & Mozanbique & 664 \\
\hline Cameroun & 288 & Niger & 128 \\
\hline Gabon & 1 '129 & & \\
\hline Bolivie & 1 '030 & & \\
\hline
\end{tabular}

Source : Office fédéral des affaires économiques extérieures. 


\section{$\square$ Réaménagements bilatéraux en $1995^{14}$}

En 1995, la Suisse a passé des accords bilatéraux de rééchelonnement de la dette avec quatre pays (8 en 1994), soit le Togo, la Sierra Leone, la Jordanie et la Russie (deux accords). Du montant rééchelonné de 240,7 millions de francs, 136,7 millions représentaient des échéances de dettes déjà réaménagées qui ont ainsi fait l'objet d'une nouvelle consolidation, et 104 millions se rapportaient à de nouvelles échéances d'anciens crédits. La conversion de dette adoptée pour la Sierra Leone comprend un allégement de 50\% qui correspond aux conditions de Trinidad, tandis que la remise accordée au Togo - dixième rééchelonnement bilatéral - se chiffre à $67 \%$ et s'inspire ainsi des conditions de Naples.

En 1996, la Suisse a conclu des accords de rééchelonnement de dettes avec huit pays.

Tableau $n^{\circ} 12$

Rééchelonnements de dettes en 1995 et 1996

\begin{tabular}{lrlr}
\hline Pays & (mio. de CHF) & Pays & (mio. de CHF) \\
\hline Jordanie 3 & $\mathbf{1 9 9 5}$ & & $\mathbf{1 9 9 6}$ \\
\hline Sierra Leone 5 & 24.0 & Croatie 1 & 35.0 \\
\hline Russie 2 & 7.0 & Algérie 2 & 64.6 \\
\hline Russie 3 & 61.5 & Gabon 6 & 7.4 \\
\hline Togo 10 & 73.0 & Honduras 3 & 2.6 \\
\hline Total & 75.2 & Cameroun 4 & 15.8 \\
\hline & $\mathbf{2 4 0 . 7}$ & Macédoine 1 & 16.0 \\
\hline & & Sierra Leone 6 & 4.3 \\
\hline & & Congo 4 & 8.0 \\
\hline
\end{tabular}

Source : Section GRE/Office fédéral des affaires économiques extérieures.

Les pays débiteurs se sont avérés d'une manière générale plus solvables et mieux disposés à payer en 1995 que l'année précédente. Ils ont effectivement réglé durant l'année sous revue $60,7 \%$ (25\% en 1994) des remboursements de capital, et $66,8 \%$ (56\% en 1994) des intérêts qui leur étaient demandés.

On comptait à fin 1995 un total de 93 accords bilatéraux de rééchelonnement de dettes avec 31 pays.

\section{$\square$ Allégement bienvenu mais insuffisant}

Le secrétariat de la CNUCED a utilisé une méthode de simulation pour calculer les effets des conditions de Naples (avec l'option d'une remise de dettes de 67\%) sur les pays concernés, dont 22 PMA. L'allégement pourrait être considérable pour la moitié de ces pays, et quatre d'entre eux verraient leur ratio service de la dette/recettes d'exportation ramené au-dessous de la limite souhaitée de $20 \%$.

\footnotetext{
${ }^{14}$ Les données relatives aux opérations de consolidation des dettes multilatérales et bilatérales ont été réunies par la section GRE/Office fédéral des affaires économiques extérieures.
} 
Cet allégement serait moins sensible pour les onze autres pays. Cette simulation prouve, aux dires de la CNUCED, que des remises ponctuelles ne diminuent pas suffisamment le service de la dette qui grève certains pays. Les intérêts à verser restent très lourds, pour les dettes multilatérales notamment. De plus, les négociations laborieuses et compliquées dans le cadre du Club de Paris, puis avec chaque créancier bilatéral, entraînent des coûts énormes en argent et en temps pour le pays débiteur. La CNUCED préconise une gestion de la dette plus efficace en ce sens que les accords du Club de Paris pourraient s'appliquer par analogie aux dettes commerciales et multilatérales. ${ }^{15}$

Les pays créanciers ont le loisir de faire des concessions plus généreuses que celles convenues par le biais du Club de Paris. La Suisse, par exemple, a annulé il y a un certain temps déjà l'ensemble de ses créances datant de l'époque où son APD prenait encore la forme de crédits de développement. La facilité suisse de désendettement constitue également une solution innovante, dont notre pays avait espéré qu'elle ferait davantage d'émules parmi les autres Etats créanciers.

\subsection{MESURES PRISES PAR LA SUISSE EN MATIĖRE D'ENDETTEMENT}

A l'occasion du $700^{e}$ anniversaire de la Confédération, la Suisse a ouvert un crédit-cadre de 700 millions de francs pour financer des mesures de désendettement et des programmes en faveur de l'environnement dans des pays en développement. L'argent mis à disposition pour des opérations de désendettement totalise 500 millions de francs, dont 400 millions proviennent $d u$ "fonds d'anniversaire » et 100 millions relèvent du crédit de programme destiné à des mesures de politique économique et commerciale. ${ }^{16}$ Ce fonds a servi jusqu'ici surtout pour des actions bilatérales de désendettement; 276 millions de francs au total avaient été engagés à fin 1995. Il s'agira désormais de répondre aux défis que pose le problème des dettes multilatérales.

La Suisse a concentré ses mesures de désendettement au domaine bilatéral. Leur élément central était le désendettement créatif, système qui consiste à convertir l'équivalent de la dette remise en monnaie locale afin de constituer un fonds de développement destiné à financer des projets à caractère social et écologique. ${ }^{17}$ La Suisse a entièrement abandonné ses créances bilatérales envers les pays dont le gouvernement et le système économique ont donné des preuves de crédibilité, donc qui respectent les critères de «bonne gestion des affaires publiques ».

Les dettes bilatérales constituent la plus grande partie (61\% en 1993) de l'endettement extérieur des pays pauvres et surendettés, cependant que la proportion de dettes multilatérales $(25 \%)$ va en augmentant. Ces dernières impliquent en général une forte part en donation (autour de 70\%) ; par contre, elle n'admettent en principe aucune conversion ou réduction. Mais la dette extérieure de nombreux pays en développement démunis et paralysés par leur endettement est formée en très grande partie de créances multilatérales ; l'Ouganda, par exemple, avait, fin

\footnotetext{
${ }^{15}$ Ces données sont tirées de : UNCTAD, The Least Developed Countries 1996 Report, April 1996, chapitre Debt Relief for $L D C^{\prime} s$, p. 29 ss.

${ }^{16}$ Le nouveau crédit de programme pour le financement de mesure économiques et commerciales est commenté au chapitre VI du présent Annuaire.

${ }^{17}$ Les éditions 1992 à 1996 de l'Annuaire présentent les mesures de désendettement bilatérales qui ont été prises et explicitent le principe du désendettement créatif.
} 
1994, une dette extérieure de 3,3 milliards de dollars (80\% du PIB) dont $70 \%$ d'origine multilatérale, ce qui l'oblige à consacrer chaque année $29 \%$ de ses recettes d'exportation au service de la dette multilatérale.

Un pays qui omet d'honorer le service de sa dette multilatérale risque la rupture de ses relations avec l'institution financière concernée. Nombreux sont aujourd'hui les PMA dont l'endettement multilatéral pose des problèmes tels que le moment est venu d'agir pour trouver une solution. La Suisse a déjà participé à des opérations de désendettement multilatérales, et en a réalisé de son propre chef. Elle a également pris part au règlement d'arriérés de pays pauvres et surendettés vis-à-vis des institutions financières internationales.

\section{$\square$ Dettes multilatérales}

La facilité de désendettement sert aussi à régler les échéances de dettes multilatérales. Soixante-neuf millions de francs y avaient été consacrés à fin 1995. La Suisse s'est ainsi associée à d'autres donateurs pour payer les exigibilités de sept Etats pauvres et lourdement endettés envers le FMI, la Banque mondiale et la Banque africaine de développement. Les pays en question étaient le Nicaragua, le Viêt-nam, Haïti, le Rwanda (dettes envers le FMI et la Banque mondiale), le Niger et la Guinée-Bissau (Banque africaine de développement), le Pérou (Programme d'accumulation de droits du FMI - IMF Rights Accumulation Programme, $R A P)^{18}$.

Les dettes multilatérales doivent être remboursées à leur valeur nominale. Les 70 millions de francs prévus à cet effet dans la facilité de désendettement peuvent ainsi réduire d'autant la charge des pays endettés. Cependant, le principe du remboursement à la valeur nominale fait l'objet de critiques toujours plus vives. Le Service suisse de désendettement tient le raisonnement suivant ${ }^{19}$ :

- Ce principe est en contradiction avec celui de la responsabilité partagée (burden sharing) que les organisations de développement préconisent pour résoudre les problèmes posés par le surendettement. Les ONG demandent que le FMI et la Banque mondiale abandonnent leur statut de créanciers prioritaires. Le remboursement à la valeur nominale est une manière inefficace d'utiliser des ressources limitées, et cela à des fins purement politiques (maintien du statut en question).

- La Suisse a adopté une attitude progressiste en matière de désendettement bilatéral. De ce fait, elle est moralement en position de proposer de nouvelles mesures d'allégement de la dette ; une mesure importante serait d'éponger les dettes multilatérales à la valeur marchande résiduelle, comme cela se fait pour les dettes bilatérales.

Un pays en développement doit régler ses échéances multilatérales s'il veut de l'argent frais du FMI et de la Banque mondiale, et même, souvent, pour obtenir des crédits de développement publics directement d'un pays industrialisé. Dans le cas des remboursements que la Guinée-Bissau devait faire à la Banque afri-

18 « Pour un pays en demeure vis-à-vis de la Banque mondiale ou du FMI, souscrire à un RAP c'est s'engager à mettre en œuvre un programme d'ajustement structurel de trois ans. Si le FMI considère ensuite la réalisation du programme comme réussie, il débloque des fonds considérables (2,3 milliards de dollars dans le cas du Pérou) pour régler les arriérés multilatéraux. » (Tiré de : Die schweizerische Entschuldungsfazilität : Hit oder Flop ?, Berne, janvier 1996, publié par le Service de désendettement).

${ }_{19}$ Cf. l'article de Jutta Blesse-Venitz, «Swiss Debt Reduction Facility (SDRF) », in Swiss Coalition News $\mathrm{N}^{\circ} 7 / \mathrm{March}$ 1996. 
caine de développement, les pays bailleurs de fonds ont demandé à la banque d'assainir son portefeuille de crédits à l'égard de ce débiteur. Des améliorations qualitatives de la politique de crédit pratiquée par les institutions de financement multilatéral peuvent effectivement contribuer à résoudre la crise de l'endettement.

\section{$\square$ Fonds de la dette multilatérale de l'Ouganda}

Pour résoudre le problème de son endettement multilatéral, l'Ouganda a ouvert un fonds géré par la banque centrale de ce pays et qui doit être alimenté par des donateurs bilatéraux. Ce fonds est destiné à financer régulièrement le service de la dette envers le FMI, la Banque mondiale et la Banque africaine de développement. La Suisse a participé avec le Danemark, les Pays-Bas et la Suède au financement de ce fonds qui totalise 60 millions de francs ; l'apport helvétique a été de 10 millions de francs. L'Ouganda a été l'un des premiers pays à bénéficier du fonds fiduciaire créé par la Banque mondiale dans le cadre de l'initiative PPTE.

\section{SOURCES \\ OCDE, Coopération pour le développement, Rapport du CAD 1995, Paris : OCDE, février 1996.}

UNCTAD, World Investment Report 1995, Transnational Corporations and Competitiveness, New York/Genève, September 1995, et CNUCED, Rapport sur l' investissement dans le monde, 1995 - Vue d'ensemble, Genève, février 1996. UNCTAD, World investment Report 1996, Investment, Trade and International Policy Arrangements, New York/Genève, September 1996, et communiqué de presse du 13 septembre 1996 (TAD/INF/2680).

UNCTAD, Trade and Development Report 1996, New York/Genève, September 1996, et CNUCED, Rapport sur le commerce et le développement 1996 : Aperçu général, New York/Genève, septembre 1996.

Banque des règlements internationaux, 66e Rapport annuel, Bâle : BRI, juin 1996.

OCDE, Communiqué de presse, "L'OCDE et les Economies dynamiques non membres examinent l'accord multilatéral sur l'investissement ", (SG/COM/NEWS(96)28).

OCDE, Communiqué de presse, "Apports de ressources financières aux pays en développement en 1995 : forte baisse de l'aide publique ; augmentation des apports du secteur privé ", (SG/COM/NEWS(96)63), 11 juin 1996.

UNCTAD, The Least Developed Countries 1996 Report, New York/Genève, avril 1996, et CNUCED, communiqué de presse de mars 1996 (TAF/INF/2645).

CNUCED, Bulletin n 34, novembre-décembre 1995, "Rapport sur l'investissement dans le monde, Activités de la CNUCED en matière de gestion de la dette ».

IMF, Survey, éditions 1995 et 1996.

La Vie économique, 5/96, "Transition économique dans les pays d'Asie centrale partenaires de la Suisse au FMI ». epd-Entwicklungspolitik, 7/96, mars 1996, « Weltbank schlägt neue Entschuldungsstrategie vor ».

Déclaration de Berne, Vers un développement solidaire, ${ }^{\circ} 134$, mai 1996, " Programme suisse de désendettement ».

Finanzplatz-Informationen, 3/96, September 1996, "Entschuldungskampagne : Banken machen nicht mit », 2/96, "Von » sagesse « keine Spur - IWF und Schuldenstreichung ».

Mosquito, Nr. 2/März 1996, « Die Schulden der ärmsten Länder - Abkehr vom Stückwerkansatz ».

Swiss Coalition News, Nr. 6/December 1995, Nr. 7/March 1996, Nr. 8/June 1996 et Nr. 9/September 1996.

Arbeitsgemeinschaft der Hilfswerke, « Die schweizerische Entschuldungsfazilität : Hit oder Flop ? Eine Beurteilung aus der Sicht der Entschuldungsstelle der Arbeitsgmeinschaft », Bern, Januar 1996.

Neue Zürcher Zeitung, 13. März 1996, «Zunehmende Direktinvestitionen » (Croissance des investissements directs, commentaire sur les World Debt Tables), 27/28. April 1996, « Entwicklung ohne Schuldenlast », 14. Mai 1996, « Fünf Jahre kreative Entschuldung », 21. Mai 1996, «Frühjahrstagung des IWF », 28. Juni 1996, « Weltentwicklungsbericht », 13/14. Juli 1996, "Osteuropa wächst nicht in den Himmel ", 13. September 1996, "Kreditvergabe des IWF auf Rekordhöhe », 19. September 1996, « Ungebrochene Mitttelfluss in die Dritte Welt »; 27. September 1996, 28/29. September 1996, 1. Oktober 1996, 2. Oktober 1996, 4. Oktober 1996 (session annuelle FMI et Banque mondiale).

Tages-Anzeiger, 10. September 1996, « Globalisierung ohne Ende - Neue BIZ-Mitglieder », 1. Juli 1996, « Mehr Hilfe für die Ärmsten »; 30. September 1996, 1. Oktober 1996 (session annuelle FMI et Banque mondiale). 


\subsection{CNUCED IX}

La Conférence des Nations Unies sur le commerce et le développement d'avril/mai 1996 a permis de définir le programme de travail de la CNUCED pour les années à venir. La CNUCED IX a décidé de poursuivre les réformes de l'organisation qui avaient été entamées lors de la Conférence précédente, en axant ses travaux sur un plus petit nombre de questions prioritaires dans le domaine du commerce et du développement. La CNUCED va continuer à porter son attention sur l'analyse du commerce et du développement, et sur l'assistance technique aux pays en développement et aux pays en transition. Une importance plus grande que par le passé sera donnée aux politiques que les pays doivent adopter pour attirer les investissements étrangers, et à la promotion des activités du secteur privé.

La CNUCED est le principal organe des Nations Unies en matière de commerce et de développement, avec pour mission la promotion du commerce international, notamment celui des pays en développement. La Conférence des Nations Unies sur le commerce et le développement a lieu tous les 4 ans, alternativement sur un autre continent. Elle permet de définir, au niveau intergouvernemental, les grandes orientations du travail de l'Organisation. La $9^{\mathrm{e}}$ Conférence des Nations Unies sur le commerce et le développement (CNUCED IX) s'est déroulée du 27 avril au 11 mai 1996 à Midrand, en Afrique du Sud, avec la participation de plus de 2000 délégués des 188 Etats membres.

Les précédentes conférences de la CNUCED ont eu lieu en 1992 en Colombie ; en 1987 à Genève; en 1983 à Belgrade. La Thaïlande s'est proposée pour accueillir la CNUCED X en l'an 2000.

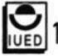
1993 Cartagena de Indias, 1992

\section{Thèmes abordés pendant la CNUCED IX}

Le thème général de la CNUCED IX portait sur la " promotion de la croissance et d'un développement durable dans une économie internationale en voie de mondialisation et de libéralisation ». Les débats ont porté sur les aspects suivants :

- politiques et stratégies de développement dans une économie mondiale de plus en plus interdépendante ;

- promotion du commerce international en tant qu'instrument de développement, compte tenu de l'aboutissement de l'Uruguay Round ;

- promotion du développement et de la compétitivité des entreprises au Sud et à l'Est ;

a travaux futurs de la CNUCED selon son mandat et incidences institutionnelles.

Trois groupes de négociation ont discuté à Midrand les thèmes suivants :

口 mondialisation, commerce et développement ;

口 investissements, développement des entreprises, technologie et promotion du commerce ;

- thèmes transversaux, dont coopération technique, ainsi que les réformes institutionnelles de l'Organisation. 
De sévères critiques à l'encontre du fonctionnement de la CNUCED ont été adressées ces dernières années, certains préconisant même la suppression pure et simple de cette institution (commission on global governance par exemple, voir Annuaire 1996). Les Etats-Unis doutaient aussi de plus en plus de l'utilité de la CNUCED. En 1995, les organes internes de contrôle de l'ONU ont relevé une série de dysfonctionnements : effectifs pléthoriques, manque de transparence, inefficacité et activités faisant double emploi avec celles de l'OMC et du Centre de commerce international. La crise financière des Nations Unies a aussi des répercussions sur le fonctionnement de la CNUCED. Il faut noter la situation particulière de la CNUCED, car le programme de travail est déterminé par l'organisation elle-même (par la Conférence et le Conseil), alors que les budgets sont fixés et le Secrétaire général nommé par l'Assemblée des Nations Unies. Le Secrétariat dépend directement des Nations Unies (comme 1'ECOSOC par exemple). Des diminutions de postes de travail ont été annoncées par le Secrétaire général de la CNUCED en février 1996 (moins 7 à 12\% de postes selon les catégories). Les méthodes de travail et l'efficacité de la CNUCED doivent être améliorées, en évitant notamment les doubles emplois avec le travail d'autres organisations internationales. Le nombre de divisions internes va diminuer et le budget pour les deux années 1996/1997 a été coupé de 10\%. Le Secrétariat de la CNUCED basé à Genève occupe actuellement 470 personnes.

Beaucoup de pays industrialisés, dont la Suisse, estiment depuis quelques années que le mandat de la CNUCED doit s'adapter aux changements du contexte mondial (effondrement du bloc communiste et plus grande reconnaissance des principes de l'économie de marché). La survie de l'organisation internationale dépend de ces réformes et l'adaptation de la CNUCED est même considérée comme un test de la capacité du système des Nations Unies à se réformer. Le temps n'est plus à la négociation d'instruments internationaux juridiquement contraignants, ni aux discussions sur un nouvel ordre économique mondial ou sur des modèles de développement alternatifs. Pour beaucoup de pays, la tâche de la CNUCED devrait être de contribuer à l'intégration des pays en développement et en transition dans l'économie mondiale et dans le système commercial multilatéral. La conclusion de l'Uruguay Round et la création de l'Organisation mondiale du commerce (OMC) sont des événements qui ont relégué la $\mathrm{CNU}$ CED à l'arrière-plan. De nouvelles complémentarités doivent être trouvées entre la CNUCED et l'OMC. Nombreux dossiers importants pour les relations NordSud sont maintenant négociés à l'OMC ou discutés dans d'autres organisations internationales: investissements internationaux, services, droits de propriété intellectuelle, commerce et environnement, clauses sociales, endettement international.

Les Etats avaient entamé le processus de réforme lors de la CNUCED VIII, sur la base d'un « nouveau partenariat pour le développement », mais le changement n'a été appliqué que lentement et avec de fortes résistances de certains pays en développement et de certains employés de la «vieille garde » du Secrétariat. Le changement est plus marqué depuis la nomination du nouveau Secrétaire général en septembre 1995, le brésilien Rubens Ricupero. Certains pays en développement insistent sur l'importance d'un forum de discussion sur les questions de développement, en contrepoids aux politiques préconisées par les organisations 
multilatérales dominées essentiellement par les pays industrialisés (institutions de Bretton Woods et OMC).

\section{$\square$ Principaux résultats de la Conférence}

Les Etats ont adopté deux documents finaux, la courte Déclaration de Midrand, ainsi que le texte intitulé « Un Partenariat pour la croissance et le développement ». Dans la Déclaration, les Etats plaident en faveur d'un partenariat triangulaire entre les pays développés, les pays en développement relativement avancés et les pays les moins avancés (PMA). Seul le Partenariat permettra à terme de combler les disparités entre nations. Préoccupation exprimée par beaucoup de pays en développement, la Déclaration relève que des conditions d'ordre écologiques et sociales ne devraient pas constituer de nouveaux obstacles à l'accès aux marchés du Nord.

Le document final principal est composé de quatre parties. Une première partie examine les enjeux de la mondialisation, puis le document recense les actions que les Etats et la communauté internationale devraient mener pour maximiser l'impact de la libéralisation sur le développement, tout en réduisant les risques d'instabilité et de marginalisation (en particulier dans les PMA). Une deuxième partie relève la contribution que peut apporter la CNUCED pour favoriser le développement durable. La dernière partie précise les réformes institutionnelles de l'Organisation. Selon le texte final, les analyses de la CNUCED devraient se concentrer sur les domaines suivants : investissements internationaux, renforcement de l'accès aux marchés pour les produits en provenance des pays en développement, amélioration de l'efficacité commerciale, pays les moins avancés. La CNUCED peut rechercher un consensus au niveau intergouvernemental sur certains sujets, en vue de préparer les négociations multilatérales futures de l'OMC. Les pays industrialisés plaidaient dans l'ensemble pour une concentration des activités de la CNUCED sur moins de thèmes, alors que les pays en développement souhaitaient un mandat plus large. La délimitation des tâches entre l'OMC et la CNUCED n'est pas facile à trouver.

Le Secrétaire général de la CNUCED a proposé la création d'un fonds d'affectation spéciale en faveur des pays les moins avancés. Le document final relève que la CNUCED pourra examiner l'opportunité de la mise sur pied d'un tel fonds.

\section{$\square$ Développement de l'entreprise privée}

La communauté internationale reconnaît de plus en plus l'importance du secteur privé. Les politiques de développement devraient ainsi selon le document final promouvoir des entreprises viables et compétitives sur les marchés nationaux et internationaux. La Conférence invite les gouvernements à poursuivre leurs efforts pour créer des conditions propices aux flux d'investissements : administration publique transparente, cadre administratif et réglementaire plus simple, respect des droits de propriété, amélioration de l'infrastructure, appui aux petites et moyennes entreprises, formation. La CNUCED est chargée de faciliter les échanges d'expériences pour la définition de stratégies de promotion du secteur privé. 


\section{$\square$ Efficacité commerciale}

Parallèlement à la CNUCED IX, le Secrétaire d'Etat pour les affaires économiques extérieures Franz Blankart a inauguré le Symposium national sud-africain sur l'efficacité commerciale (symposium cofinancé par l'OFAEE). Pour Franz Blankart, les opportunités commerciales créées suite à l'Uruguay Round « ne seront pas réparties équitablement tant que les pays les plus pauvres ne disposeront pas de l'infrastructure nécessaire pour tirer parti de la libéralisation du commerce ».' L'Initiative sur l'efficacité commerciale permet de renforcer la transparence, de diffuser l'information, de développer la concurrence et de fournir des informations commerciales à ceux qui n'y avaient pas accès dans le passé.

\section{INITIATIVE POUR L'EFFICACITÉ COMMERCIALE}

L 'Initiative pour l'efficacité commerciale est une des réalisations de la CNUCED les plus importantes de ces dernières années (voir Annuaire 1995). Elle cherche à favoriser une participation plus intense des pays en développement au commerce mondial.

Une quarantaine de "pôles de commerce" étaient opérationnels dans le monde (en mars 1996) et plus d'une centaine de pôles sont en projet ou en installation (dont deux pôles en Suisse, Genève et Lausanne). Ces pôles de commerce réunissent sous le même toit (ou mettent en réseau) les bureaux des principaux acteurs du commerce international (exportateurs, services douaniers, services de certification, banques, compagnies d'assurances, entreprises de transport, de télécommunication, etc.). Cette simplification du déroulement des opérations commerciales est utile particulièrement pour les PME et les pays les plus pauvres. Le réseau mondial des pôles commerciaux permet aussi d'échanger toute une gamme d'informations commerciales et représente un point d'accès aux réseaux d'information internationaux. ${ }^{2}$ L'Initiative est financée par des pays européens, les Etats-Unis, le PNUD et la Suisse.

\section{Activités d'assistance technique}

La CNUCED IX a permis de définir des lignes directrices pour la coopération technique fournie par la CNUCED aux pays en développement et pays en transition. La délimitation des tâches entre l'assistance technique fournie par la CNUCED, l'OMC et le Centre de commerce international (CCI) n'est pas facile à trouver. La Suisse est l'un des principaux bailleurs de fonds des programmes de coopération technique de la CNUCED. La Suisse soutient les programmes dans les domaines suivants : formation et conseils pour l'utilisation du Système généralisé des préférences, pôles de commerce, formation dans les activités commerciales (Trainfortrade), assistance pour une meilleure gestion de la dette, mise sur pied de politiques pour attirer les investissements étrangers (Forinvest), formation pour conclure des accords commerciaux, renforcement des capacités

1 CNUCED, Communiqué de presse, « Déclaration de Franz Blankart lors du symposium national sur l'efficacité commerciale ", n TAD/INF 2653, 29 avril $1996^{2}$ L'information du réseau mondial des pôles commerciaux, par exemple sur les possibilités de commercer et d'investir, est diffusée sur internet (http ://www.unicc.org/untpdc).

2 L'information du réseau mondial des pôles commerciaux, par exemple sur les possibilités de commercer et d'investir, est diffusée sur internet (http ://www.unicc.org/untpdc). 
techniques (pour les PME). ${ }^{3}$ La CNUCED mène en outre une douzaine d'autres programmes d'assistance technique (non financés par la Suisse), notamment dans le domaine des transports. Selon le document adopté lors de la Conférence, ce sont les pays les moins avancés qui devraient bénéficier en priorité de l'assistance technique fournie par la CNUCED.

\section{$\square$ Poursuite des réformes institutionnelles}

Des réformes dans le fonctionnement de la CNUCED avaient été entamées lors de la CNUCED VIII. Lors de cette nouvelle session de la Conférence, les Etats ont accepté la poursuite et consolidation de ces réformes. A la satisfaction de la Suisse, le nombre des organes subsidiaires (commissions) sera encore fortement diminué, en passant de huit à trois. Le nombre des réunions intergouvernementales a été pratiquement réduit de moitié et elles seront moins longues. Le Conseil du commerce et du développement ne se réunira en session ordinaire plus qu'une fois par année (au lieu de deux), en automne. Certains thèmes seront traités non plus dans une division ou commission particulière, mais de manière transversale (pays les moins avancés, lutte contre la pauvreté, développement durable, coopération Sud-Sud, renforcement du rôle des femmes). Le Conseil renforce son contrôle sur les activités du Secrétariat.

\section{$\square$ Nouvelles commissions de la CNUCED}

Le Conseil du commerce et du développement a constitué trois nouvelles commissions le 8 juillet 1996. La première traitera du commerce des produits de base, des biens et services. Elle s'est réunie début novembre 1996 pour examiner les incidences des Accords du Cycle d'Uruguay sur le développement des pays en développement et sur les moyens de mieux profiter du nouveau système commercial multilatéral. La réunion prévue mi-février 1997 examinera les liens entre commerce, développement et environnement. La deuxième commission se penchera sur l'investissement, la technologie et les questions financières connexes. La troisième commission étudiera le rôle des entreprises, ainsi que les mesures pour faciliter le commerce. Elle permettra notamment de suivre l'Initiative pour l'amélioration de l'efficacité commerciale (et «pôles de commerce »). Ces commissions se réuniront en principe une fois par an (plus quelques réunions d'experts).

\section{$\square$ Organisations non gouvernementales}

Selon le texte final de la Conférence, le secteur privé et les autres acteurs de la société civile seront associés plus fortement aux travaux de la CNUCED (ONG, milieux scientifiques et universitaires). L'ouverture aux acteurs non gouvernementaux de ces dernières années s'est surtout opérée envers l'économie privée. Le Forum des ONG qui s'est déroulé parallèlement à la CNUCED IX a attiré une centaine d'ONG, la plupart des continents africain et asiatique (très peu d'ONG du Nord). Les ONG souhaitent mieux pouvoir participer aux discussions et négociations de la CNUCED et de l'OMC.

\footnotetext{
${ }^{3}$ Une brochure de la CNUCED détaille l'ensemble des nombreux programmes de coopération technique. United Nations, Meeting the Development Challenge, Technical Cooperation Programmes of the UNCTAD, New York and Geneva : United Nations, 1995.
} 
Pour la Suisse, la CNUCED devrait permettre d'intensifier le dialogue entre les représentants des gouvernements et le secteur privé, considéré comme le moteur du développement économique. La Suisse a par contre refusé la demande de la Communauté de travail des œuvres d'entraide portant sur l'intégration dans la délégation suisse officielle d'un représentant des ONG. Les ONG regrettent aussi que la Suisse n'ait pas contribué financièrement à l'organisation du forum parallèle des ONG (forum financé par l'Union européenne, le Danemark, la Norvège et la Suède).

Le texte de préparation de la Conférence évoquait la possibilité d'établir un " sénat (ou assemblée) du développement " composé d'une centaine de représentants de gouvernements, de personnalités de l'économie privée ou de la société civile. Cette assemblée consultative pourrait formuler des recommandations pour le Conseil de la CNUCED. Le texte final ne retient pas cette proposition mais le Secrétaire général peut continuer à étudier cette question et faire des propositions au Conseil.

\section{Engagement de la Suisse en faveur d'une réforme du travail de la CNUCED}

La Suisse s'est fortement engagée en faveur des réformes institutionnelles de la CNUCED, dans la préparation et le déroulement de la CNUCED IX, ainsi que dans la médiation pour la rédaction des documents finaux. En sa qualité de Président du Conseil (de septembre 1995 à l'été 1996), l'ambassadeur suisse William Rossier a mené la phase de préparation de la Conférence et les négociations à Midrand. La délégation suisse auprès de la CNUCED IX était menée par le secrétaire d'Etat Franz Blankart, et composée de représentants de l'OFAEE, de la Mission de la Suisse auprès des organisations internationales, de la DDC et de l'Ambassade suisse à Pretoria. Représentant les pays industrialisés, le président de la Confédération Jean-Pascal Delamuraz a assisté à la table ronde d'ouverture de la Conférence (face à quatre chefs d'Etats de pays en développement). Le suisse Markus Kummer présidait en outre le deuxième groupe de négociation sur les investissements et les entreprises.

La Suisse tire un bilan très positif de cette CNUCED IX. Elle estime que le document final représente une bonne base pour revitaliser l'Organisation et rationaliser son fonctionnement et ses structures. La Suisse a plaidé en faveur d'une concentration des activités et d'une meilleure complémentarité avec l'OMC. Si l'OMC est un forum de négociation et de contrôle des règles multilatérales, avec le règlement des différends, la Suisse estime que la CNUCED garde un rôle dans l'analyse des problèmes et la préparation de certains thèmes de négociations futures. La CNUCED peut aussi appuyer les pays en développement dans leurs efforts d'intégration dans le commerce international et de développement du secteur privé. Les documents adoptés à la CNUCED IX vont dans le sens de ces orientations souhaitées par la Suisse.

CNUCED, Rapport du Secrétaire général de la CNUCED à la neuvième session de la Conférence, Genève : CNUCED, TD/366, 2 janvier 1996.

UNCTAD, Midrand Declaration and A Patnership for Growth and Development, UNCTAD, TD/377, 1996.

CNUCED, 30 ans au service de la croissance et du développement. Guide de la CNUCED : 30 ans et au-delà, New York et Genève : Nations Unies, 1994.

CNUCED, Communiqués de presse n TAD/INF/2637, 2652, 2657, 2669, 2676, année 1996. 
CNUCED Bulletin $\mathrm{n}^{\circ} 35$, janvier-mars 1996.

CNUCED IX, notes d'information $\mathrm{n}^{\circ} 1$ à 15 , avril-mai 1996

CNUCED, Déclaration de Caracas (réunion préparatoire des Ministres des pays d'Amérique latine et des Caraïbes), CNUCED LA/MM/77(VIII)/1, 23 janvier 1996.

CNUCED, Position de base de l'Union européenne sur la IX ${ }^{e}$ CNUCED, CNUCED TD/369, 7 mars 1996.

Declaration of NGO, Globalisation must not be at the expense of people, Joint international NGO Statement for Unctad-

9. Midrand, 24-28. April 1996.

Der Bund, 7. Mai 1996.

Croissance, $\mathrm{n}^{2} 392$, avril 1996, pp. 38-41.

Development Update, $\mathrm{n}^{\circ}$ 14, United Nations, March-April 1996.

Journal de Genève, 15 décembre 1995.

Neue Zürcher Zeitung, 13/14. Januar 1996 « Deutlicher Handlungsbedarf bei der Unctad », 23. April 1996 « Unctad IX als Aufbruch in die Zukunft », 27/28. April 1996, 29. April 1996, 2. Mai 1996, 13. Mai 1996 « Die Unctad zwischen gestern und morgen ".

24 Heures, 13.5.1996.

Les documents de la CNUCED peuvent être commandés au service des ventes de publications des Nations Unies, Palais des Nations, CH-1211 Genève 10, tél : 022/907.26.15.

SITE INTERNET

http ://www.unicc.org/unctad/

\subsection{ORGANISATION MONDIALE DU COMMERCE (OMC)}

La Suisse est membre de l'OMC depuis le ler juillet 1995, après avoir été membre du GATT et avoir participé activement aux négociations de l'Uruguay Round. L'OMC est chargée notamment d'assurer le suivi de l'application des accords de l'Uruguay Round. La politique commerciale de la Suisse a été l'objet d'un examen au sein de l'OMC en mai 1996. Le Rapport final relève le contraste entre un régime commercial libéral appliqué par la Suisse pour les produits industriels et le protectionnisme relativement élevé dans les domaines de l'agriculture et des services. La première. Conférence réunissant les Etats membres de l'OMC a eu lieu en décembre 1996 à Singapour. Elle avait notamment pour tâche d'examiner la mise en æuvre des accords de l'Uruguay Round. Les discussions de la Conférence ministérielle risquaient de se polariser sur le débat des clauses sociales. Les gouvernements des pays en développement étaient fortement opposés à la proposition de certains pays industrialisés d'étudier à l'OMC les moyens de lier le respect des normes sociales fondamentales et le commerce international. Ce débat controversé a été finalement désamorcé en ne donnant pas de mandat à l'OMC pour des travaux dans ce domaine, tout en réaffirmant le rôle de l' OIT dans la promotion de normes de travail fondamentales. Cette relative victoire des pays en développement a été accompagnée par une avancée importante dans des domaines qui intéressent plus particulièrement les pays industrialisés (Etats-Unis et Union européenne en tête) ou les pays en développement nouvellement industrialisés. Un Accord sur les technologies d' information a été finalisé à Singapour et l'OMC a reçu le mandat de mener des études dans de nouveaux domaines, en vue de négociations futures (investissements directs et politique des cartels, marchés publics).

L'Organisation mondiale du commerce (OMC) a été créée le 1er janvier 1995, dans la foulée de la conclusion des négociations multilatérales de l'Uruguay Round. L'OMC aura sans doute un plus grand nombre de pays membres que l'Accord général sur les tarifs douaniers et le commerce (GATT), qu'elle a remplacé. Son champ d'action est aussi plus vaste, puisqu'il ne couvre pas seulement le commerce des marchandises, mais aussi le commerce des services et les droits 
de propriété intellectuelle. Comme postulat de base, l'OMC estime qu'une expansion du commerce international facilitée par la libéralisation du commerce entraînera des créations d'emplois, la croissance économique et une augmentation du niveau de vie.

Les principales fonctions de l'OMC sont les suivantes :

๖ « administrer et mettre en œuvre les accords commerciaux multilatéraux qui, ensemble, constituent les règles de l'OMC ;

a offrir un cadre aux négociations commerciales multilatérales ;

๖ s'efforcer de résoudre les différends commerciaux ;

- examiner les politiques commerciales nationales ;

- coopérer avec les autres institutions internationales qui s'occupent de l'élaboration des politiques économiques au niveau mondial $»{ }^{4}$

Dans l'année passée sous revue, les activités de l'OMC se sont concentrées sur l'examen de la mise en œuvre des accords de l'Uruguay Round, avec notamment le suivi des procédures de notification. Le système de l'OMC repose sur la surveillance mutuelle pour évaluer les politiques commerciales des pays membres. Ceux-ci doivent notifier à l'OMC les mesures prises pour se conformer aux accords multilatéraux. Ils doivent aussi notifier les nouvelles mesures commerciales prises ou modifications apportées dans le domaine commercial. Des problèmes apparaissent dans ce processus car la notification de certains pays est incomplète. 130 pays sont membres de l'OMC et une trentaine de pays sont candidats pour en devenir membres (dont beaucoup de pays en transition). La préparation de la première Conférence ministérielle de l'OMC a été la deuxième activité importante de l'année 1996.

\section{$\square$ Conférence ministérielle de Singapour}

L'Accord instituant l'Organisation mondiale du commerce prévoit des réunions biennales ordinaires à l'échelon ministériel. La première Conférence ministérielle des Etats membres de l'OMC s'est déroulée à Singapour du 9 au 13 décembre 1996. Elle avait pour tâche :

๖ d'évaluer la mise en œuvre des Accords de l'Uruguay Round ;

a de faire le point des négociations en cours et d'examiner le programme de travail pour les années à venir, avec un élargissement des travaux de l'OMC à de nouveaux domaines ;

」 de faire un tour d'horizon de l'évolution du commerce mondial.

La Suisse est membre de l'OMC depuis le $1^{\text {er }}$ juillet 1995. La délégation suisse était menée par le conseiller fédéral Jean-Pascal Delamuraz et le directeur de l'OFAEE Franz Blankart. Dans sa déclaration à Singapour, le Conseiller fédéral a souhaité que les négociations en cours à l'OMC débouchent sur des résultats plus concrets, notamment dans les domaines suivants : négociations pour la libéralisation des services financiers, relation entre commerce et environnement. Il est selon lui important d'assurer une cohérence entre les règles de l'OMC et des accords multilatéraux sur l'environnement.

4 OMC, Rapport annuel de l'OMC 1996, p. 98. Le Rapport annuel de l'OMC contient des données statistiques sur le commerce mondial (commerce par région et par secteur), une analyse de l'évolution des politiques commerciales, un dossier sur le commerce et l'investissement étranger direct. Il fait aussi le point sur les activités de l'OMC en 1995/96. Organisation mondiale du commerce, Rapport annuel 1996, Volume I, 218 p., Volume II, 170 p., OMC, Genève : OMC, 1996. 
La Déclaration ministérielle adoptée à Singapour contient les éléments suivants : - intégration des pays en développement au système commercial multilatéral ; - plan d'action en faveur des pays les moins avancés (PMA);

a confirmation du rôle de l'OIT dans le domaine des liens entre le commerce et les normes de travail fondamentales.

La Déclaration confirme aussi l'importance donnée à la mise en œuvre complète et effective des Accords de l'Uruguay Round, notamment dans les domaines des textiles et vêtements. Certains pays en développement auraient souhaité une accélération du processus de libéralisation dans ce secteur, l'Uruguay Round ne prévoyant cette libéralisation que d'ici l'an 2005. Les négociations en cours sur les télécommunications de base et celles sur les services financiers devraient se terminer en 1997. La prochaine conférence ministérielle de l'OMC aura lieu au début 1998 à Genève.

Trois groupes de travail sont mis sur pied, l'un sur les liens entre commerce et investissements et un autre sur l'interaction du commerce et de la politique en matière de concurrence (examen des pratiques anticoncurrentielles, comme les monopoles ou cartels). Un troisième groupe de travail devra mener une étude sur la transparence des pratiques de passation des marchés publics. ${ }^{5}$ La Conférence de Singapour a permis d'avancer dans la libéralisation de certains secteurs : dans le secteur des médicaments, la suppression des droits de douanes sur certains produits pharmaceutiques a été étendue à 400 produits supplémentaires (à la satisfaction de la Suisse). Les Etats-Unis et l'Union européenne ont décidé pour leur part la suppression (d'ici 5 ans) des droits de douanes sur les alcools forts et spiritueux.

Certains pays en développement on'exprimé leurs craintes face à l'élargissement du mandat de l'OMC à de nouveaux thèmes, car les pays les plus pauvres n'ont pas l'infrastructure administrative et le personnel suffisant pour suivre des négociations de plus en plus techniques et complexes. Les exigences de notification auprès de l'OMC et l'adaptation des lois nationales aux nouvelles règles de l'Uruguay Round entraînent de grandes difficultés. Certains pays en développement préféreraient d'abord une consolidation de la libéralisation dans les secteurs qui les concernent en premier lieu, et ne sont donc pas prêts à envisager un élargissement additionnel à d'autres secteurs comme les investissements.

Les ONG suisses de développement et d'environnement ont exprimé leurs revendications pour la Conférence ministérielle de Singapour. ${ }^{6}$ Ces organisations souhaitent d'une part une meilleure transparence sur le processus de négociation et une démocratisation de l'OMC. Les ONG demandent à l'OMC de mieux collaborer avec elles, en leur accordant par exemple un statut d'observateur et un meilleur accès à l'information. La libéralisation du commerce ne devrait pas, d'autre part, se faire aux dépens des politiques de protection de l'environnement.

La Communauté de travail des œuvres d'entraide estime que les résultats de la Conférence sont décevants, car elle n'a permis aucun progrès pour les pays les plus pauvres. L'agenda des discussions à Singapour a été dicté par les pays industrialisés, sans permettre d'améliorer concrètement l'accès aux marchés du Nord

\footnotetext{
5 Un accord plurilatéral existe déjà entre 20 pays industrialisés, dont la Suisse. L'OMC aimerait étendre l'accord à tous les pays, pour soumettre les commandes des Etats à des offres publiques internationales.

${ }^{6}$ Communiqué de presse de la Communauté de travail des œuvres d'entraide, Lausanne, 28 novembre 1996.
} 
pour les produits agricoles et textiles provenant des pays les plus pauvres? ${ }^{7}$. Dans le domaine des textiles et vêtements par exemple, certains pays en développement reprochent aux pays industrialisés de recourir abusivement aux clauses de sauvegarde et de ne libéraliser en premier lieu que des produits peu sensibles. Des reproches semblables sont adressés dans le secteur agricole, alors que ces deux dossiers sont d'une grande importance pour les pays en développement. Des avancées ont été enregistrées par contre dans les domaines qui intéressent plutôt les pays du Nord (baisse des tarifs douaniers pour les alcools forts, les produits pharmaceutiques, domaine des investissements et secteur des télécommunications).

\section{Plan d'action de l'OMC en faveur des PMA}

Les ministres réunis à Singapour se sont engagés dans leur déclaration finale à faire face au risque de marginalisation économique de certains pays en développement, en particulier les PMA (les PMA ne représentent qu'à peine $0,4 \%$ du commerce mondial, avec $12 \%$ de la population mondiale). Une réunion aura lieu à Genève en 1997 avec la CNUCED, le Centre du commerce international (CCI) et des organismes d'aide, pour favoriser une approche intégrée des moyens d'aider ces pays à accroître leurs possibilités d'échanges commerciaux. Un Plan d'action en faveur des PMA a été adopté pendant la conférence de Singapour. Selon les termes de cette décision, les pays membres de l'OMC devraient assister les PMA dans leurs efforts pour répondre aux obligations de notification auprès de l'OMC. Une attention particulière doit être accordée à l'assistance technique pour ces pays, en apportant un appui institutionnel dans le domaine commercial et en développant les capacités humaines. Un appui particulier devrait être apporté pour la diversification des exportations et la promotion d'un climat favorable aux investissements. Il faut aussi aider les PMA à mieux bénéficier des opportunités commerciales offertes par les accords de l'Uruguay Round. Les pays industrialisés devraient examiner les moyens de favoriser l'accès aux marchés du Nord pour les produits exportés par les PMA : préférences douanières, accès plus grand aux marchés pour les produits textiles et les vêtements. La proposition du directeur de l'OMC, Renato Ruggiero, d'éliminer les obstacles tarifaires sur tous les produits en provenance des PMA, n'a pas été reprise dans le Plan d'action.

Lors de sa déclaration devant la Conférence, le conseiller fédéral Jean-Pascal Delamuraz a estimé que l'intégration des pays en développement dans le système multilatéral est en passe d'être réussie sur le plan institutionnel. Mais cette intégration doit maintenant se traduire par une participation accrue de ces pays (en particulier des PMA) au commerce mondial. Il est selon lui nécessaire d'adopter des mesures qui améliorent réellement les débouchés d'exportation des pays les moins avancés.

\footnotetext{
7 La Communauté de travail a dressé en juillet 1996 une liste des actions que la Suisse pourrait entreprendre pour que les pays en développement puissent mieux profiter des opportunités offertes suite à l'Uruguay Round : amélioration de l'accès au marché suisse (diminuer la progressivité des droits de douanes sur les produits transformés et les crêtes tarifaires), mesures de politique commerciale en faveur des exportateurs des pays du Sud plutôt que de favoriser les exportateurs suisses, appui en infrastructure et en formation pour les délégations des pays les plus pauvres à Genève, démocratisation du processus de négociation de l'OMC en améliorant la transparence et en intégrant les ONG dans les délégations.

Voir Arbeitsgemeinschaft der Hilfswerke, Entwicklungspolitischer Dokumentations- und Pressedienst, Dokument $\mathrm{Nr}$ 1, Juli 1996. Voir aussi leur communiqué de presse « Werden den schönen Worten Taten folgen ? ", Bern, 13.12.1996.
} 
Un appel signé par 130 parlementaires suisses a été remis le 2 décembre 1996 au directeur général de l'OMC, Renato Ruggiero. Les parlementaires demandaient à la Conférence de tenir compte du problème de marginalisation des pays les plus pauvres, notamment en décidant de supprimer toutes les barrières commerciales à l'importation de produits en provenance de ces pays d'ici l'an 2000. L'appel relève que le commerce n'est pas un but en soi, mais qu'il doit être mesuré aussi à l'aune de son efficacité globale, de sa contribution au développement durable.

\section{Normes de travail fondamentales et commerce international}

La question des clauses sociales a suscité un débat très vif pendant la préparation et le déroulement de la Conférence de Singapour. Certains pays industrialisés ont proposé ces dernières années d'examiner, à l'OMC, l'opportunité de recourir à des mesures commerciales pour promouvoir une amélioration des conditions de travail (proposition des Etats-Unis, de la France, de la Belgique et de la Norvège). L'Union européenne restait divisée sur cette question car la Grande-Bretagne et l'Allemagne étaient plutôt contre cette proposition. Beaucoup de pays en développement craignent que l'application de clauses sociales ne soit un prétexte pour les pays industrialisés pour ériger de nouvelles barrières protectionnistes à l'encontre des importations en provenance de pays à bas salaires. Plusieurs délégués de pays en développement se sont vivement opposés à ce que l'OMC traite de la question des clauses sociales (Bangaldesh, Inde, Pakistan par exemple). sous la pression des pays qui veulent éviter un débat sur les clauses sociales, l'invitation à s'exprimer devant la Conférence a été retirée à Michel Hansenne, directeur de l'OIT.

La Suisse a une position très nuancée sur la question des clauses sociales. ${ }^{8}$ Dans sa déclaration, le conseiller fédéral Jean-Pascal Delamuraz a précisé que la Suisse était d'accord sur trois points : « notre engagement d'observer les normes fondamentales du travail; le refus de recourir à des mesures protectionnistes pour en imposer le respect ; le rôle primordial de l'OIT dans l'élaboration et la mise en œuvre de ces normes $»^{9}$. Pour la Suisse, la réflexion devrait se poursuivre encore, en étroite collaboration avec l'OIT.

L'OMC souhaitait éviter un trop grand antagonisme Nord-Sud, puisque l'organisation se fonde plutôt sur la recherche de consensus. Dans la Déclaration ministérielle adoptée à Singapour, les pays renouvellent leur engagement d'observer les normes du travail fondamentales reconnues sur le plan international. Le rôle de l'OIT dans l'établissement de ces normes est réaffirmé. Les pays estiment que la croissance économique et le développement favorisés par la libéralisation contribuent à la promotion de ces normes. Ils affirment rejeter l'usage des normes du travail à des fins protectionnistes et conviennent qu'il ne faut pas remettre en question l'avantage comparatif des pays en développement à bas salaires. Le texte va complètement dans le sens des revendications de certains pays en développement puisqu'il n'inscrit pas ce thème commerce et normes de travail à l'agenda des travaux de l'OMC, mais parle simplement d'une collaboration nécessaire entre l'OIT et l'OMC.

1997 OIT, p. 72.

\footnotetext{
8 Voir le Dossier de l'Annuaire Suisse-Tiers Monde 1996 sur les clauses sociales et le commerce Nord-Sud.

9 Organisation mondiale du commerce, communiqué de presse du 12 décembre 1996, WT/MIN(96)/ST/109 (Déclaration de la Suisse).
} 
Accord sur les technologies d' information

Les Etats-Unis, l'Union européenne, le Japon, le Canada et la Suisse accordent une très grande importance à la libéralisation des échanges dans ce secteur en pleine expansion (exportations de près de 600 milliards de dollars en 1995). L'Accord prévoit d'éliminer progressivement (en 4 ans, jusqu'en l'an 2000) les droits de douanes sur les échanges de produits des technologies de l'information. La palette des produits couverts par l'Accord est assez large, et comprend par exemple les composants d'ordinateurs et de téléphones, les écrans d'ordinateurs, photocopieurs, semi-conducteurs, fibres optiques et circuits intégrés, les programmes d'ordinateurs (mais pas les programmes musicaux ou les films).

L'Accord qui sera finalisé dans le premier semestre de l'année 1997 est de type plurilatéral. C'est-à-dire que peuvent devenir membres de l'Accord tous les pays qui souhaitent le ratifier (donc aussi les pays qui ne sont pas encore membres de l'OMC), et non pas d'office tous les pays membres de l'OMC. ${ }^{10}$ L'application de la clause de nation la plus favorisée implique toutefois que les pays qui deviennent membres doivent étendre les réductions douanières à tous les pays et non pas seulement aux pays ratifiant l'accord.

Cet Accord a été accueilli favorablement par les pays qui occupent une place importante sur le marché des technologies d'information, dont la Suisse, mais aussi des pays en développement comme Singapour, la Malaisie, la Corée du Sud, Taiwan, la Thaillande et le Mexique. 29 pays, dont la Suisse, ont signé l'Accord pendant la Conférence de Singapour.

\section{Investissement et commerce international}

Un groupe de travail de l'OMC sera chargé d'examiner les liens entre commerce et investissement, pour permettre éventuellement d'engager des négociations futures sur ce thème. Plusieurs pays industrialisés souhaitent ouvrir des négociations dans ce domaine.

La Suisse est favorable à la préparation par l'OMC d'un cadre multilatéral prévisible et cohérent dans ce domaine de l'investissement lié au commerce. Beaucoup de pays en développement restent réticents à l'idée d'un accord multilatéral dans ce domaine, car ils craignent qu'il puisse entraver des politiques nationales de développement, de contrôle des investissements et des activités des entreprises transnationales. Ils souhaitent canaliser les investissements étrangers en fonction de leurs propres priorités et besoins de développement.

\section{Examen de la politique commerciale de la Suisse}

Le mécanisme d'examen des politiques commerciales a été établi en 1988 lors de l'examen à mi-parcours de l'Uruguay Round. Ce mécanisme permet d'améliorer la transparence sur les politiques et pratiques commerciales des Etats membres, d'apprécier et d'évaluer collectivement et à tour de rôle ces politiques. Les examens ont lieu lors des réunions de l'Organe d'examen des politiques commerciales, sur la base d'un rapport du Secrétariat de l'OMC et d'un exposé de politique générale établi par le gouvernement intéressé. La politique commerciale de

${ }^{10}$ D'autres accords plurilatéraux ont été conclus à l'OMC : sur les aéronefs civils, les marchés publics, le secteur laitier et la viande bovine. 
la Suisse a été examinée les 28 et 29 mai 1996. ${ }^{11}$ Les Etats examinateurs étaient les Etats-Unis et Singapour. D'autres représentants d'Etats peuvent poser des questions à la délégation suisse lors de l'examen (délégation menée par l'ambassadeur Pierre-Louis Girard). Le rapport du Secrétariat relève les réformes législatives entreprises pour mettre en œuvre les accords de l'OMC (surtout dans l'agriculture et les marchés publics). Le Secrétariat de l'OMC et plusieurs pays relèvent que le régime commercial libéral appliqué aux produits manufacturés contraste pourtant avec la relative forte protection accordée à l'agriculture, aux industries alimentaires. Le secteur des services connaît aussi toute une série de restrictions.

Plusieurs pays s'inquiètent de la relative forte protection de l'agriculture suisse (Argentine, Australie, Canada, Etats-Unis, Hongrie, Nouvelle-Zélande, Roumanie, Slovaquie, Tchéquie). Le remplacement des quotas d'importation sur certains produits agricoles par des droits de douanes améliore certes la transparence, mais pas sensiblement l'accès au marché à court terme, car le niveau des droits sur les produits agricoles et les produits alimentaires est très élevé. Le système de prise en charge a été critiqué par certains pays. Ce système subordonne l'accès à certains contingents tarifaires à l'achat d'une certaine quantité de produits nationaux. Des pays se demandent pourquoi la Suisse juge nécessaire de continuer à encourager la production de céréales, de graines oléagineuses, de pommes de terre et de sucre (Etats-Unis). La progressivité des droits de douanes persiste encore, en particulier sur des produits présentant de l'intérêt pour les pays en développement. Certains pays ont demandé à la Suisse d'étendre le schéma de préférences douanières à d'autres produits agricoles, articles textiles et vêtements (demandé par exemple par l'Inde). La persistance d'accords de cartels dans l'économie suisse a aussi été critiquée et des pays demandent à la Suisse une ouverture du secteur de l'assurance à la participation étrangère et une déréglementation dans le transport aérien (Etats-Unis). Certains pays regrettent aussi les entraves à la liberté de circulation de personnes (permis de travail) (Chili et Singapour) et à l'acquisition de biens immobiliers. La délégation helvétique a apporté des informations sur les réformes en cours pour libéraliser le secteur agricole et d'autres secteurs de l'économie, dont le secteur des télécommunications.

\section{$\square$ Création du Centre international de commerce et de développement durable}

Le Centre international de commerce et de développement durable (CICDD) a été créé à Genève le 25 septembre 1996, par la Communauté de travail des œuvres d'entraide, en collaboration avec l'Union internationale pour la conservation de la nature (UICN, Gland), l'Institut international pour le développement durable (Canada), la Fundacion futuro Latinoamericano (Equateur) et la Consumer Unity \& Trust Society (Inde). ${ }^{12}$ Le nouveau centre a pour but de promouvoir le développement durable dans le commerce international. Il soutiendra l'action des ONG du Nord et du Sud par des analyses, en facilitant l'accès à la docu-

\footnotetext{
${ }^{11}$ Le Rapport sur l'examen de la politique commerciale de la Suisse est paru à l'OMC. World Trade Organization, Trade Policy Review - Switzerland 1996, Geneva : 1996, 176 p. (à paraître en français). Il contient un rapport du Secrétariat de l'OMC sur la politique commerciale, les textes fournis par le gouvernement suisse, ainsi que le compte rendu des débats devant l'Organe d'examen des politiques commerciales.

${ }^{12}$ Adresse du Centre international de commerce et de développement durable CICDD : Ch. des Anémones 13, 1219 Châtelaine. Tél : 022/979 94 92. Fax : 022/979 9093.
} 
mentation de l'OMC et de la CNUCED, en encourageant le dialogue entre ONG. Il souhaite être un pont entre la société civile et l'OMC. Le CICDD est financé par la Communauté de travail, d'autres ONG (dont OXFAM et NOVIB) et des contributions gouvernementales (Suisse : OFAEE, Danemark, Pays-Bas, Suède).

\section{SOURCES}

Organisation mondiale du commerce, OMC, un commerce ouvert sur l'avenir, Genève : OMC, 1995,36 p. (structure et fonctionnement de l'OMC).

Organisation mondiale du commerce, communiqués de presse (de la Conférence ministérielle de Singapour, 9-13 décembre 1996), communiqués n WT/MIN(96)/ST/5 (déclaration des Etats-Unis), WT/MIN(96)/ST/8 (déclaration du Brésil), 27 (déclaration de l'Inde), 81 (déclaration de la CNUCED), WT/MIN(96)/ST/109 (déclaration de Jean-Pascal Delamuraz, Suisse).

Organisation mondiale du commerce, communiqué de presse n WT/MIN(96)/DEC/W, 13 décembre 1996 « Déclaration ministérielle de Singapour ».

OMC, communiqués de presse PRESS/57, 9.10.1996 «Commerce et investissement étranger direct ».

Organisation mondiale du commerce, Rapport annuel 1996, Volume I, Dossier spécial : Le commerce et l'investissement étranger direct, 218 p., Volume II, 170 p., Genève : OMC, 1996.

World Trade Organization, Trade Policy Review - Switzerland 1996, Geneva, 1996, 176 p.

World Trade Organization, communiqué de presse ${ }^{\circ} \mathrm{WT} / \mathrm{MIN}(96) / \mathrm{W} / 2,18.11 .1996$ "Comprehensive and integrated WTO Plan of action for the least-developed countries ».

Myriam Vander Stichele, The Ministerial Conference in Singapore and the Developing Countries. An Introduction. Amsterdam, Transnational Institute, 8 November 1996, 16p. (Transnational Institute - TNI, Paulus Potterstraat 20, NL 1071, DA Amsterdam, The Netherlands.)

Arbeitsgemeinschaft der Hilfswerke, Entwiclungspolitischer Dokumentations- und Pressedienst, Dokument Nr. 1, Juli 1996 «Ein Jahr schweizerische Mitgliedschaft bei der Welthandelsorganisation (WTO) : Eine entwicklungspolitische Bilanz ».

Swiss coalition of development organizations, Swiss coalition news, Bern, Nr. 10, December 1996, « Enhancing the Accountability of The World Trade Organizazion ».

Le Courrier, 18 octobre 1996 «Centre international pour le commerce et le développement durable : Une ONG veut contrôler le libéralisme économique », 6 décembre 1996 «Les ministres du commerce de 128 pays feront le point sur la toute jeune OMC », 10 décembre 1996, 13 décembre 1996 « Jean-Pascal Delamuraz met en garde contre le protectionnisme $"$.

Journal de Genève/Gazette de Lausanne, 3 décembre 1996 «Une pléiade de parlementaires suisses dépose ses doléances auprès de I'OMC », 10 décembre 1996 « A Singapour, la clause sociale bute sur un front d'opposition ", 12 décembre 1996 " OMC : le marchandage bat son plein à la Conférence de Singapour ", 14/15 décembre 1996 « L’OMC jette les bases du marché mondial ».

La Liberté, 17 décembre 1996 « Les pays riches ont trouvé leur compte dans les marchandages de Singapour ».

Neue Zürcher Zeitung, 3. Dezember 1996, 5. Dezember 1996, 10. Dezember 1996 "Gemässigter Ton an der Welthandelstagung », 11. Dezember 1996, 12. Dezember 1996 « Verständigungsbemühungen der WTO-Minister », 13. Dezember 1996 « Impuls für ein Informationstechnologie-Abkommen. Ein Nebenergebnis der WTO-Ministertagung ", 14/15. Dezember 1996 « Die Welthandelskonferenz am Ziel. Erfolgreicher Abschluss der Gespräche in Singapour ».

Tages-Anzeiger, 14/15. Dezember 1996.

Pour les commandes de publications de l'OMC : publications de l'OMC, OMC, 154, rue de Lausanne, 1211 Genève 21. Tél. : 022/739.52.08.

Commande des communiqués de presse : Division de l'information et des relations avec les médias de l'OMC, centre William Rappard, 154, rue de Lausanne, 1211 Genève 21. Tél. : 022/739.50.07 ou 739.50.19.

\section{SITE INTERNET}

http ://www.unicc.org/wto 


\section{ENVIRONNEMENT ET DÉVELOPPEMENT}

Depuis la Conférence de Rio (1992), la politique internationale de l'environnement joue un rôle prioritaire pour la résolution des problèmes environnementaux globaux et la concrétisation du développement durable. La Suisse tente de prendre ses responsabilités dans ce domaine et de nombreux travaux sont en cours sur le plan national et international.

Dans le cadre du suivi de Rio, la Suisse s'engage dans la mise en auvre des conventions signées à Rio (Conventions sur le climat et la biodiversité) et participe activement au Panel intergouvernemental sur les forêts, en soutenant les travaux par des contributions techniques et financières. En février 1996, le Conseil fédéral a pris connaissance d' un rapport sur le développement durable, première étape en vue de la rédaction d'un plan d'action (mise en æuvre de l'Agenda 21 pour la Suisse). De plus, depuis 1993 la Suisse a participé, comme observateur, à la Commission pour le développement durable (CDD) qui se tient chaque année à New York. Depuis 1996, et pour trois ans, la Suisse en est membre.

En plus du Suivi de Rio, la Suisse participe aux diverses activités d'organisations internationales visant à lutter contre les problèmes environnementaux mondiaux (PNUE, OCDE, FAO). Au sein du Comité du commerce et de l' environnement de l'Organisation mondiale du commerce $(O M C)$, la Suisse lutte pour une meilleure prise en compte des intérêts de l'environnement dans les règles internationales en matière de commerce. Elle participe au Fonds mondial pour l'environnement, qui vient d'être réapprovisionné pour un montant de 64 millions de francs.

Au plan national, la Suisse s'est attelée à la révision de la loi sur la protection de l'environnement. Cette "loi-cadre " nécessitera un droit d'exécution supplémentaire, telles de nouvelles ordonnances ou la modification de certaines ordonnances existantes.' A noter que pour la première fois, le "Rapport sur le programme de législature 1995-1999 " fait mention de la nécessité pour la Suisse de concrétiser la notion de développement durable. ${ }^{2}$

\subsection{COMMISSION POUR LE DÉVELOPPEMENT DURABLE}

La Commission pour le développement durable $(\mathrm{CDD})^{3}$ a été instituée à Rio en 1992, lors de la Conférence des Nations Unies pour l'environnement et le développement. La CDD est une commission technique du Conseil économique et social de l'ONU, composée de 53 membres élus pour une période de trois ans selon une clé de répartition géographique. Le Suisse en est membre pour la première fois depuis 1996. Chaque année depuis le Sommet de Rio, la CDD, dont le siège est à New York, cherche à renforcer la coopération internationale. Forum de discussion et d'échange d'expériences dans le domaine du développement

\footnotetext{
L'OFEFP a publié des fiches d'information concernant notamment la révision de la LPE, «L'évolution de la politique en matière d'environnement » avril 1996.

2 Rappport du Conseil fédéral sur le Programme de législature 1995-1999 du 18 mars 1996 (96.016).

3 En décembre 1992, la 47e session de l'Assemblée générale des Nations Unies adoptait la résolution 47/191 qui déterminait les objectifs de la CDD, sa composition, les lignes directrices pour la participation des ONG, l'organisation du travail, ainsi que les relations de la Commission avec le Secrétariat et les autres organes des Nations Unies. Commission for sustainable development (CSD) en anglais.
} 
durable, la Commission examine les progrès de la mise en œuvre de l'Agenda 21 au plan national, régional et international.

La Commission pour le développement durable (CDD-4), qui s'est réunie à New York pour la quatrième fois du 18 avril au 3 mai 1996, a passé en revue un certain nombre de chapitres de l'Agenda 21 tels que ceux consacrés à la protection et la gestion des océans (ch. 17) et la protection de l'atmosphère (ch. 9). Pour les thèmes intersectoriels, la commission s'est penchée sur le chapitre 4 " Changer les modes de consommation et de production ", ainsi que sur le financement du développement durable (ch. 33), commerce et environnement (ch. 2) et transfert de technologies (ch. 34) ${ }^{4}$. Lors du segment ministériel, une cinquantaine de ministres de l'environnement ou de hauts fonctionnaires sont intervenus. S'ajoutait aux rapports nationaux des différentes délégations deux thèmes de discussion, d'une part les jeunes et l'Agenda $21^{5}$, d'autre part, l'organisation de la session spéciale de l'Assemblée générale des Nations Unies en 1997, qui doit faire le point 5 ans après Rio.

Le chapitre 25 de l'Agenda 21 est consacré aux « Enfants et aux jeunes dans le processus du développement durable». Le chapitre souligne que les jeunes représentent près d'un tiers de la population mondiale et les encourage à participer activement à l'édification de leur avenir. La part qu'ils prendront dans la protection de l'environnement sera déterminante pour la réussite à long terme de l'Agenda 21. Différents Etats ont présenté la situation dans leur pays. La Suisse a rédigé un rapport « Passeport pour le futur $\aleph^{6}$ qui fait le point sur l'éducation au développement durable dans notre pays.

La préparation de la cinquième Commission pour le développement durable (CDD-5) a provoqué de nombreux débats sur le rôle et le travail de cette dernière. Il est également apparu qu'un certain nombre de réformes devait être apporté afin d'améliorer la coordination et le contrôle du processus dans le cadre du système des Nations Unies. Certains Etats ont également insisté sur le renforcement du rôle politique de la CDD. A ce propos, « la Suisse souhaite une Commission forte qui aide à développer de nouveaux instruments pour avancer sur le chemin du développement durable ${ }^{7}$.

La délégation suisse, conduite par la Conseillère fédérale Ruth Dreifuss, était composée de représentants de l'OFEFP, du Département fédéral des affaires étrangères (DDC et Direction politique V) et de l'Office fédéral de l'énergie soutenue par la Mission suisse auprès des Nations Unies. Dans sa déclaration, Ruth Dreifuss a abordé deux points supplémentaires. Elle a d'une part insisté sur « la nécessité d'un transfert accru de techniques écologiquement rationnelles vers les pays en développement et les pays avec économie en transition » en présentant le rapport « Transfert and Cooperation in the Area of Environmentally Sound Technologies » issu d'un groupe de travail du CIRio ${ }^{8}$. D'autre part, en perspective de

${ }^{4}$ Sur le site Internet http ://www.iisd.ca/linkages/ se trouve un compte rendu de la CDD-4 jour par jour, ainsi qu'une synthèse et une analyse des travaux de la Commission.

5 L'Agenda 21 est un plan d'action négocié lors de la Conférence des Nations Unies sur l'environnement et le développement entre les différents Etats à Rio en 1992. Il contient une liste de mesures à mettre en oeuvre aux niveaux national et international pour promouvoir le développement durable du point de vue social, économique et environnemental.

${ }^{6}$ OFEFP, Passeport pour le développement durable en Suisse, mars 1996. Disponible gratuitement au service d'information de l'OFEFP, tél. 031/322.93.56.

7 Déclaration de la Conseillère fédérale Ruth Dreifuss lors de la CDD-4, mai 1996.

8 Comité interdépartemental pour le suivi de Rio. 
la Conférence ministérielle de l'OMC de Singapour, elle a relevé que la Suisse souhaite la création d'un mécanisme pour prévenir d'éventuels conflits entre les accords multilatéraux environnementaux et les règles de l'OMC.

New York accueillera la CDD-5 du 7 au 25 avril et l'Assemblée extraordinaire des Nations Unies du 23 au 27 juin 1997.

SOURCES

OFEFP, Passeport pour le développement durable en Suisse, mars 1996.

Déclaration de la Conseillère fédérale Ruth Dreifuss lors de la CDD-4, 1-3 mai 1996.

Earth Negociations Bulletin, Vol. 5, n 57 (site http ://www.iisd.ca/linkages/)

epd-Entwicklungspolitik, 10/11 96, Mai 1996, «Un-Kommission für Nachhaltige Entwicklung : Ein Forum ohne politische Profil ».

\subsection{SUIVI DE RIO EN SUISSE}

Trois ans après avoir lancé le processus de rédaction d'un plan d'action pour la mise en œuvre de l'Agenda 21 en Suisse, le Conseil fédéral a pris acte en février 1996 d'un rapport sur «Le développement durable en Suisse ». Préparé par le Comité interdépartemental pour le suivi de Rio (CIRio), le rapport explique le concept du développement durable, pose les exigences à remplir et définit les principales stratégies à mettre en place en Suisse. Dix-sept offices fédéraux, provenant de six départements, ont été associés à sa rédaction. En outre, les milieux externes à l'administration, comme l'économie privée, la science et les organisations d'environnement et de développement ont été consultés. La difficile recherche d'un consensus et le manque de moyens financiers dégagés peuvent expliquer les trois ans nécessaires à la finalisation du rapport.

\section{$\square$ Le rapport sur le développement durable en Suisse ${ }^{9}$}

Dans une première partie, le rapport présente la notion de développement durable comme étant « le nouvel objectif pour l'humanité ; il doit permettre un développement à long terme, sans que les bases naturelles de vie soient mises en péril ; ceci exige des possibilités d'accès aux ressources limitées équitables pour tous, une solidarité entre les hommes qui vivent de nos jours dans des conditions inégales dans les différentes parties du monde, une solidarité envers les générations futures, ainsi que du respect pour la nature dans sa beauté et dans sa diversité. » Le développement durable dépend d'une étroite synergie entre les trois facteurs-clés que sont la protection de l'environnement, l'efficacité économique et la solidarité.

Le rapport dessine un certain nombre de stratégies de mise en œuvre. Dans le domaine des finances, une réorientation des priorités doit être effectuée, passant de la suppression de certaines subventions à l'application du principe du pollueur-payeur. Il est en effet nécessaire d'envisager une réforme fiscale écologique. Le rapport insiste également sur l'importance d'un dialogue entre tous les partenaires sociaux au plan national, ainsi qu'une collaboration internationale, pour favoriser une politique cohérente sur le chemin du développement durable.

${ }^{9}$ CIRio, Le développement durable en Suisse, rapport du Comité interdépartemental pour le suivi de Rio, à commander au service d'information, OFEFP, 3003 Berne. 
Les mécanismes pour un contrôle efficace des résultats des mesures prises doivent être renforcés. La seconde partie se base sur certains chapitres de l'Agenda 21 considérés comme les principaux secteurs d'action pour la Suisse ; telles la solidarité internationale, la protection et promotion de la santé, la sauvegarde de la diversité biologique et son utilisation dans les biotechnologies, la protection de l'air et l'utilisation rationnelle de l'énergie, la promotion d'une agriculture et d'une exploitation forestière durable, l'élimination des déchets.

Lors de la préparation de ce document, de nombreuses critiques ont été émises, de la part des organisations de développement et d'environnement ${ }^{10}$ notamment, qui considéraient que ce rapport ne remplissait pas les ambitions de départ, soit la rédaction d'un plan d'action opérationnel pour le développement durable mentionnant les objectifs à atteindre, le calendrier et les mécanismes de financement. Pour répondre à ces critiques, le rapport est présenté comme une première étape sur la voie du développement durable en Suisse. Le Conseil fédéral estime qu'il est indispensable de poursuivre les travaux pour concrétiser aussi vite que possible ce concept et les mesures proposées. L'OFEFP a confié à un groupe de personnalités du monde économique et social la rédaction d'un rapport qui doit concrétiser la notion du développement durable. Sur cette base, le CIRio va élaborer un plan d'action pour la Suisse. Ce plan d'action sera présenté lors de la session spéciale de l'Assemblée générale de l'ONU qui se tiendra en juin 1997. Cette Assemblée générale a pour objectif de tirer un premier bilan du suivi de Rio cinq ans après la conférence.

\section{$\square$ Rapport des ONG «Au-dessus de nos moyens - chiffres et objectifs pour une Suisse durable "}

Déçues de l'évolution de la réflexion et de la faiblesse des propositions de l'Administration fédérale, cinq organisations d'environnement et six œuvres d'entraide $^{11}$ ont chiffré la transition de l'économie suisse vers la durabilité. Le résultat de l'étude est simple : si tous les humains consomment autant de quantité d'air, d'eau, de sol, de métaux, de bois, d'énergie que la moyenne des Suisses la terre entière ne suffirait pas. Il faudrait cinq planètes comme la nôtre ! Les onze organisations proposent les réductions suivantes de la pression sur la biosphère :

口 d'environ $85 \%$ les métaux non recyclés,

口 de $75 \%$ pour les énergies non renouvelables,

$\checkmark$ de $50 \%$ pour les engrais chimiques,

口 de $30 \%$ pour l'eau,

- de $10 \%$ pour le bois.

Le rapport définit les objectifs pour une Suisse durable, sans toutefois indiquer la manière de les atteindre, ce qui devrait faire l'objet d'une étude ultérieure. Cette étude s'inscrit dans le cadre d'un projet européen, Friends for the Earth.

\footnotetext{
${ }^{10}$ Communauté de travail, Prise de position de la politique de développement 1995.

${ }^{11}$ WWF, LSPN, Greenpeace, SPE, FES, Déclaration de Berne, Communauté de travail Swissaid/Action de Carême/Pain pour le prochain/Helvetas/Caritas. Ce rapport peut être commandé au WWF-Suisse, Documentation, ch. de Poussy 14, 1214 Vernier, tél. 022/939.39.90, au prix de 10.-
} 


\section{SOURCES}

OFEFP, Dossier de presse, « L'évolution de la politique en matière d'environnement ", ler avril 1996.

CIRio, Le développement durable en Suisse, Rapport du Comité interdépartemental pour le suivi de Rio, Berne, février 1996.

LSPN, Greenpeace, SPE, FES, Déclaration de Berne, Communauté de travail Swissaid/Action de Carême/Pain pour le prochain/Helvetas/Caritas, WWF, Sur un trop grand pied - chiffres et objectifs pour une Suisse durable, 1996. Basler Zeitung, 29. Februar 1996, « Nachhaltige Schweiz : Aktionsplan bis Frühling 1997 ».

Der Bund, 29. Februar 1996, « Aktionsplan bis Frühling 1997 ».

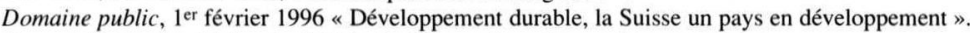

Journal de Genève, 24 janvier 1996 « La Suisse vit au-dessus de ses moyens ».

La Liberté, 24 janvier 1996 « Ecologie et société, le niveau de vie suisse perturbateur », 29 février 1996, « Responsabilités face à l'avenir ".

Neue Zürcher Zeitung, 29. Februar 1996, « Reflexionen zur nachhaltigen Entwicklung ».

Tages Anzeiger, 29. Februar 1996, «Aktionsplan von Rio : es geht langsam ».

\subsection{MISE EN EUUVRE DE LA CONVENTION SUR LA DIVERSITÉ BIOLOGIQUE}

La diversité biologique est constituée par l'ensemble des espèces animales et végétales, de leur matériel génétique et des écosystèmes dont elles font partie. Elle procure à l'homme aliments, vêtements, médicaments, mais aussi matériaux et substances pour ses activités agricoles, industrielles, artisanales et artistiques. L'uniformité génétique risque de conférer un haut degré de vulnérabilité, alors que la biodiversité garantit la capacité d'adaptation de l'environnement, donc de l'humanité, face aux problèmes tels que le réchauffement climatique et l'appauvrissement de la couche d'ozone. De fait, la biodiversité est devenue l'un des enjeux majeurs entre les pays industrialisés et les pays du Sud, qui se résume en trois domaines de marchandage :

$\checkmark$ accès aux ressources génétiques,

- accès aux biotechniques (par les transferts technologiques),

๖ juste rétribution financière pour ceux dont le travail et le savoir ont maintenu une riche biodiversité (apport des peuples autochtones et des communautés paysannes) et pour ceux qui élaborent de nouveaux produits à partir de ressources génétiques.

La Convention sur la diversité biologique signée à Rio est le fruit d'interminables négociations qui ont duré plus de deux ans. Elle comporte bien peu d'engagements précis, mais les débats autour de ce texte sont révélateurs des enjeux économiques et géopolitiques liés à la préservation des ressources naturelles, ainsi qu'à leur accès. La Convention est un accord-cadre. Contraignante sur le plan du droit international public, elle détermine des principes généraux. Les objectifs en sont :

- la préservation de la diversité biologique :

- elle établit le principe d'une aide à la préservation des espèces en faveur des pays abritant des espèces protégées, par le biais de crédits ou en favorisant le transfert de technologies, sans porter préjudice aux droits de propriété intellectuelle (art. 6,7),

- les pays membre de la Convention doivent inventorier et prévoir une conservation des espèces dans leur milieu (in situ, réserves naturelles, plantations traditionnelles, art. 8) ou hors du site d'origine (ex-situ, dans des jardins botaniques ou des banques de gènes, art. 9).

$\checkmark$ le partage équitable des bénéfices issus de l'utilisation durable des ressources génétiques. La Convention est sous-tendue par le postulat d'un «partage équitable et équilibré des bénéfices » de l'utilisation économique des ressources 
biologiques entre les pays du Sud et ceux du Nord. Le compromis auquel les Etats sont arrivés à Rio se fonde sur quelques principes :

- la Convention reconnaît le rôle et les droits des sociétés traditionnelles et indigènes (art. 8),

- elle admet le principe de souveraineté nationale sur les ressources naturelles (art. 15),

- elle prévoit donc une compensation sous forme d'accès aux (bio)technologies et de transfert technologique au bénéfice des fournisseurs de la matière première génétique, soit les pays en développement (art. 16.3), mais dans le respect du droit de la propriété intellectuelle (art. 16.2),

- elle introduit également les principes de l'accès prioritaire et de la participation à la recherche en biotechnologie (art. 19.1 et art. 19.2).

En septembre 1996, 150 Etats ont signé la Convention sur la biodiversité. Elle est entrée en vigueur en décembre 1993 et les Chambres fédérales ont donné le feu vert pour la ratification de la Suisse en novembre 1994.

Trois conférences des parties (COP) à la Convention ont eu lieu : la première en décembre 1994 à Nassau (Bahamas), la deuxième en novembre 1995 à Jakarta (Indonésie), la troisième en novembre 1996 à Buenos Aires (Argentine).

\section{$\square$ La première conférence des parties (COP-1)}

La réunion de Nassau étant la première conférence des parties, les négociations ont porté essentiellement sur les travaux d'organisation, sur les modalités de financement, et sur l'organisation de la circulation des informations (Clearinghouse mechanism), qui règle la coopération technique et scientifique. La Conférence de Nassau a créé un «Organe subsidiaire chargé de fournir des avis scientifiques, techniques et technologiques » (OSASTT) accessible à toutes les parties et jouant un rôle de conseil. ${ }^{12}$

\section{$\square$ La deuxième conférence des parties (COP-2)}

La deuxième conférence des parties s'est tenue à Jakarta du 6 au 17 novembre 1995. La COP-1 avait établi les lignes de travail pour la mise en œuvre de la Convention, la COP-2 a dû en initier le processus et un certain nombre de détisions d'importance y ont été prises : désignation du lieu du secrétariat, ouverture de négociation pour un nouveau protocole, mécanisme d'échange d'information, établissement d'un programme de travail basé sur un important budget, discussion sur la diversité biologique côtière et marine, ainsi que le renforcement des synergies avec des instruments internationaux existants, tels la FAO, l'UNESCO, et la CDD qui ont des programmes sur la biodiversité.

Sur le plan politique, la Conférence a enregistré un affaiblissement de plus en plus marqué des groupes politiques traditionnels (pays industrialisés/G 77 et Chine) au profit de groupes régionaux qui développent des positions concertées, autonomes des grands rassemblements usuels.

La délégation suisse, menée par Philippe Roch, directeur de l'OFEFP, était composée de représentants de différents départements (DFAE, OFEFP, OFAEE). Pour

12 OFEFP, Dossier de presse, Planète Suisse 1/95, « Convention sur la diversité biologique : Résultats de la première conférence des parties contractantes ». 
promouvoir la candidature de Genève, qui postulait pour l'obtention du siège du secrétariat, la délégation a été appuyée par le Conseiller d'Etat genevois Claude Haegi.

\section{Emplacement du secrétariat}

La COP a décidé d'établir définitivement à Montréal le siège du secrétariat. Après avoir, comme les trois autre candidats - Nairobi, Madrid et Montréal présenté son offre le jour d'ouverture de la Conférence, la délégation suisse a mené une intense campagne de promotion, qui n'aura cependant pas suffi à convaincre les délégations.

\section{Protocole international sur la sécurité biologique}

Le risque écologique d'introduire des plantes produites par génie génétique dans l'environnement n'est pas négligeable. Par exemple, des variétés transgéniques, pour la plupart résistantes aux herbicides, ont été mises au point pour plus de quarante plantes cultivées. Un transfert de gènes des plantes résistantes aux mauvaises herbes pourrait avoir des conséquences incalculables. En effet, celles-ci résisteraient alors aux herbicides et seraient difficiles à contrôler et néfastes pour les cultures ainsi que pour l'écosystème environnant. Tout en reconnaissant les potentialités immenses offertes par les biotechnologies modernes, dans des secteurs comme la santé ou l'agriculture, la Conférence a relevé que celles-ci ne pourront être pleinement réalisées que dans un cadre qui garantisse la sécurité de l'homme et de l'environnement à tous les niveaux et qu'il est donc nécessaire de combler les lacunes existantes dans le droit international. Le protocole devra s'occuper en priorité des mouvements transfrontaliers d'organismes vivants modifiés par des biotechnologies modernes, qui risqueraient d'avoir des effets défavorables sur la conservation et l'utilisation durable de la diversité biologique. De plus le protocole doit intégrer le principe de «l'accord préalable donné en connaissance de cause » (Prior Informed Consent - PIC), qui assure que l'exportation d'organismes vivants modifiés est soumise à l'accord des autorités du pays destinataire et que l'information nécessaire à l'évaluation des impacts sur la santé et l'environnement est mise à disposition.

La COP-2 a décidé de créer un groupe de travail qui doit commencer ses travaux au plus vite afin de finaliser le protocole avant 1998. La délégation suisse, qui a participé activement à l'élaboration du mandat du groupe, joue un rôle de pionnier dans ce secteur puisque les directives de la Commission suisse de la sécurité biologique ont été complétées en 1995 par une directive sur l'exportation d'organismes génétiquement modifiés qui intègre le principe du PIC.

\section{Promotion des transferts de technologies}

Les nouvelles biotechniques, le génie génétique en particulier, sont des domaines à forte intensité de connaissances. Elles permettent à l'homme de modifier de façon spécifique l'ADN (acide désoxyribonucléique) ou le matériel génétique des plantes, des animaux et des organismes microbiens, afin de créer des produits ou des techniques utiles. Les pays du Sud, riches en ressources génétiques, ne disposent généralement ni du personnel, ni des capitaux, nécessaires pour leur exploitation par ces procédés. Dans ce contexte, les pays du Sud revendiquent une collaboration scientifique, notamment par le biais de transferts de technologies, de façon à tirer eux-mêmes parti des ressources biologiques se trouvant sur 
leur territoire. Un article de la Convention est consacré à ce sujet dans le but de favoriser un transfert Nord/Sud.

Cette question a été abordée lors de la COP-2. La Suisse a souligné l'importance de l'évaluation des besoins en matière de transfert de technologies et a mis l'accent sur la nécessité d'un centre d'échange d'information, qui constitue un pas concret pour favoriser les transferts de technologies, et sur la nécessité de mieux associer le secteur privé aux travaux de la Convention. Sur ce point la Conférence a décidé de demander au Secrétariat de préparer un document sur les moyens de faciliter les transferts de technologies en consultant les Parties, les organisations internationales et le secteur privé.

\section{Accès aux ressources génétiques}

Le libre accès aux ressources génétiques est déterminant pour les pays du Nord et leurs industries et parallèlement les pays du Sud ne veulent plus laisser échapper ces précieuses richesses sans contrepartie. La Convention a dû déterminer quels étaient les propriétaires de la biodiversité. Deux tendances se sont affrontées lors des négociations ; les pays industrialisés ont cherché à conserver un accès libre et gratuit aux ressources génétiques et ont revendiqué la notion de patrimoine commun de l'humanité, les pays en développement au contraire se sont battus pour la reconnaissance du principe de souveraineté nationale sur les ressources biologiques, qui leur permettrait de négocier, sous une forme ou sous une autre, une rétribution financière. Après d'âpres débats la Convention a retenu le principe de la souveraineté nationale sur les ressources biologiques (art. 15). Cependant la Convention reste floue sur les modèles d'application et l'on s'oriente vers des systèmes d'accords bilatéraux, voire commerciaux. Un des exemples les mieux connus est l'accord entre la multinationale Merck et l'institut de la biodiversité du Costa Rica (INBIO). ${ }^{13}$

Lors de la COP-2, la question de l'accès aux ressources génétiques a été traitée à l'initiative de plusieurs pays en développement. L'art. 15, al.1 de la Convention stipule que «le pouvoir de déterminer l'accès aux ressources génétiques appartient aux gouvernements et est régi par la législation nationale ». Sur cette base certains pays, comme les Philippines, ont commencé à mettre en œuvre des législations relativement restrictives et compliquées pour l'accès à leurs ressources génétiques. L'attitude relativement restrictive de plusieurs PVD risque de s'étendre de manière plus ou moins disparate et de compliquer les échanges de ressources génétiques. La Conférence a prié le Secrétariat de procéder à une collecte d'information sur les mesures prises. Sur la base de ces données, la prochaine COP décidera d'une marche à suivre. La Suisse, qui n'a pas encore de position définitive sur cette question, consolidera sa position pour la COP-3.

\section{Ressources financières et mécanismes de financement}

Le débat concernant les ressources financières et le mécanisme de financement (FEM) a été extrêmement difficile et a fait l'objet d'un blocage de plusieurs jours sur des positions opposées entre les pays donateurs du FEM et les pays du Groupe des G-77 et de la Chine. Il en résulte que le FEM reste le mécanisme de financement intérimaire de la Convention. La COP devrait prendre une décision définitive lors de sa troisième réunion à Buenos Aires en novembre 1996.

${ }^{13}$ Déclaration de Berne, Vers un développement solidaire, $\mathrm{n}^{\circ}$ 121, février 1994, « Biodiverstié au Costa Rica ». 
Convention des Nations Unies sur la diversité biologique.

Message concernant la Convention des Nations Unies sur la diversité biologique.

Earth Negotiations Bulletin, Second meeting of the Conference of the parties to the Convention on biological diversity,

6-17 november 1995, vol. 9: 39, disponible sur Internet : http ://www.iisd.ca/linkages/

OFEFP, Dossier de presse, Planète Suisse 1/95, « Résultats de la COP-1 ».

OFEFP, Communiqué de presse, « Sécurité biologique, ouverture d'un protocole », 17 novembre 1995.

Vers un développement solidaire, Déclaration de Berne, $\mathrm{n}^{\circ}$ 121, février 1994, dossier « Biodiversité et brevetabilité du vivant ".

\subsection{MISE EN CEUVRE DE LA CONVENTION SUR LES CHANGEMENTS CLIMATIQUES}

\section{$\square$ Deuxième rapport du GIEC}

Réunis à Rome du 11 au 15 décembre 1995, les experts du Groupe d'experts intergouvernemental sur l'évolution du climat (GIEC) ${ }^{14}$ ont accepté officiellement les conclusions du rapport scientifique, qui comporte un document de synthèse sur les informations scientifiques et techniques actuelles, ainsi que trois résumés à l'intention des décideurs sur :

1) l'aspect scientifique de l'évolution du climat,

2) l'analyse scientifique et technique des incidences de l'évolution du climat, mesures d'adaptation et d'atténuation,

3) l'aspect socio-économique de l'évolution du climat.

Ce deuxième rapport d'évaluation est le fruit du travail commun de plus de 2000 scientifiques et experts du monde entier. Le document final comporte plus de 2000 pages. Le document de synthèse et les résumés destinés aux décideurs ont été rassemblés dans un volume intitulé : Deuxième rapport d'évaluation du GIEC, Changements climatiques, $1995^{15}$.

Pour la première fois, le rapport du GIEC dresse une liste détaillée des dangers économiques et écologiques qui menacent la planète. Le rapport estime que le monde se réchauffe à une allure inconnue depuis la fin de l'ère glaciaire, il y a dix mille ans. En un siècle la température globale a augmenté de 0,6 degré. Les scientifiques ne sont pas encore d'accord sur les hausses de température (entre 1 à 5 degrés), ni sur l'élévation du niveau de la mer (entre 15 à 95 centimètres) d'ici à l'an 2000. Mais le rapport confirme que le réchauffement atmosphérique observé depuis le début du siècle passé est dû en partie aux activités humaines. Une liste de mesures visant à maîtriser les émissions de gaz à effet de serre est présentée. Les conclusions et les mesures proposées dans ce rapport sont très importantes, puisqu'elles ont été la base de discussions et de décisions lors de la deuxième conférence des parties à la Convention sur les changements climatiques (COP-2).

\section{$\square$ La deuxième conférence des parties (COP-2)}

La deuxième conférence des parties sur la Convention cadre sur les changements climatiques (CCCC) s'est tenue à Genève du 8 au 19 juillet 1996. Les travaux ont été menés en séance plénière, ainsi que sous la direction des organes subsi-

\footnotetext{
${ }^{14}$ IPCC en anglais, Intergovernemental panel on climate change.

${ }^{15}$ GIEC, Deuxième rapport d'évaluation du GIEC, Changements climatiques, 1995, Genève OMM-PNUE, décembre 1995. A commander GIEC, c/o OMM, case postale 2300, 1211 Genève 2, tél. 022/730.82.15. Disponible dans les six langues officielles des Nations Unies.
} 
diaires ${ }^{16}$ et du Groupe spécial du Mandat de Berlin ${ }^{17}$. Les 17 et 18 juillet s'est tenu le segment ministériel et le 19 juillet l'assemblée plénière s'est réunie pour adopter les recommandations des organes subsidiaires. La délégation suisse, pour la partie de négociation, était conduite par Philippe Roch, directeur de l'OFEFP, et composée de représentants des offices fédéraux (OFAEE, OFEN, DP V, Office fédéral de l'agriculture et Mission de Genève), ainsi que d'un représentant issu des milieux économiques, scientifiques et des ONG (WWF). Ruth Dreifuss, Conseillère fédérale et cheffe du DFI, était présente lors du segment ministériel.

\section{Conférence de haut niveau}

Une centaine de ministres et de chefs de délégation se sont rencontrés les 17 et 18 juillet 1996. Bon nombre de déclarations soulignaient l'importance de l'adoption d'un protocole ou de tout autre instrument légal. Ruth Dreifuss ${ }^{18}$ a recommandé d'endosser le Deuxième rapport d'évaluation du GIEC afin qu'il serve de base pour les travaux de la Conférence. La grande majorité des ministres, à l'exception des pays producteurs de pétrole, ont accepté sa proposition. Ruth Dreifuss a également affirmé que « la Suisse est disposée à intensifier ses efforts afin de satisfaire aux engagements existant vis-à-vis des pays en développement. » Une table ronde ministérielle s'est tenue le 17 juillet sous la présidence de Ruth Dreifuss. La table ronde a permis une discussion «informelle » entre les ministres sur les obstacles de la mise en œuvre de la Convention. L'ordre du jour comportait trois points essentiels : une discussion sur les éléments nouveaux contenus dans le deuxième rapport du GIEC et leurs effets sur l'action politique, la seconde question portait sur les efforts nécessaires afin de satisfaire aux obligations de la Convention, enfin le troisième point s'adressait plus particulièrement aux pays qui se sont engagés à des obligations supplémentaires dans le cadre du Mandat de Berlin. ${ }^{19}$ Les conclusions de la table ronde ont facilité l'accord sur le contenu de la déclaration ministérielle.

\section{La Déclaration de Genève}

La Déclaration ministérielle confirme les conclusions du rapport du GIEC, demande d'accélérer le processus de négociation du protocole ou d'un autre instrument juridique et contient l'engagement des pays industrialisés à négocier des réductions contraignantes et significatives des émissions de gaz à effet de serre pour le siècle prochain. Elle a été adoptée sans vote et a été publiquement rejetée par 14 Etats principalement pétroliers ${ }^{20}$. L'Australie et la Nouvelle Zélande ont exprimé de sérieuses réserves. La Déclaration ne contient pas de propositions chiffrées pour une réduction de gaz à effet de serre, mais donne une impulsion au processus de mise en œuvre de la Convention et en particulier au Mandat de Ber-

${ }^{16}$ Les organes subsidiares de la CCCC sont chargés d'élaborer des recommendations sur les évaluations scientifiques, les communications nationales et les activités menées conjointement, le transfert de technologies et les besoins en matière d'appui financier. Ils doivent en outre fournir les éléments d'information nécessaires au processus d'un protocole dans le cadre du Mandat de Berlin.

${ }^{17}$ Le Groupe spécial du Mandat de Berlin a été chargé des négociations visant à l'adoption d'un protocole ou autre instrument juridique qui doit déterminer des objectifs quantitatifs de limitation et de réduction des émissions de gaz à effet de serre après l'an 2000 et les politiques et les mesures à mettre en oeuvre à cette fin.

${ }_{18}$ Allocution de la conseillère fédérale Ruth Dreifuss lors de la COP-2 sur les changements climatiques, le 17 juillet 1996 à Genève.

${ }^{19}$ Les ministres des pays industrialisés ont confirmé leur volonté de mener à bien le Mandat de Berlin avant la COP-3 à Kyoto en 1997.

${ }^{20}$ L'opposition la plus virulente est venue de l'Arabie Saoudite qui représentait également treize autres pays : Vénézuela, Iran, Koweit, Emirats, Syrie, Qatar, Jordanie, Nigeria, Russie, Oman, Bahreïn, Soudan et Yémen. 
lin (chargé des négociations visant à l'adoption d'un protocole ou d'un autre instrument d'ici à la troisième Conférence des parties) $)^{21}$. L'Allemagne, qui accueillera le secrétariat de la Convention au détriment de Genève, a proposé de désigner cette déclaration "Déclaration de Genève ", ce que la Conférence a accepté.

\section{Bilan de la deuxième conférence des parties}

Durant la COP-2, les milieux économiques ont fait de fortes pressions sur les délégations. Une centaine de grandes entreprises des Etats-Unis (Amoco, Caterpillar, Boeing, Ford, etc.) ont adressé une lettre à l'administration Clinton estimant que « leur pays devrait prendre garde aux risques de chômage et de croissance économique retardée en cas d'adhésion à l'accord discuté à Genève ». Non content de faire pression sur la Maison-Blanche, le lobby industriel s'est également montré très agressif au cours de la Conférence. ${ }^{22} \mathrm{~A}$ l'inverse, les compagnies d'assurance sont affolées par l'augmentation des catastrophes climatiques et font pression sur les gouvernements pour les obliger à légiférer plus durement contre les gaz à effet de serre. ${ }^{23}$

Dans un contexte difficile, la COP-2 a donné un certain nombre de signaux politiques d'importance afin que la Conférence des parties poursuive l'objectif d'un renforcement de l'engagement des pays industrialisés à réduire les émissions de gaz à effet de serre après l'an 2000. Le contenu de la Déclaration de Genève est considéré comme satisfaisant. ${ }^{24} \mathrm{D}$ 'autre part la Conférence aura vu le retournement de la position des Etats-Unis, qui se déclarent maintenant partisans d'un protocole ou autre instrument juridique avec des objectifs contraignants. Cette nouvelle attitude américaine devrait entraîner de nombreux pays qui calquent leur politique sur celle des Etats-Unis, ce qui devrait faciliter les négociations à venir.

De nombreuses sessions des organes subsidiaires et du Groupe spécial sur le Mandat de Berlin sont agendées en 1997 et la prochaine conférence des parties (COP-3) se tiendra du 1 au 12 décembre 1997 à Kyoto au Japon.

\section{$\square$ Loi sur la réduction des émissions de $\mathrm{CO}_{2}$}

En ratifiant, en 1993, la Convention sur les changements climatiques, la Suisse s'est engagée à stabiliser les émissions de $\mathrm{CO}_{2}$ au niveau de 1990 d'ici à l'an 2000, puis à les réduire. Le Conseil fédéral avait proposé en 1994 d'introduire une taxe sur le $\mathrm{CO}_{2}$. Après le résultat négatif de la procédure de consultation, le Conseil fédéral prépare une nouvelle loi sur la réduction des émissions de $\mathrm{CO}_{2}$ qui a été mise en consultation en octobre 1996. L'objectif de la loi est une réduction des émissions de gaz carbonique de $10 \%$ d'ici à 2010 , grâce aux efforts volontaires des milieux économiques et d'autres mesures. La taxe $\mathrm{CO}_{2}$ ne sera introduite que si les objectifs ne sont pas atteints par ce biais.

\footnotetext{
${ }^{21}$ Ce protocole doit définir pour les pays de l'OCDE et pays en transition économique des objectifs quantitiatifs de limitation et de réduction des émissions des gaz à effet de serre après l'an 2000 et des politiques et mesures à mettre en œuvre à cette fin.

${ }^{22}$ Le Nouveau Quotidien, 18 juillet 1996 « Le business américain veut saboter l'accord sur le climat ».

${ }^{23} 24$ Heures du 27 février 1996.

${ }^{24}$ Greenpeace et le Fonds mondial pour la nature (WWF) ont salué l'adoption de la déclaration, mais ont regretté le manque d'engagement précis.
} 


\section{$\square$ Protocole de Montréal}

La Suisse a ratifié le 16 septembre 1996 l'amendement de Copenhague au Protocole de Montréal. Cet amendement, qui vise à renforcer la protection de la couche d'ozone, a été adopté à Copenhague en 1992 par 75 Etats. Il ramène les dates d'interdiction des chlorofluocarbures (CFC) et des halons, composés des bromures de méthyle, de 2000 à respectivement 1996 et 1994.

\section{$\square$ Pétition des Églises "Le climat change "}

En juin 1996, le Conseil œcuménique des Eglises $^{25}$ (COE) a lancé une pétition internationale aux gouvernements et parlements des pays industrialisés " Le climat change! Agissons maintenant ». La pétition du COE est également relayée en Suisse par la COTE (Communauté Ecuménique de Travail Eglise et Environnement) soutenue par plus de 40 Eglises et organisations d'environnement et de développement. La pétition appelle le Conseil fédéral et les Chambres :

- à tenir les promesses faites lors du Sommet de la Terre à Rio en 1992 en ramenant d'ici l'an 2000 les émissions de $\mathrm{C}_{2}$ à leur niveau de 1990 ;

- à établir des objectifs contraignants pour le troisième millénaire en ramenant en Suisse les émissions de $\mathrm{CO}_{2}$ de 6,5 tonnes à un maximum de 2 tonnes par habitant et par an ;

- à faire respecter ces objectifs au niveau international et à aider les pays les plus touchés à faire face aux conséquences des changements climatiques. La pétition a récolté environ $30^{\prime} 000$ signatures en Suisse et a été déposée auprès des autorités fédérales le 24 février 1997.

1996 Conférence de Berlin sur les changements climatiques, pp. 51-57.

\section{SOURCES}

GIEC, Deuxième rapport d'évaluation du GIEC, Changements climatiques, 1995, Genève : OMM-PNUE, décembre 1995.

UICC, PNUE, OMM, Comprendre les changements climatiques: ce qu'il faut savoir sur la Convention-cadre des Nations Unies, nov. 1995.

Earth Negotiations Bulletin, Vol. 12, Summary of COP-2, Convention on Climate Change.

Nouvelles du climat mondial, publié par l'OMM, $\mathrm{n}^{\circ}$ 9, juin 1996.

Terre Nouvelle, juin 1996, dossier sur le climat.

Journal de Genève, 10 juillet 1996, 18 juillet 1996 (COP-2 à Genève).

Le Monde, 14 décembre 1995 « Face au réchauffement de la planète, les experts de l'ONU placent la stratosphère sous haute surveillance », 17 décembre 1995 « Les gouvernements reconnaissent la responsabilité humaine dans le réchauffement climatique ".

Nouveau Quotidien, 17 juillet 199618 juillet 1996 « Le business américain veut saboter l'accord sur le climat ",

Neue Zürcher Zeitung, 9. Juli 1996 « Ringen um eine griffigere Kimapolitik », 10., 18. und 19. Juli 1996 (Deuxième Conférence des parties à Genève), 20. Juli 1996 « Klima - kein Kollaps, sondern Daueraufgabe ».

Tribune de Genève, 18 et 19 juillet 1996 (Deuxième Conférence des parties à Genève).

\section{SITES INTERNET}

Official Web site of the Climate Change Convention : http : www.unfccc.de/index.html

The United Nations Framework Convention on Climate Change : http : www.unep.ch/iucc.html

The Intergovernemental Panel on Climate Change (IPCC) : http : www.unep.ch/ipcc/ipcc-O.html

Earth Negotiations Bulletin, Vol. 12, Summary of COP-2, Convention on Climate Change http : www.iisd.ca/linkages/vol.12/128000e.html

${ }^{25}$ Pour tout renseignement sur la pétition et ses résultats : Communauté Oecuménique de Travail - Eglise et environnement, case postale 7449, 3001 Berne, tél. 031/372.44.14. 


\subsection{FORÊTS}

Jusqu'au milieu du $\mathrm{XX}^{\mathrm{e}}$ siècle se sont surtout les forêts (boréales) des régions tempérées qui ont été exploitées, mais au cours des trente dernières années cette situation a évolué. La déforestation a pris les dimensions d'une catastrophe écologique globale. La vitesse de la coupe excède de beaucoup le taux de renouvellement naturel des ressources forestières. De nos jours, ce sont surtout les forêts tropicales qui sont victimes d'exploitations abusives et d'incendies intentionnels.

Entre 1980 et 1990 , la superficie des forêts tropicales a diminué en moyenne de 15,4 millions d'hectares par année, soit l'équivalent de trois fois la superficie de la France. Les taux annuels moyens de déforestation varient d'un continent à l'autre : Afrique $0,7 \%$, Amérique latine $0,8 \%$ et Asie $1,2 \%$. Selon les estimations de la $\mathrm{FAO}$, plus de la moitié des forêts tropicales originelles ont été détruites à ce jour.

La situation n'est pas meilleure pour les forêts boréales. A l'heure actuelle, environ $10 \%$ de leur superficie totale, soit environ 150 millions d'hectares se trouvent à un stade de succession précoce (graminées, peu d'arbres, buissons) suite à des incendies, à des coupes rases ou à d'autres dommages. Bien que l'on suppose que cette surface se reboisera, il est inquiétant de constater qu'elle s'étend. En raison de la charge de plus en plus lourde que constitue la pollution atmosphérique, un danger plane également sur le renouvellement des forêts. Tous les pays de la zone boréale signalent dans leurs forêts des dégâts visibles croissants qui sont imputables à l'affaiblissement des arbres causé par les immissions. L'effet de l'intensification du rayonnement UV-B auquel les forêts boréales sont soumises en raison de l'amincissement de la couche d'ozone est encore mal défini. Les changements les plus radicaux dans l'état de la forêt sont dus de plus en plus souvent aux incendies provoqués par l'homme et aux infestations par des parasites. On estime que chaque année, 5 à 10 millions d'hectares de forêts subissent des incendies et 15 millions des attaques de parasites.

\section{$\square$ Politique forestière internationale - Forest Panel}

Lors de la troisième réunion, qui s'est tenue du 11 au 28 avril 1995 à New York, la CDD a institué un panel intergouvernemental sur les forêts (PIF) doté d'un mandat limité dans le temps et l'a chargé de se pencher sur les modalités d'une politique forestière globale. Quatre réunions du panel sont prévues à ce jour : une première réunion organisationnelle a eu lieu du 11 au 15 septembre 1995 à New York, Genève a accueilli la deuxième (mars 1996) et la troisième conférence (septembre 1996), et la quatrième (début de 1997) est prévue à New York.

Le PIF-2 a mis en lumière quelques points qui risquent de demeurer épineux jusqu'à la fin des travaux du panel.

\section{La formulation d'indicateurs du développement durable de la forêt}

Les discussions sur ce point ont fait apparaître des approches très opposées entre les considérations écologiques, sociales, esthétiques, liées à la gestion de la forêt et les préoccupations de la sylviculture qui se limitent à la production de bois d'œuvre et aux valeurs économiques. Le PIF devra concilier ces deux approches pour l'avancée de ses travaux.

\section{」 Commerce et environnement}

Le commerce international de bois d'œuvre et autres produits forestiers a des 
effets positifs selon les uns, négatifs selon les autres sur la gestion durable des forêts. Cette divergence demande l'analyse de l'accès aux marchés et des barrières commerciales, de la certification et la labellisation, de l'intégration de l'ensemble des coûts, de la transparence des marchés, l'assistance financière et les transferts de technologies.

\section{- La discussion à propos des institutions et des instruments}

Une bonne partie du débat du PIF-2 sembla indiquer un manque de coordination avec d'autres forums de discussion. ${ }^{26}$ La problématique des forêts se trouve à l'intersection de nombreux domaines, ce qui implique des efforts de coordination importants au niveau international.

Lors du PIF-3 (9 au 20 septembre 1996) les délégués ont entamé des discussions substantielles sur les douze thèmes ${ }^{27}$ du programme de travail et ont également initié une discussion sur une éventuelle convention internationale. Le PIF-3 s'était donné pour objectif la rédaction d'un document contenant les éléments à introduire dans le rapport final du panel. Certains se sont dit satisfaits des échanges de vue et de l'émergence de quelques idées novatrices issues des discussions, mais la plupart des délégués ont exprimé leur déception quant à l'incapacité du panel à entrer dans une phase de négociation. L'ampleur du champ de discussion divisé en douze programmes de travail, les délais très courts pour consolider des positions par groupe régional, les documents n'étant disponible qu'en anglais et le temps qu'a pris le Panel pour discuter des modifications d'ordre du jour plutôt que des sujets eux-mêmes, expliquent les résultats du PIF3. La plupart des groupes de travail ont été confronté à de profondes divergences de vue entre les pays industrialisés et les pays en développement, sur des thèmes très politisés comme l'accès aux moyens financiers, le transfert de technologies, le commerce de produits forestiers ou la rédaction d'une éventuelle convention sur les forêts.

En prévision du PIF-4, les deux coprésidents du panel ont pour tâche de rédiger un document d'une vingtaine de pages qui doit présenter un compromis entre les divers points de vue exprimés lors des premières négociations. Ce document servira de base aux négociations des recommandations de la CDD.

\section{$\square$ Initiative Suisse - Pérou}

Le PIF a entre autres pour tâches d'évaluer le travail fourni par d'autres organisations internationales et organes multilatéraux dans le domaine forestier. Environ dix manifestations organisées et financées par différents pays sont prévues entre les quatre réunions du panel.

Le PIF-1 a pris note d'une initiative de la Suisse et du Pérou de charger un groupe d'experts indépendant d'examiner dans le cadre d'une étude le travail des organismes internationaux et des instruments juridiques en relation avec la question forestière. Cette étude vise à identifier les lacunes et les synergies de l'actuelle politique forestière internationale ainsi qu'à définir les domaines dans lesquels il

\footnotetext{
${ }^{26}$ FAO, PNUE, PNUD, Organisation internationale des bois tropicaux, Banque mondiale, les Conférences des parties des conventions sur la diversité biologique, les changements climatiques, la désertification et la Convention de Washington sur le commerce international des espèces de flore et de faune sauvages menacées d'extinction.

${ }^{27}$ Les douze thèmes : plan national sur les questions forestières, cause de la déforestation, connaissance indigène et autochtone sur les forêts, écosystème affecté par la désertification, pays confronté à un petit couvert forestier, assistance financière et technologique, valorisation des bénéfices forestiers, critères et indicateurs, commerce et environnement, organisations internationales et agences multilatérales, mécanismes légaux.
} 
convient d'accentuer les efforts. Lors du PIF-3, la Suisse et le Pérou ont remis le rapport du Groupe d'experts ${ }^{28}$. Le contenu du rapport a servi de base aux discussions du Panel. La Suisse a cependant regretté la faiblesse du degré de concrétisation des propositions, qui n'a pas correspondu aux résultats escomptés.

La Suisse s'est déclarée prête à contribuer au fonctionnement du groupe d'experts en finançant le travail du groupe et la rémunération de consultant, en fournissant l'appui scientifique d'une unité suisse de recherche (EPF de Zurich) et en mettant à disposition l'infrastructure organisationnelle.

\section{SOURCES}

OFEFP, Dossier de presse, Planète Suisse, février 1996, « Les forêts, pilier du développement durable ».

Bulletin des Négociations de la Terre, vol 13, $\mathrm{n}^{\circ}$ 14, mars 1996 et vol. 13, $\mathrm{n}^{\circ} 25$, sept. 1996.

SITE INTERNET

Le résumé du PIF est disponible sur Internet : http ://www.iisd.ca/linkages/

\subsection{UN ENVIRONNEMENT POUR L'EUROPE}

Depuis la deuxième Conférence européenne des ministres de l'environnement de 1993 à Lucerne, la Suisse n'a pas relâché ses efforts pour une mise en œuvre régionale de l'Agenda 21. Dans le cadre du programme d'action pour l'environnement en Europe centrale et orientale (EAP), la Suisse soutient des projets concernant l'environnement de ces pays. Lors de la troisième Conférence d'octobre 1995 à Sofia, la Suisse a signé avec la Bulgarie une remise de dette en faveur de l'environnement (« Debt for Nature-Swap »), d'un montant de 20 millions de francs. Par ce système de financement de projets dans le pays débiteur, le pays créditeur décrète une remise de dette en échange de l'investissement de ce montant dans un fonds écologique national par pays débiteur. ${ }^{29}$ La Suisse continue à participer activement au développement et à la mise en œuvre du EAP ainsi qu'à la préparation de la quatrième Conférence ministérielle « Un environnement pour l'Europe » qui se tiendra à Aarhus (Danemark) en juin 1998.

1994 p. 69.

\footnotetext{
${ }^{28}$ Le rapport « Swiss-Peruvian initiative on forests, Report of the Independent experts group », Genève, juillet 1996 est disponible en anglais, français, espagnol auprès de P. Mühlemann, Direction fédérale des forêts, OFEFP, 3003 Berne.

${ }^{29}$ OFEFP, Un environnement pour l'Europe, la contribution suisse, septembre 1995. A commander au service d'information de l'OFEFP.
} 


\section{DÉVELOPPEMENT SOCIAL}

\subsection{SECONDE CONFÉRENCE DES NATIONS UNIES SUR LES ÉTABLISSEMENTS HUMAINS (HABITAT II)}

Lorsque la première Conférence des Nations Unies sur les établissements humains s' est tenue à Vancouver (Canada) en 1976, la conception et la mise en œuvre des programmes et des politiques destinés à régler les problèmes du logement et des établissements humains étaient considérées comme incombant presque exclusivement aux gouvernements. A cette époque, on croyait encore pouvoir ralentir l'urbanisation. Mais au cours des vingt dernières années, l'urbanisation et le développement des grandes métropoles se sont poursuivis sans relâche. Au début du XXIe siècle, la majorité de la population mondiale vivra en ville. En 1992, l'Assemblée générale des Nations Unies a estimé qu'il était urgent d'attirer l'attention du monde sur la question du logement et de l'urbanisation. La seconde Conférence des Nations Unies sur les établissements humains (Habitat II) a mis en évidence le rôle crucial que joue la société civile au côté du secteur public et des entreprises privées, dans le règlement de ces problèmes.

Il y a cent ans, à peine $5 \%$ de la population mondiale vivait dans les villes de plus de 100 '000 habitants. Aujourd'hui, on estime que 45\% - soit environ 2,5 milliards de personnes - vivent dans des zones urbaines. Au cours des dernières années, c'est le monde en développement qui a subi la plus forte croissance des villes, puisque la population urbaine a triplé au cours des 30 dernières années. Entre 1950 et 1995 , le nombre des villes dans les pays industrialisés dont la population dépasse le million d'habitants a doublé, passant de 49 à 112 . Pendant la même période, le nombre de villes de plus d'un million d'habitants dans le tiers monde a été multiplié par 6, passant de 34 à 213.' Les trottoirs et les bidonvilles de ces agglomérations n'ont plus beaucoup de place pour accueillir plus de familles, mais la migration vers les villes continue. Les emplois se font rares et peu nombreuses sont les villes qui ont les infrastructures de base indispensables : - logement, eau potable, élimination des déchets, électricité, transport.

\section{$\square$ Evolution de l'urbanisation dans le monde}

En chiffre absolu, c'est en Asie que les concentrations urbaines sont les plus importantes : les cités abritent plus d'un milliard d'habitants, soit environ un tiers de la population de la région. En Afrique, l'urbanisation est un phénomène relativement récent ; pourtant, plus d'un tiers de la population vit déjà dans des villes et les taux de migrations urbaines augmentent. En Amérique latine, par contre, $75 \%$ de la population est déjà urbanisée - scénario qui pourrait bien laisser présager de l'avenir du monde en développement. Cependant, de nombreux observateurs ne s'inquiètent pas tant de la croissance des villes que des disparités flagrantes entre les conditions de vie des pauvres et celles des nantis.

La seconde Conférence des Nations Unies sur les établissements humains (Habitat II) s'est déroulée à Istanbul, en Turquie, du 3 au 14 juin 1996. Plutôt que de freiner l'exode rural, les Etats sont convenus de la nécessité de se donner les moyens de rendre les villes vivables. Les représentants de 185 pays y ont négo-

' Choix, la Revue du développement humain, PNUD, juin 1996, p. 18. 
cié la Déclaration d'Istanbul, ainsi que le Plan d'action Habitat qui traite des objectifs du logement adéquat pour tous et du développement durable des établissements humains. Outre les négociations proprement dites, un certain nombre d'événements en parallèle ont offert aux participants d'Habitat II et aux délégations gouvernementales l'opportunité d'explorer les thèmes de la Conférence.

\section{Tableau no 13 \\ Evolution de l'urbanisation \\ Pourcentage de la population totale vivant dans les zones urbaines}

\begin{tabular}{lrrrr}
\hline Région & $\mathbf{1 9 5 0}$ & $\mathbf{1 9 7 9}$ & $\mathbf{1 9 9 0}$ & $\mathbf{2 0 0 0}$ \\
\hline Afrique & 14.5 & 22.9 & 33.9 & 40.7 \\
\hline Amérique latine et Caraïbes & 41.5 & 57.3 & 71.5 & 76.4 \\
\hline Amérique du Nord & 63.9 & 73.8 & 75.2 & 77.3 \\
\hline Asie & 16.4 & 22.9 & 34.4 & 42.7 \\
\hline Europe & 56.5 & 66.7 & 73.4 & 76.7 \\
\hline Ex-URSS & 39.3 & 56.7 & 65.8 & 67.5 \\
\hline Océanie & 61.3 & 70.7 & 70.6 & 71.3 \\
\hline
\end{tabular}

Source : United Nations, World Urbanization Prospects (New York, 1991).

Les discussions qui ont eu lieu au Sommet des villes ont tourné autour de deux thèmes principaux :

๖ un logement convenable pour tous,

- le développement durable des établissements humains dans un monde de plus en plus urbanisé.

L'objectif d'Habitat II était de créer, dans un monde qui s'urbanise, les conditions permettant d'améliorer l'environnement vital de toutes les populations sur une base durable, en portant une attention particulière aux besoins et aux contributions des femmes et des groupes sociaux vulnérables dont la qualité de vie et la participation sont encore touchées par l'exclusion et autres inégalités affectant les pauvres en général. Pour atteindre ces objectifs, des principes et des stratégies d'action ont été définis dans un plan d'action mondiale (le Plan d'action Habitat) destiné à guider les efforts nationaux et internationaux au cours des deux premières décennies du $\mathrm{XXI}^{\mathrm{e}}$ siècle.

\section{$\square$ Position de la Suisse}

La coopération technique suisse a principalement orienté ses efforts vers les problèmes de développement ruraux. Cependant, depuis une quinzaine d'années, de modestes mais persistants efforts ont été déployés dans les établissements urbains d'Asie, d'Amérique latine et d'Afrique. Depuis 1995, la DDC a revu sa position dans ce secteur et mis sur pied une politique sectorielle urbaine. ${ }^{2}$

En Suisse, rares sont les ONG spécialisées dans ce secteur. La délégation suisse n'était pas renforcée par des représentants d'ONG comme ce fut le cas aux Conférence de Rio, du Caire, de Copenhague et de Beijing. Aucune organisation

${ }^{2}$ La politique sectorielle urbaine est présentée dans une brochure disponible à la DDC, Urban developement Policy, Series SDC Sector Policies, June 1995. 
non gouvernementale n'a fait le voyage en Turquie. L'administration fédérale a constitué l'ensemble de la délégation helvétique, dirigée par Peter Gurtner, directeur de l'office fédéral du logement, accompagné de fonctionnaires de son office, ainsi que des représentants de la DDC.

Dans la perspective Nord-Sud du développement urbain, la DDC a choisi de mettre l'accent sur huit points spécifiques :

- favoriser un développement humain centré sur les personnes dans une conception démocratique,

a promouvoir une bonne gouvernance et la participation de tous les acteurs sociaux,

- soutenir une décentralisation des droits, responsabilités et décisions apte à promouvoir une meilleure autonomie locale,

口 . promouvoir les villes intermédiaires pour un meilleur équilibre urbain-rural,

a porter une aide aux plus pauvres et défavorisés, en particulier les femmes, en renforçant leurs initiatives et capacités propres,

- garantir une sécurité juridique minimale aux plus défavorisés quant aux évictions forcées et aux rackets,

口 favoriser un meilleur accès à l'emploi et aux services de base, ainsi que les initiatives locales dans le secteur économique informel,

- garantir un meilleur environnement urbain aux plus défavorisés quant aux risques portant atteintes à la santé.

\section{$\square$ L'Agenda d' Habitat II}

Le document final, rédigé dans un langage très onusien, se compose de quatre chapitres : Préambule, Principes, Engagements, Plan d'action global et stratégie de mise en œuvre, ce dernier constituant le corps du document.

Dans le Préambule, les gouvernements reconnaissent le besoin impératif d'améliorer la qualité des établissements humains et identifient deux objectifs principaux : un logement convenable pour tous et le développement durable des établissements humains dans un monde de plus en plus urbanisé. Malgré les réalités différentes entre régions et pays, l'Agenda Habitat représente un appel à l'action à l'échelle mondiale, qui réaffirme le rôle positif des villes dans le développement économique, social, culturel et démocratique. Le chapitre consacré aux Principes engage les Etats à adopter une vision politique, économique, environnementale, éthique et spirituelle des établissements humains, fondée sur les principes d'égalité, de solidarité, de partenariat, de dignité humaine, de respect et de coopération, ces engagements devant être pris aux échelons local, national et international. C'est la conception d'un développement humain durable centré sur les personnes qui oriente globalement les Engagements pris par les Etats. Ces engagements sont précisés dans le Plan d'action.

La partie clé de l'Agenda, soit le Plan d'action global et stratégie de mise en œuvre, couvre près de 150 paragraphes. L'introduction du Plan d'action décrit les changements intervenus depuis la première conférence d'Habitat, tenue il y a vingt ans, notamment dans les domaines de la croissance démographique, de l'urbanisation et de la mondialisation économique. Les actions à l'échelon local sont reconnues comme de plus en plus importantes. Des actions sont recommandées dans les domaines suivants :

口 logement adéquat pour tous ; 
\ développement durable des établissements humains dans un monde en urbanisation ;

- renforcement des capacités de développement institutionnel ;

a coopération et coordination internationales ;

๖ mise en œuvre et suivi du Plan d'action d'Habitat. ${ }^{3}$

\section{DROIT AU LOGEMENT}

Lan $e$ droit à un "logement adéquat" est apparu comme l'une des questions les plus contestées des débats d' Habitat II. La Conférence a finalement admis que le droit au logement adéquat est une composante importante du droit à des conditions de vie adéquates. Les actions identifiées par le Plan d'action comprennent: habilitation des marchés à opérer efficacement ; facilitation de la production de logements de base communautaire; accès à la terre et de la sécurité juridique de la tenure, mobilisation des sources de financement, ouverture de l'accès aux services et à l'infrastructure de base, amélioration de la planification, de la construction, de la maintenance et de la réhabilitation. Parmi les actions reconnues pour les besoins particuliers des groupes vulnérables et défavorisés : la mise en place et l'application de lois préventives contre la discrimination ;

la promotion de systèmes de transports publics accessibles et à portée de bourse ; une couverture accrue en matière d' approvisionnement en eau et assainissement; la fourniture de subventions, de services sociaux et de filets de sécurité ; l' instauration d'une protection juridique contre les évictions forcées.

Au centre des débats de la Conférence, la proclamation du droit au logement a donné lieu à une controverse significative entre Européens, partisans d'une nette affirmation de ce droit, et Américains, rétifs à l'idée d'imposer aux Etats une obligation de résultat. La formulation d'un compromis difficilement négocié affirme l'engagement des Etats à la "réalisation pleine et progressive du droit à un logement convenable " mais surtout l'obligation "des gouvernements à faciliter l'accès au logement».

\section{$\square$ Déclaration d'Istanbul sur les établissements humains}

La Déclaration d'Istanbul, qui fut entièrement proposée et négociée à Istanbul, retrace tous les sujets traités dans le plan d'Action Habitat II. Elle s'étale sur 15 paragraphes et réaffirme «l'engagement des gouvernements à de meilleures conditions de vie dans une plus grande liberté pour l'humanité ». Les gouvernements doivent lutter contre la détérioration des conditions de vie en traitant entre autres « les modes non durables de consommation et de production, en particulier dans les pays industrialisés ». L'interdépendance des développements rural et urbain est notée. La promotion de "l'égalité entre l'homme et la femme au niveau des politiques, des programmes et des projets » d'Habitat est promise. « L'engagement à la pleine et progressive réalisation du droit à un logement adéquat, telle que prévue dans les instruments internationaux » est réaffirmé. Eu égard aux différentes contributions à la dégradation de l'environnement mondial, les gouvernements réaffirment le principe stipulant que les pays ont des respon-

${ }^{3}$ Les mesures du plan d'action sont détaillées sur le site Internet du Earth Negociations Bulletin http ://www.iisd.ca/linkages/habitat/ 
sabilités communes mais différenciées. L'action locale doit être conduite « à travers des programmes locaux basés sur le Plan d'Action 21, sur le plan d'Action d'Habitat ou autre programme équivalent ». La Déclaration appelle, par ailleurs, à une mobilisation des ressources aux niveaux nationaux et international avec des ressources nouvelles et supplémentaires provenant de toutes les sources, et réitère les engagements antérieurs, en particulier ceux pris dans le cadre du Plan d'Action 21 pour le financement et le transfert de technologies. Enfin la Déclaration stipule que la mise en œuvre du Plan d'action Habitat requiert « le renforcement du rôle et des fonctions du Centre des Nations Unies chargé des établissements humains », en tenant compte de la nécessité pour le Centre « de se focaliser sur des objectifs clairement élaborés et des questions stratégiques bien définies. »

\section{$\square$ Débat sur le rôle des partenaires}

Les planificateurs du développement insistent sur le fait que la décentralisation politique est essentielle pour obliger les responsables à rendre des comptes à leurs administrés, à tous les échelons de la société, et à tenir compte de leurs besoins. Robertson Work, administrateur des programmes du $\mathrm{PNUD}^{4}$, constate que « pour que les gens se sentent bien dans les villes, il faut opérer quartier par quartier, communauté après communauté. Il ne suffit pas au gouvernement de rester sur leur piédestal et d'ordonner des changements ». Le principal tournant négocié à Istanbul a été la nécessité de renforcer les « autorités locales démocratiques ", donc la décentralisation, considérée comme indispensable à l'efficacité de l'action et à la prise en compte des besoins des populations. En permettant la participation officielle de maires, de responsables ONG et de chefs d'entreprises, la Conférence aura ouvert une brèche dans le système onusien réservé aux Etats. Les nouvelles stratégies de développement insistent sur le partenariat entre divers groupes - fonctionnaires municipaux et nationaux, hommes d'affaires et organisations communautaires - afin de définir les problèmes et d'y apporter les solutions qui conviennent. Quelque 800 organisations non gouvernementales ont été accréditées à la Conférence.

Comme le relevait le quotidien français Libération ${ }^{5}$, ce soudain engouement des Nations Unies pour le partenariat avec les acteurs locaux et privés de la Ville n'est pas sans arrières pensées : les caisses des Nations Unies sont vides ! Beaucoup de pays réduisent ou reportent leurs contributions en attendant une réorganisation de la machine onusienne. D'où l'idée de faire payer à ses nouveaux partenaires leur strapontin. Et de relayer les propos de Jorge Wilheim, secrétaire général adjoint de la conférence «La présence des acteurs locaux et privés dans les nouvelles instances s'accompagnera d'engagements et de responsabilités ».

\section{$\square$ Présentation d' une initiative suisse à Habitat II}

L'une des innovations d'Habitat II a été la création d'instruments de suivi, dont le principal est un catalogue d'initiatives intitulé «Les Meilleures Pratiques ». Ce catalogue est constitué de 500 expériences urbaines réalisées et réussies, complément concret au Plan d'action.

${ }_{5}^{4}$ Choix, la Revue du développement humain, PNUD, juin 1996, p. 19.

5 Libération, 4 juin 1996, «Un Sommet pour humaniser la ville ». 
Dans ce cadre, un projet suisse conduit par l'Institut de Recherche sur l'Environnement Construit de l'EPFL a été présenté à Istanbul. L'Institut helvétique s'est associé à des universités et centres de recherches d'Argentine, de Bolivie, du Brésil et du Venezuela pour développer un cycle de perfectionnement à la planification participative de l'habitat populaire en Amérique latine. Depuis 1993, plus de dix séminaires ont eu lieu dans des villes intermédiaires. Cette présentation avait pour objectif de démontrer l'importance de la prise en compte des besoins exprimés par les habitants eux-mêmes des bidonvilles des grandes cités sud-américaines. Les séminaires ont débouché sur des interventions concrètes financées par les Etats et les villes concernées. ${ }^{6}$

\section{$\square$ Le Sommet alternatif d'Habitat}

En marge de certaines conférences internationales se sont parfois tenus des sommets dits alternatifs, organisés par et pour les organisations non gouvernementales ; ce fut également le cas à Istanbul. Selon les organisateurs le Sommet alternatif des ONG a connu un franc succès, puisqu'il a enregistré plus de 8500 entrées, dont $30 \%$ de participants turcs et $70 \%$ de représentants d'ONG du monde entier. 360 stands étaient occupés par des ONG présentant leur travail et leurs réflexions sur les questions débattues à la Conférence.

Des tensions sont cependant survenues entre les organisateurs de Sommet alternatif et les autorités locales. L'Association des droits de l'homme de Turquie (IHD) n'a pas manqué de protester contre la tenue d'une conférence internationale sur les «établissements humains » dans un Etat qui a détruit plus de 2500 villages kurdes et mis près de 3000 personnes sur les routes (estimation de l'IHD). Le contre-sommet a été interrompu temporairement par les forces de police turques un jour seulement après son ouverture.

La Conférence n'aura mobilisé, ni les ONG d'ordinaire massivement présentes dans ce genre de manifestation, ni les chefs d'Etats. L'ONU leur avait pourtant demandé d'assister au Sommet, mais ils n'étaient que quatorze. Les seuls à avoir vraiment répondu à l'appel ont été les maires de quelque cinq cents villes de toutes les régions du monde, qui ont exposé les problèmes auxquels ils sont confrontés et réclamé que les Etats et les institutions financières internationales les considèrent comme des partenaires à part entière de la gestion de cités dont ils ont pratiquement la charge. De plus aucun engagement financier n'a été pris afin de faciliter la mise en œuvre du Plan d'action. Les grands pays de l'OCDE avaient d'entrée de jeu fait savoir qu'ils n'avaient aucune intention de desserrer les cordons de leur bourse. Malgré l'annonce par la Banque mondiale et le PNUD du déblocage de modestes enveloppes, le Plan d'action se contente d'affirmer la nécessité de trouver des financements additionnels pour répondre à l'explosion des besoins en matière d'infrastructures urbaines et de faire appel au secteur privé pour pallier la défaillance des Etats et des bailleurs de fonds.

La seconde Conférence des Nations Unies sur les établissements humains met fin à la série de conférences mondiales conçues pour définir et lancer un plan d'action mondial permettant de relever les défis complexes créés par un siècle de

\footnotetext{
6 Jean-Claude Bolay, Planifier autrement : Habitat urbain et participation populaire en Amérique latine. Un exemple de coopération scientifique au développement urbain entre partenaires suisses et latino-américains, Granges : Office fédéral du logement, 1996.
} 
changements sans précédent. Le Plan d'action, avec l'engagement d'une mise en œuvre à l'échelon local, confère un élan opportun à la nouvelle étape de l'engagement onusien vis-à-vis de l'émergence d'une société civile (autorités locales, mouvements féminins, organisations de base communautaires, syndicats...).

\section{SOURCES}

Plan d'action de la Conférence des Nations Unies sur les établissements humain.

Déclaration d'Istanbul sur les établissements humains.

Bulletin du développement social de l'UNRISD, $\mathrm{n}^{\circ} 14$, printemps/été 1996.

Choix, la Revue du développement humain, PNUD, juin 1996.

Habitat II, $\mathrm{n}^{\circ}$ 7, May 1996, United Nations Conference on Human Settlements.

Jeune Afrique, ${ }^{\circ} 1852$, juillet 1996 , « Le cancer des villes ».

epd-Entwiklungspolitik, 13/96, Juni 1996, « Zurück zu Stadtstaaten ».

Mosquito, Nr. 3, Mai 1996, « Habitat II : Ja, aber nicht in der Turkei ».

NGLS Roundup, « Habitat II », September 1996, United Nations non-governemental liaison service.

Le Courrier, 3 juin 1996, « Le Sommet alternatif sur l'Habitat se fait expulser ».

Le Monde, 17 juin 1996, « La conférence d'Istanbul réaffirme la nécessité de rendre » vivables « les grandes villes ".

Neue Zürcher Zeitung, 3. Juni 1996, « Die Uno für manschenwürdige Städte », 15. Juni 1996, « Uno-Deklaration über das Recht auf Wohnung ".

Tribune de Genève, 3 juin 1996, «Conséquence du boum démographique, le village mondial sera urbain ».

\section{SITE INTERNET}

http ://www.undp.org/un/habitat/

Le site officiel de la Conférence des Nations Unies sur les établissements humains (Habitat II) est très complet. Il contient les documents préparatoires pour la Conférence, la Déclaration et le Plan d'action, les communiqués de presse, ainsi que des liaisons pour d'autres sites utiles concernant Habitat II (ONG, universités, communautés locales, etc.).

http ://www.iisd.ca/linkages/habitat/

Ce site contient notamment le Earth Negotiation Bulletin qui offre un résumé jour après jour des débats qui se sont tenus lors de la Conférence.

\subsection{ORGANISATION INTERNATIONALE DU TRAVAIL}

Deux ans après avoir fêté son $75^{\mathrm{e}}$ anniversaire, $\mathrm{l}^{\prime}$ OIT se cherche une nouvelle raison d'être, minée par des soucis financiers et remise en cause par sa difficulté à faire respecter ses conventions dans une économie en mutation. Au mois de juin, la Conférence annuelle du travail a conclu ses travaux en adoptant une convention destinée à protéger les travailleurs à domicile ; elle a aussi invité les Etats membres à redoubler d'efforts pour parvenir au plein emploi et pour intensifier leur lutte contre le travail des enfants. Le deuxième rapport sur l'emploi dans le monde a été rendu public en novembre 1996.

\section{$\square 83^{e}$ Conférence internationale du travail, juin 1996}

La promotion de l'emploi, la lutte contre le travail des enfants et les droits sociaux de millions de travailleurs à domicile dans le monde figuraient parmi les principaux points à l'ordre du jour de la $83^{\mathrm{e}}$ Conférence internationale du travail qui s'est tenue à Genève du 5 au 20 juin 1996. 2600 délégués de 160 Etats membres de l'OIT, représentant les gouvernements, les employeurs et les travailleurs se sont réunis. La Suisse est membre de l'OIT depuis sa fondation en 1919. La délégation helvétique était dirigée par Jean-Luc Nordmann, directeur de l'OFIAMT.

Le président français Jacques Chirac, hôte d'honneur de la 83e Conférence, a prononcé un discours devant l'Assemblée des délégués déclarant : « Pour réussir 
la mondialisation au service de tous... il faut mettre l'économie au service de l'Homme et non l'Homme au service de l'économie » ?.

\section{Travail à domicile, premières normes internationales}

Lors de la $83^{\mathrm{e}}$ Conférence les délégués ont adopté ${ }^{8}$ une convention et une recommandation $^{9}$ sur le travail à domicile, ce document constitue les premières normes internationales concernant ce secteur. Cette convention (la $176^{\mathrm{e}}$ ) fixe les conditions cadre de protection de cette catégorie particulière de travailleurs, auxquels elle confère les mêmes droits qu'aux autres travailleurs.

Selon un rapport du $\mathrm{BIT}^{10}, 8$ millions d'Américains, 1 million de Japonais et au moins 2,1 millions d'Européens peuvent être classés dans la catégorie des travailleurs à domicile, outre le secteur informel. Ce mode de travail est encore plus courant dans de nombreux autres pays : par exemple, 6 millions de Philippins et $20 \%$ de la population de Java central (Indonésie) le pratiquent. De nombreux Latino-américains travaillent à leur domicile, surtout pour l'industrie du vêtement ; le phénomène est aussi répandu en Afrique. Les travailleurs à domicile sont normalement rémunérés aux pièces, et leurs salaires sont inférieurs, soúvent de deux tiers, à celui des travailleurs en entreprise pour un travail comparable en quantité et en qualité. Leur durée de travail n'est pas réglementée et ils bénéficient rarement d'une protection sociale égale à celle des autres travailleurs effectuant les mêmes tâches. « La surcharge de travail porte atteinte à leur santé et à leur qualité de vie en général » constatent les auteurs du rapport. Les femmes constituent la grande majorité des travailleurs à domicile (jusqu'à 95\%), ainsi que les enfants.

Néanmoins, les délégués ont admis que le travail à domicile pouvait présenter des avantages non négligeables pour les employeurs, les travailleurs et les économies nationales. Pour de nombreux travailleurs, en particulier les femmes, ce mode de travail offre la possibilité de percevoir un revenu, tout en pourvoyant aux affaires domestiques. Dans le cas de certains professionnels, il correspond à un choix délibéré. L'opposition la plus nourrie à cette convention est venue des rangs des employeurs, qui ne voulaient pas d'un tel instrument. De même, les gouvernements des pays asiatiques, dans lesquels le travail à domicile est largement répandu, ne l'ont pas non plus accueillie favorablement. La délégation suisse s'est abstenue lors du vote d'adoption en raison de divergences existant entre le droit, la pratique suisse et la Convention.

\section{Le travail des enfants}

La question du travail des enfants (dans ses formes les plus préjudiciables et les plus intolérables) a occupé une place particulièrement importante lors de la Conférence, puisqu'une réunion tripartite informelle au niveau ministériel s'est penchée sur cette question. ${ }^{11}$ Selon le BIT, le nombre d'enfants qui travaillent

\footnotetext{
7 Travail, le magazine de l'OIT, $\mathrm{n}^{\circ} 17$, sept. 1996, p. 15 .

8 Vote sur la Convention : oui : 246 , non : 14, abstention : 152 . Vote sur la recommandation : oui : 303 , non : 4 ; abstention : 111 .

${ }^{9}$ Les recommandations ne sont pas destinées à ratification. Elles sont souvent adoptées en même temps que les conventions portant sur le même sujet qu'elles complètent de façon plus détaillée. Les recommandations s'adressent aux pays membres et ont pour but de stimuler et d'orienter l'action nationale dans des domaines donnés.

${ }^{10}$ Le travail à domicile, Rapport à la $82^{\mathrm{e}}$ session (1995) de la Conférence internationale du travail, BIT, Genève, 1994.

${ }^{11}$ Le BIT a préparé un rapport soumis aux fins de discussion à la Réunion ministérielle. Le travail des enfants : Que faire? BIT, Genève, 1996.
} 
demeure extrêmement élevé dans le monde. 73 millions d'enfants de 10 à 14 ans exercent actuellement une activité économique, ce qui représente plus de $13 \%$ de tous les enfants de ce groupe d'âge. ${ }^{12}$ Si l'on élargit la tranche d'âge (de 5 à 14 ans) ce sont 250 millions d'enfants qui occupent illégalement des emplois dans le monde. ${ }^{13}$ Michel Hansenne, directeur général du BIT, a rappelé lors de la Conférence la doctrine de l'Organisation : «Le travail des enfants de 15 ans ou moins dans des conditions qui entravent leur développement physique, psychologique et intellectuel doit être aboli ».

La Commission des résolutions s'est penchée sur la question du travail des enfants. Elle a invité les gouvernements à élaborer des politiques formelles et une législation nationale, afin d'abolir les formes les plus intolérables du travail des enfants (travail forcé ou esclavage, exposition à des produits toxiques et prostitution enfantine). Elle a en outre préconisé l'adoption de mesures "destinées à faire en sorte que l'opinion publique ait davantage conscience du coût économique et humain, ainsi que de la non-viabilité à long terme du recours au travail des enfants ».

Le Conseil d'administration a du reste décidé d'inscrire à l'ordre du jour de la Conférence de 1998, l'élaboration d'un nouvel instrument international sur cette question. Le recours à la procédure de double discussion permet d'augurer de l'adoption en 1999 d'une convention proscrivant les formes les plus intolérables du travail des enfants, qui pourrait être ratifiée par un grand nombre de pays industrialisés et en développement.

Le BIT assume un rôle de plus en plus important dans la lutte contre le travail des enfants notamment par le biais du Programme international pour l'abolition du travail des enfants (IPEC) créé en 1992. Ce programme est aujourd'hui opérationnel dans plus de 25 pays répartis sur trois continents. L'IPEC favorise l'instauration d'un véritable partenariat entre les services gouvernementaux, les organisations d'employeurs, les syndicats, les ONG et les autres secteurs concernés, les universités et les médias.

\section{Commission d' application des normes}

La Conférence a approuvé les décisions de la Commission d'application des normes, présidée par la Suisse, qui s'est penchée en particulier sur les cas de l'Iran, du Myanmar et du Nigéria.

Dans son rapport, la Commission déplore « la grave situation qui sévit au Myanmar » depuis de très nombreuses années ; l'on y recourt systématiquement au travail forcé, en violation de la convention sur le travail forcé ( $\left.n^{\circ} 29\right)$. A l'initiative de 24 délégués des travailleurs une procédure de plainte a été engagée contre Myanmar en vertu de l'article 26 de la Constitution de l'OIT. Dans leur demande, ils indiquaient qu'au Myanmar le travail forcé est systématique, atteint des proportions sans précédent et sévit dans un nombre croissant de secteurs. Selon les auteurs de cette demande, « de nombreux travailleurs sont astreints au travail forcé dans la construction des chemins de fer et des routes, dans le bâtiment et dans d'autres projets d'infrastructure qui résultent souvent des efforts déployés par le gouvernement pour promouvoir le tourisme ». L'ar-

\footnotetext{
${ }^{12}$ Travail, le magazine de l'OIT, $\mathrm{n}^{\circ} 16$, juin 1996, « Halte au travail des enfants !».

${ }_{13}$ OIT, Communiqué de presse, mardi 12 novembre 1996 (BIT/96/38).
} 
ticle 26 dispose qu'une commission spéciale d'enquête peut être instituée en cas de non-respect des normes internationales du travail et d'allégations faisant état de violations des droits de l'homme dans les Etats membres de l'OIT. Cette procédure, la plus contraignante prévue par l'OIT, sera appliquée au Myanmar. Elle sera mise en œuvre en 1997, lors de l'Année du Tourisme décrétée par le gouvernement.

Le gouvernement du Nigéria est cité pour non-respect de la Convention 87 relative à la liberté syndicale. La commission constate « une fois encore qu'aucun progrès n'a pu être observé en dépit des observations formulées par la Commission d'experts de l'OIT » au sujet de «très graves violations des droits de l'homme à l'encontre de syndicalistes ». En ce qui concerne la République islamique d'Iran, la commission conclut à l'existence de graves manquements à la convention $\mathrm{n}^{\circ} 111$ concernant la discrimination à l'emploi, notamment pour ce qui est de la politique de l'emploi appliquée aux membres de la communauté Baha'i et d'autres religions qui ne bénéficient pas d'égalité de traitement dans la pratique. La commission note également avec intérêt l'abolition des restrictions relatives à l'admission des femmes à l'université, mais elle exprime d'une manière générale sa « préoccupation quant à l'absence d'égalité pour les femmes dans la société et au travail».

\section{Politique de l'emploi dans une économie mondialisée}

La Conférence internationale du travail a également adopté un rapport sur les politiques de l'emploi dans une économie mondialisée. La Commission des politiques de l'emploi a insisté sur le fait que la recherche d'un plein emploi demeurait l'un des principaux objectifs des politiques économiques, sociales et de l'emploi. La Commission a invité l'OIT à analyser en collaboration avec ses mandants et les institutions de Bretton Woods :

- l'incidence de la libéralisation commerciale et financière sur le niveau et la qualité de l'emploi,

- l'établissement d'institutions et de réglementations du marché du travail qui puissent satisfaire au mieux le double impératif d'une plus grande croissance de l'emploi et de la compétitivité,

- les formes appropriées d'appui gouvernemental aux infrastructures, à la formation et aux petites et moyennes entreprises.

\section{Election au Conseil d'administration}

Le Conseil d'administration, qui guide les travaux de l'OIT, est composé de 28 membres gouvernementaux, 14 membres des travailleurs et 14 membres de employeurs. Les élections au Conseil d'administration pour la période 19961999 ont eu lieu lors de la Conférence.

\section{$\square$ L'emploi dans le monde 1996/97}

L'emploi dans le monde $1996 / 97^{14}$ est le deuxième rapport du BIT consacré à l'analyse des problèmes de l'emploi sous l'angle international. Ce rapport dresse un tableau plutôt morose sur la situation de l'emploi dans les différentes régions

\footnotetext{
${ }^{14}$ Bureau international du travail, L'emploi dans le monde 1996/97, Les politiques nationales à l' heure de la mondialisation, Genève : BIT, oct. 1996. Le rapport peut être obtenu au prix de 35.- auprès du Service des publications du BIT, 1211 Genève 22, tél. (022) 799.73.01.
} 
du monde. Le chômage et le sous-emploi touchent $30 \%$ de la population active dans le monde, soit près d'un milliard de personnes. Les pays industrialisés (OCDE) comptent au moins 34 millions de chômeurs ; au sein de l'Union européenne par exemple le chômage touchait en 1995 11,3\% de la population active. Dans les économies en transition, le chômage est monté en flèche et les inégalités de revenus sont de plus en plus criantes. Enfin, selon le rapport, dans de nombreux pays en développement on ne crée pas suffisamment d'emplois à haute productivité pour faire reculer la misère.

Le rapport, véritable plaidoyer en faveur du plein emploi, égratigne au passage les chercheurs et les décideurs qui affirment qu'en vertu de la révolution des techniques et de la mondialisation des échanges, la croissance économique ne pourra plus créer suffisamment d'emplois nouveaux, que le plein emploi est un concept désuet et que tout effort visant à stimuler la demande n'aboutirait, à terme, qu'à une accélération de l'inflation.

Les auteurs du rapport, qui considèrent que les taux de chômage actuels sont injustifiables sur le plan économique et inadmissibles d'un point de vue politique et social, identifient trois grands facteurs à la détérioration du marché du travail :

- la faiblesse des taux de croissance enregistrés depuis 1973,

- la lenteur de l'ajustement des salaires, le ralentissement de la productivité du travail et l'apparition de pressions salariales inflationnistes, qui ont perduré jusque dans le milieu des années 80 ,

- l'éviction progressive des chômeurs de longue durée du marché du travail.

Les auteurs proposent trois remèdes. D'une part, ils affirment qu'une croissance plus vigoureuse est possible, sous réserve que les politiques expansionnistes s'accompagnent de mesures crédibles pour éviter une recrudescence des tensions salariales inflationnistes et pour parer à la pénurie des compétences. Ils invitent également les gouvernements à « corriger les insuffisances du marché en matière de formation en lançant des programmes en faveur des catégories les plus désavantagées sur le marché du travail ». Enfin ils jugent contestable la solution la plus souvent préconisée pour résoudre les problèmes liés au chômage, à savoir la déréglementation du marché du travail et ils rappellent le rôle positif de la réglementation du marché du travail dans l'augmentation de la productivité et dans la protection des travailleurs vulnérables.

\section{Situation financière}

L'OIT est confrontée à des difficultés financières sans précédent, en raison du retard des Etats-Unis à payer leurs contributions (soit 25\% du budget de 673 millions de francs pour 1996 et 1997). L'année 1995 s'est achevée avec un déficit de trésorerie de 51,3 millions de francs. Les crédits affectés à titre préliminaire pour 1996 et 1997 ont été fixés à $80 \%$ des montants prévus dans le budget. ${ }^{15}$

\section{$\square$ Forum des entreprises 1996}

Le premier Forum des entreprises organisé par l'OIT s'est tenu les 8 et 9 novembre 1996 à Genève. Il a réuni des hauts responsables d'entreprises, de gouvernements, d'organisations d'employeurs et de travailleurs, d'universités et

${ }^{15}$ La Liberté, 6 juin 1996, « Le patronat international rejette l'instauration d'une clause sociale ». 
d'écoles de gestion d'une grande partie des 174 Etats membres. Le Forum s'est articulé autour d'un thème principal «L'entreprise et l'OIT : promouvoir le progrès social et la compétitivité des entreprises dans une économie mondiale ».

\section{Normes du travail et libéralisation du commerce international}

L'OIT et l'OMC sont les deux organisations concernées par la délicate question de l'introduction de normes sociales dans le cadre des échanges commerciaux internationaux.

En mars 1996, le Conseil d'administration a décidé de reconduire le mandat du groupe de travail sur la dimension sociale de la libéralisation du commerce international qui s'était réuni pour la première fois en novembre 1995, et de lui confier la tâche particulièrement ambitieuse d'examiner les nombreuses conséquences de la libéralisation des échanges et de la mondialisation de l'économie sur le plan social et sur celui de l'emploi. Lors du Conseil d'administration Michel Hansenne avait affirmé : " Aucune perspective d'accord ne peut être raisonnablement envisagée si l'attitude adoptée consiste à vouloir à tout prix imposer des sanctions commerciales ou à s'opposer résolument à l'établissement d'un lien quelconque entre le commerce et les normes de travail. La voie dans laquelle nous nous sommes engagés est celle qui permettra de mieux identifier la meilleure manière d'exploiter et de répartir les bénéfices tirés de la libéralisation du commerce et d'établir des règles du jeu favorables à tous les partenaires sociaux de l'économie mondiale. » Il a ajouté que les Etats membres de l'OIT et de l'OMC doivent pouvoir s'engager à promouvoir parallèlement la libéralisation du commerce et le progrès social afin d'honorer les obligations qu'ils ont contractées au sein de chacune de ces organisations. La décision du Conseil d'administration d'étendre les activités du Groupe de travail reflète sa conviction « que l'OIT, en raison de son mandat, de son caractère universel et de sa composition tripartite, doit jouer un rôle prépondérant dans le débat international sur le commerce et les normes de travail et s'efforcer d'exercer un impact maximal en la matière ${ }^{16}{ }^{16}$

La question de la clause sociale n'était pas à l'ordre du jour de la Conférence, mais différents lobbys en ont profité pour faire connaître leur position. L'Organisation internationale des employeurs (OIE) a précisé qu'elle refuse tout lien entre commerce et normes de travail ${ }^{17}$; à l'inverse la Confédération des syndicats libres a exigé que les accords commerciaux contiennent une clause sociale ${ }^{18}$. Le groupe de travail sur la dimension sociale de la libéralisation des échanges a mené une enquête sur les effets de la libération du commerce et la globalisation de l'économie. Il ressort de cette analyse qu'il est judicieux de procéder à des études spécifiques par pays. Le Directeur général du BIT s'étant adressé dans ce sens à notre pays, la délégation suisse assistant au Conseil d'administration de novembre 1996 a fait part de la volonté suisse de participer à une telle étude ; par la même occasion, la délégation suisse a présenté succinctement son point de vue en matière sur la relation entre droits fondamentaux des travailleurs et libéralisation du commerce : la Suisse étant attachée tant au libre échange qu'à la promo-

\footnotetext{
${ }^{16}$ BIT, Communiqué de presse, vendredi 29 mars 1996 (BIT/96/9).

${ }_{17}$ La Liberté, 6 juin 1996, "Le patronat international rejette l'instauration d'une clause sociale ».

18 Journal de Genève, 15 juin 1996, «Les accords commerciaux doivent contenir une clause sociale ».
} 
tion des droits de l'homme, ces deux domaines sont indispensables pour garantir un fondement stable au «village global " en cours d'élaboration.En décembre 1996 s'est tenue à Singapour la première Conférence ministérielle de l'Organisation mondiale du commerce. L'introduction d'une clause sociale dans les échanges commerciaux a été largement débattue entre les Etats. Quelques jours avant le début de la Conférence, Michel Hansenne s'est vu retirer, par le Conseil général de l'OMC présidé par l'ambassadeur suisse William Rossier, l'invitation qu'il avait reçue pour se rendre à Singapour. Cette décision aurait été prise suite aux pressions de quatre Etats d'Amérique latine, d'Asie et d'Afrique qui étaient opposés à ce que les normes de travail y soient débattues. ${ }^{19}$

En septembre 1996, les organisations non gouvernementales et les syndicats suisses ont créé une plate-forme commune intitulée "Forum normes sociales et commerce international ». Le Forum se veut un lieu de réflexion, de coordination, de formation et d'échange d'informations sur cette question. Trois groupes de travail ont été créés (Clause sociale et label, Monitoring, Label femmes). Une Newsletter sera publiée deux fois par an. ${ }^{20}$

1996 Clauses sociales et commerce Nord-Sud, pp. 186-270.

1996 OMC, p. 35.

\section{SOURCES}

Bureau international du travail, Compte-rendu provisoire, «Quatre-vingt-troisième session de la Conférence internationale du travail ", Genève : BIT, juin 1996.

BIT, Communiqués de presse publiés en 1996.

Bureau international du travail, L'emploi dans le monde 1996/97 - Les politiques nationales à l' heure de la mondialisation, Genève : BIT, oct. 1996.

Travail, le magazine de l'OIT, $\mathrm{n}^{\circ} 16$ - juin 1996, ${ }^{\circ} 17$ - septembre 1996.

Le Courrier, 16 novembre 1996 « Les normes de travail sont-elles source de concurrence déloyale ? ".

Journal de Genève, 19 mars 1996 « Le BIT se cherche une nouvelle raison d'être ", 13 juin 1996 " La Suisse propose une nouvelle Convention pour lutter contre le travail des enfants », 26 novembre 1996 « Le BIT lance un plaidoyer en faveur du plein emploi ".

Neue Zürcher Zeitung, 7. März 1996 « Welthandel und Sozialnormen », 8. November 1996 « Uberprüfungsbedürftige ILO-Konventionspolitik ».

\section{SITE INTERNET}

http ://www.unicc.org/ilo

Le 20 mars 1996 le BIT a ouvert un site Internet, qui contient des informations sur l'OIT (Mandat, histoire, structure et programmes). Un dossier « information », dans lequel se trouve les allocutions du Directeur général, les communiqués et les dossiers de presse, enfin des dossiers thématiques sur des sujets d'actualité. S'y trouve également les textes complets des principales conventions de l'OIT.

\subsection{ORGANISATION MONDIALE DE LA SANTÉ}

L'organisation mondiale de la santé $(O M S)$ fait face à une crise financière extrêmement grave. Lors de la $49^{\circ}$ Assemblée mondiale, il a notamment été décidé une coupe linéaire de 10\% sur le budget 1996/97, elle a également adopté une série de résolutions sur des questions de santé publique. Malgré ces difficultés l'OMS conduit des programmes de santé financés par des ressources extrabudgétaires choisis par les pays financeurs. En 1996, l'OMS a publié le deuxième rapport sur la santé dans le monde, qui est consacré aux maladies infectieuses.

\footnotetext{
19 Journal de Genève, 2 décembre 1996, "Le directeur général de l'OIT indésirable à Singapour ».

${ }^{20}$ Pour de plus amples renseignements : Pain pour le prochain, ch. du Boisy 3, 1004 Lausanne.
} 
Le rapport sur la santé dans le monde, 1996 - Combattre la maladie - Promouvoir le développement ${ }^{21}$ est le deuxième rapport de ce type publié par l'OMS. Dans cette édition consacrée aux maladies infectieuses, l'OMS lance un cri d'alarme face à ce qu'elle considère comme « une crise mondiale, qui n'épargne aucuns pays ». Les maladies infectieuses sont responsables de la mort de plus de 17 millions de personnes chaque année. Loin d'être terminée, la lutte contre les maladies infectieuses s'avère de plus en plus difficile. Certaines affections qui semblaient maîtrisées, comme la tuberculose et le paludisme, connaissent un regain d'activité (la tuberculose tue trois millions de personnes par an et le paludisme frappe jusqu'à 500 millions de personnes et en tue au moins deux millions par an). D'autres, comme le choléra et la fièvre jaune, frappent aujourd'hui des régions que l'on croyait à l'abri. Certaines infections offrent une telle résistance aux médicaments qu'il est devenu pratiquement impossible de les soigner. Parallèlement, le rôle des virus de l'hépatite et d'autres agents infectieux dans le développement de nombreux types de cancer devient de plus en plus manifeste.

De nombreuses maladies nouvelles, dont certaines incurables, font leur apparition partout dans le monde. L'exemple le plus spectaculaire est le SIDA causé par le virus de l'immunodéficience humaine (VIH), dont l'existence était inconnue il y a 15 ans encore. En l'an 2000, quelque 26,6 millions de personnes pourraient être atteintes par le VIH/SIDA. Un nouveau type de fièvre hémorragique à virus - Ebola est la plus connue - a frappé l'Afrique, l'Asie, l'Amérique latine et les Etats-Unis d'Amérique. Aux Etats-Unis est apparu le syndrome pulmonaire à hantavirus, caractérisé par un risque d'entraîner la mort dans plus de $50 \%$ des cas. D'autre part, de nombreuses régions du monde ont été confrontées à des flambées de maladies émergentes et réémergentes. Pour faire face à cette situation, l'OMS propose, dans son rapport, trois priorités au plan international pour les cinq années à venir. La première consiste à mener à bien l'éradication ou l'élimination de maladies telles que la poliomyélite, la dracunculose, la lèpre, la rougeole, la maladie de Chagas et l'onchocercose. La deuxième est de s'attaquer à des maladies anciennes, comme la tuberculose et le paludisme, qui posent des problèmes nouveaux de résistance aux médicaments et aux insecticides. La troisième est de prendre des mesures à brève et longue échéance contre les maladies émergentes.

\section{$\square 49^{e}$ Assemblée mondiale de la santé}

La 49e Assemblée mondiale de la santé s'est déroulée, pour la première fois durant une semaine seulement, du 20 au 25 mai 1996 à Genève. Quelque 1200 délégués représentant 190 pays ont délibéré sur les 32 points inscrits à l'ordre du jour, adopté 29 résolutions et entériné 13 décisions. La délégation suisse était conduite par l'Office fédéral de la santé publique et appuyée par le Département fédéral des Affaires étrangères (DDC, Division politique III), ainsi que par la Mission permanente suisse auprès des Nations Unies. Les discussions ont été marquées par les difficultés financières qu'affrontent l'Organisation. Le deuxième Rapport sur la santé dans le monde 1996 qui a servi de base pour la discussion générale est consacré aux maladies infectieuses.

\footnotetext{
${ }^{21}$ Organisation mondiale de la santé, Le rapport sur la santé dans le monde, 1996 - Combattre la maladie - Promouvoir le développement, Genève : OMS, mai 1996.
} 
Résolutions adoptées lors de l'Assemblée annuelle

L'Assemblée a adopté une trentaine de résolutions sur les questions de santé publique, dont nous citons les principales :

- Lutte contre le paludisme. L'Assemblée demande à l'OMS d'intensifier ses efforts pour combattre le paludisme qui fait des millions de nouvelles victimes chaque année (entre 300 et 500). Le Directeur général a été invité à étudier la possibilité d'instaurer un programme spécial sur le paludisme.

- Destruction des stocks de virus variolique. Les délégués ont décidé à l'unanimité de la destruction des derniers stocks de virus variolique conservé dans deux centres de recherche (Center for Diseases Control and Prevention à Atlanta (Etats-Unis) et Centre de recherche de l'Etat russe sur la Virologie et la Biotechnologie à Koltsovo (Fédération de Russie)). Cette décision parachève l'éradication totale et définitive de la variole.

- Stratégie pharmaceutique révisée. L'Assemblée a instamment prié les Etats membres « de réaffirmer leur volonté d'élaborer et d'appliquer des politiques pharmaceutiques nationales pour assurer un accès équitable aux médicaments essentiels, d'accroître leurs efforts pour promouvoir l'usage rationnel des médicaments en développant la formation des agents de santé et l'éducation du public, de renforcer les mécanismes réglementaires de surveillance et de contrôle de l'efficacité, de la qualité et de l'innocuité des médicaments, d'établir et de renforcer, si besoin est, les programmes de contrôle de l'innocuité et de l'efficacité des médicaments mis sur le marché, de combattre les pratiques de commercialisation de médicaments contraires à l'éthique et d'éliminer les dons inappropriés de médicaments $\gg{ }^{22}$

• Nutrition chez le nourrisson et le jeune enfant. L'Assemblée a souligné qu'il demeure indispensable de donner effet au Code international de commercialisation des substituts du lait maternel et aux résolutions pertinentes adoptées ultérieurement par l'Assemblée.

$\checkmark$ Programme commun des Nations Unies sur le VIH/SIDA. L'Assemblée a examiné la mise en œuvre de la stratégie mondiale de lutte contre le SIDA et les progrès du Programme commun des Nation Unies sur le VIH/SIDA (ONUSIDA), entré en vigueur le $1^{\mathrm{er}}$ janvier 1996.

๖ Lutte contre le tabagisme ${ }^{23}$. L'Assemblée a adopté deux résolutions. La première approuve le plan d'action pour le programme «Tabac ou Santé » de l'OMS pour la période 1996-2000. La seconde demande instamment à tous les Etats membres de mettre en œuvre progressivement des stratégies complètes de lutte antitabac et prie l'OMS d'entreprendre l'élaboration d'une convention-cadre consacrée à la lutte antitabac. Un tel instrument juridique contraignant, une première dans l'histoire de l'OMS, serait particulièrement important pour les pays en développement et les pays de l'Est, qui subissent de très fortes pressions de la part des industries du tabac.

\section{Situation financière}

Comme d'autres agences spécialisées des Nations Unies, l'OMS est confrontée à des difficultés financières extrêmement graves. Lors de la 49e Assemblée, le Directeur général a fait part de sa profonde préoccupation devant le niveau sans précédent des contributions non réglées par les Etats mémbres. Au 20 mai 1996,

\footnotetext{
${ }^{22}$ OMS, Communiqué de presse (WHA/1, 17 mai), « Ouverture de la 49e Assemblée mondiale de la santé ».

${ }^{23}$ Publication, par l'OMS, en 1996 du premier rapport complet sur la situation mondiale du tabagisme.
} 
28 Etats membres avaient perdu leur droit de vote à la suite du non-règlement de leurs contributions et sept autres risquent d'être touchés par cette mesure en mai 1997. Les seuls Etats-Unis doivent encore plus de 30 millions. Devant cette situation désastreuse, une coupure linéaire de 10\% sur le budget 1996-1997 (842 millions de dollars) a été décrétée et les postes vacants ne seront pas repourvus. Pour faire face à cette situation des économies substantielles devront être réalisées.

\section{Position de la Suisse}

Dans ses différentes interventions, la Suisse a notamment relevé que «si les efforts consentis ces quatre dernières années par l'OMS en matière de réformes sont prometteurs, le Rapport sur la santé dans le monde n'établit pas suffisamment de lien logique entre les changements institutionnels effectués et les nouveaux défis identifiés $"{ }^{24}$. Concernant la résolution sur le tabac, la Suisse a mentionné l'adoption, en automne 1995 par le Conseil fédéral, d'un plan d'action pour la lutte contre le tabagisme. Elle a également relevé l'importance d'un cadre législatif international pour soutenir et légitimer les actions de lutte contre le tabagisme. ${ }^{25}$ Enfin, la Suisse « se réjouit » de la création du programme ONUSIDA, qu'elle soutient financièrement. Cependant, elle relève la forte expérience acquise par l'OMS dans son programme de lutte contre le SIDA et souhaite que l'OMS puisse jouer un rôle essentiel dans le programme de l'ONUSIDA. Pour assurer une collaboration optimale, la Suisse juge «particulièrement important que le siège du programme ONUSIDA soit maintenu à Genève » ${ }^{26}$.

\section{$\square$ Contributions suisses aux programmes de l'OMS}

Les contributions financières de la Suisse comprennent d'une part les contributions ordinaires au budget de l'OMS versées par l'Office fédéral de la Santé publique de 4,9 millions de dollars, contributions qui ne sont pas comprises dans l'aide publique au développement (APD). Par ailleurs, la DDC a contribué, en 1996, pour un montant de 7 millions de francs à certains programmes spéciaux de l'OMS (ce montant est compris dans l'APD). La plupart des contributions extrabudgétaires couvrent les programmes déjà soutenus dans le passé, en tenant compte de la récente restructuration de l'OMS et de la création d'ONUSIDA. En 1996, la DDC a soutenu les programmes spéciaux et apparentés à l'OMS suivants (par ordre décroissant des contributions suisses): ONUSIDA (2,2 millions de francs), programme de santé de la famille et de la reproduction (1,7 million), programme de recherche sur les maladies tropicales ( 1 million), programme mondial de lutte contre la tuberculose (1 million), programme de développement de système de santé ( 0,35 million) et division de la promotion de la santé (0,35 million).

\section{SOURCES}

Office fédéral de la Santé publique et Direction pour la coopération et le développement (DDC).

Organisation mondiale de la santé, Rapport sur la santé dans le monde, 1996, OMS : Genève, 1996.

Neue Zürcher Zeitung, 28. Mai 1996; 23. Juli 1996.

\section{SITE INTERNET}

http ://www.who.ch/ Tous les communiqués de presse peuvent être obtenus sur Internet.

\footnotetext{
${ }^{24}$ Déclaration de la Délégation suisse lors de la 49e Assemblée mondiale de la Santé, Examen du Rapport sur la santé dans le monde, 1996.

${ }^{25}$ Intervention de la Délégation suisse lors de la 49e Assemblée mondiale de la Santé, Résolution WHA 48.10 « Tabac ou santé ".

${ }^{26}$ Intervention de la Délégation suisse lors de la 49e Assemblée mondiale de la Santé, Résolution WHA 42.33 « Stratégie mondiale de lutte contre le SIDA $»$.
} 


\subsection{LUTTE CONTRE LE SIDA}

En matière de lutte contre le SIDA, des organisations internationales se sont regroupées autour d'un nouveau programme ONUSIDA et la $11^{e}$ Conférence internationale sur cette maladie s'est tenue à Vancouver en juillet 1996.

\section{$\square$ Programme commun des Nations Unies sur le VIH/SIDA}

Le programme commun des Nations Unies sur le VIH/SIDA est établi à Genève depuis juillet 1996. Sous l'abréviation « ONUSIDA », le programme s'efforce d'améliorer et d'intensifier l'impact de l'action des Nations Unies dans la lutte contre le SIDA par la mise en commun des efforts, de l'expérience et des moyens de six organisations : UNICEF, le Programme des Nations Unies pour le développement, le Fonds des Nations Unies pour la population, l'UNESCO, l'OMS et la Banque mondiale. La Suisse finance à hauteur de 2,2 millions de francs le programme.

\section{$\square X I^{e}$ Conférence sur le Sida, Vancouver, 1996}

La XI ${ }^{\mathrm{e}}$ Conférence internationale sur le Sida a eu lieu au Canada, à Vancouver, du 7 au 12 juillet 1996. Plus de 15'000 délégués et quelque 2000 représentants des ONG et des médias internationaux, venus tant des pays en développement que des pays industrialisés, étaient présents. Depuis 1994, la Conférence se réunit chaque deux ans. Cette réunion a permis de discuter de problèmes et de solutions en rapport avec le VIH/SIDA et, pour les chercheurs et les stratèges aussi bien que pour tous ceux qui se montrent actifs à cet égard, d'envisager une action conjointe. Mises en commun, les expériences acquises partout où sévit l'épidémie permettent d'ériger des partenariats et ouvrent la voie à des mesures coordonnées et synergiques.

En plaçant la conférence sous le thème «Unis dans l'espoir »- qui a été aussi celui de la Journée mondiale SIDA 1996 - on a voulu souligner la nécessité de travailler ensemble pour freiner l'épidémie et en alléger les retombées. La Conférence a comporté quatre volets : recherche fondamentale; recherche et pratique cliniques; épidémiologie et santé publique; sciences sociales (recherche, politique et action). Trois sujets ont servi de fils conducteurs à chacun de ces volets : «Les femmes et le VIH », "Vivre avec le VIH », « Développement et VIH ».

SOURCE

Bulletin 46 de l'OFSP, 25 novembre 1996, « Vancouver 1996, Reflets de la XI ${ }^{\circ}$ Conférence internationale sur le Sida ».

\subsection{FONDS DES NATIONS UNIES POUR L'ENFANCE (UNICEF)}

L'UNICEF a célébré en 1996, le cinquantième anniversaire de sa création. Le "Fonds international des Nations Unies pour le secours de l' enfance » avait été fondé en 1946 pour répondre aux besoins des enfants après la deuxième guerre mondiale. En 1996, l'organisation a mené des activités dans les domaines de la santé, de l'éducation et des droits de l'enfant. L'UNICEF a co-organisé une importante conférence internationale sur l'exploitation sexuelle des enfants qui 
s'est tenue à Stockholm en août 1996. La Suisse participe aux activités de l'UNI$C E F$, elle est membre du Conseil d' administration et figure parmi les onze donateurs gouvernementaux les plus importants.

L'UNICEF est un organe spécial du système des Nations Unies, doté de son propre Conseil d'administration. Ce Conseil de 36 membres décide des politiques à suivre, examine les programmes et approuve le budget. Le secrétariat de l'UNICEF, dont le siège est à New York, conduit des programmes dans plus de 140 pays. L'UNICEF a également des bureaux à Sidney, Genève, Copenhague et Tokyo, ainsi que sept bureaux de coordination pour les activités régionales. En 1996, la Suisse a participé activement aux activités de l'UNICEF, d'une part par une contribution financière de plus de 17 millions de francs d'une part et d'autre part, en étant membre du Conseil d'administration, qui se réunit quatre fois par an à New York (trois séances du Conseil et une assemblée annuelle).

\section{$\square$ Cinquante ans au service de l'enfant}

L'UNICEF travaille en étroite collaboration avec des gouvernements, des ONG et d'autres organismes des Nations Unies pour identifier les besoins des enfants et pour créer des synergies entre les différents acteurs afin d'aider les pays à répondre à ces besoins. Plus de $80 \%$ du personnel de l'UNICEF travaille sur le terrain examinant les programmes et facilitant les contacts entre autorités gouvernementales et partenaires de développement. Ces activités principales sont centrées sur l'enfant et la femme, dans les domaines de la santé, de l'hygiène, de la nutrition, de l'éducation de base, des droits de l'enfant et de l'aide d'urgence. Chaque année, depuis 1993, l'UNICEF publie Le progrès des Nations qui rend compte de la situation des enfants dans le monde. Riche en données statistiques, cette publication comprend également des articles fouillés qui évaluent les succès ou les reculs dans certains domaines et tentent de dresser des stratégies d'action.

A l'occasion de son cinquantième anniversaire, l'UNICEF a publié un rapport $L a$ situation des enfants dans le monde 1996 qui commémore les cinq décennies de l'organisation au service des enfants. Et de rappeler, que durant cette période, chez les enfants de moins de cinq ans les taux de mortalité ont diminué d'environ $50 \%$ et le nombre de décès est passé de 25 millions à 12,5 millions. En à peine une décennie, du début des années 80 aux années 90 , la couverture vaccinale contre les six maladies infantiles les plus meurtrières est passée de $10 \%$ à plus de $80 \%$ sur l'ensemble de la planète.

Politiquement, des progrès majeurs ont été faits dans la priorité accordée aux enfants, officiellement du moins. En décembre 1996, 187 pays avaient ratifié la Convention relative aux droits de l'enfant, entrée en vigueur en 1990.

1997 Ratification de la convention des Nations-Unies relative aux droits de l'enfant, p. 110.

\section{$\checkmark$ Les enfants et la guerre}

De tout temps, des enfants ont été pris dans la guerre, mais les dernières avancées des armements et des techniques de guerre ont considérablement accru les dangers auxquels ils sont exposés. L'UNICEF estime qu'au cours des dix dernières années, les conflits ont fait, chez les enfants, environ :

$\checkmark$ deux millions de morts ; 
๑ quatre à cinq millions d'infirmes ;

๖ douze millions de sans logis ;

」 plus d'un million d'orphelins ou d'enfants séparés de leurs parents ;

」 environ dix millions de traumatisés psychologiquement.

Face à ce constat l'UNICEF a mis à l'ordre du jour de ses activités la situation des enfants dans la guerre et en a dressé un tableau exhaustif dans le rapport $L a$ situation des enfants dans le monde, 1996. En décembre 1995, l'UNICEF a proposé un agenda anti-guerre qui invite les Etats à prendre une dizaine de mesures pour limiter la tragédie frappant les enfants (brutalités, viols, tortures, mines antipersonnel, etc.).

\section{$\square$ Financement des activités de l'UNICEF}

En 1995, le montant total des dépenses de l'UNICEF s'est chiffré à 1023 millions de dollars, dont 913 millions $(89,2 \%)$ pour soutenir des programmes de coopération ou d'aide d'urgence, 99 millions $(9,6 \%)$ pour les frais d'administration, 11 millions pour l'amortissement. Les recettes de l'UNICEF se composent de contributions volontaires provenant de sources gouvernementales $(65 \%$ des ressources totales) et non gouvernementales $(35 \%)$. La Suisse figure au $11^{\mathrm{e}}$ rang des pays donateurs, avec un montant de 17 millions de francs en 1996, comme contribution annuelle ordinaire à l'UNICEF. La Suisse finance plusieurs projets spécifiques de coopération au développement et d'aide humanitaire conduits par l'UNICEF.

\section{Tableau no 14 \\ Contributions suisses à l'UNICEF}

(en mio de francs suisses)

\begin{tabular}{lrrr}
\hline & $\mathbf{1 9 9 4}$ & $\mathbf{1 9 9 5}$ & $\mathbf{1 9 9 6}$ \\
\hline Contribution annuelle ordinaire & 16.5 & 16.5 & 17 \\
\hline Contributions à des projets & 7.6 & 4.8 & d.n.d. \\
\hline Total & $\mathbf{2 4 . 1}$ & $\mathbf{2 1 . 3}$ & \\
\hline
\end{tabular}

d.n.d. données pas encore disponibles pour 1996.

Sources : $D D C$

\section{$\square$ Le Comité suisse pour l'UNICEF}

L'élément clé des activités menées par l'UNICEF dans les pays industrialisés sont ses 34 comités nationaux, organisations privées qui œuvrent avec l'UNICEF pour défendre la cause des enfants et récolter des fonds destinés aux activités des programmes. Grâce à des réseaux de bénévoles, les comités recueillent plus de $25 \%$ des fonds, principalement tirés de la vente de cartes de voeux. Le Comité suisse pour l'UNICEF se trouve à Zurich ${ }^{27}$. Ses activités sont, d'une part le travail d'information sur la situation des enfants dans le monde et d'autre part la collecte de fonds. En 1996, l'UNICEF suisse a notamment édité une brochure à l'attention des parents et des enseignants pour expliquer les points forts de la Convention des droits de l'enfant et a organisé deux colloques à Berne, l'un en

${ }^{27}$ Comité suisse pour l'UNICEF, Baumackerstrasse 24, 8050 Zurich. 
mars sur le thème Les enfants dans la guerre, l'autre en octobre sur les droits de l'enfant en Suisse. La collecte de fonds auprès du public suisse en 1995 a rapporté près de 26 millions de francs suisses ( 15 millions par du fundraising, 11 millions par la vente de produits), dont plus de 18 millions ont été reversés au siège central de l'UNICEF à New York. Enfin, Dimitri, le clown suisse, est devenu le premier ambassadeur de l'UNICEF suisse.

\section{SOURCES}

UNICEF, Rapport annuel, 1996.

Comité suisse pour l'UNICEF, Rapport annuel 1995-1996.

UNICEF, La situation des enfants dans le monde, 1996, 1996.

UNICEF, Le progrès des Nations, 1996, 1996.

SITE INTERNET

http ://www.unicef.org

\subsection{CONGRÈS MONDIAL CONTRE L'EXPLOITATION SEXUELLE DES ENFANTS À DES FINS COMMERCIALES}

Le premier Congrès mondial contre l'exploitation sexuelle commerciale des enfants s'est tenu à Stockholm du 27 au 31 août 1996. Ce Congrès a été organisé par quatre partenaires, la Suède pays hôte, l'UNICEF et deux réseaux d'organisations non gouvernementales End Child Prostitution in Asian Tourismus (ECPAT) et le groupe d'ONG pour la Convention relative aux droits de l'enfant. Une telle collaboration entre le secteur gouvernemental et non gouvernemental est originale. Elle a permis des débats plus directs et plus libres que lors d'autres conférences internationales convoquées exclusivement par les Nations Unies.

L'exploitation sexuelle des enfants est un phénomène pernicieux qui se développe à l'échelon mondial. Cette violence faite aux enfants, forme honteuse et contemporaine de l'esclavage, constitue l'une des violations les plus graves de leurs droits. Chaque jour des enfants sont exploités, piégés, vendus comme des objets sexuels. Certains sont enlevés et attirés dans des maisons de prostitution avec la promesse d'obtenir un emploi légitime. Il existe peu de données fiables sur le nombre d'enfants obligés de vendre leur corps. L'UNICEF estime à plus de deux millions le nombre d'enfants forcés de se livrer à la prostitution ou utilisés pour du matériel pornographique.

Près de 1300 participants de 125 pays ont assisté au Congrès, qui a réuni, non seulement des représentants des gouvernements et des ONG, mais également des magistrats, des policiers, des médecins, des parlementaires, des journalistes, l'industrie du tourisme et bien d'autres catégories socioprofessionnelles. Des enfants étaientprésents, acteurs essentiels dans ce processus. La délégation officielle suisse était composée de cinq membres des départements fédéraux des Affaires étrangères, de l'Intérieur et de Justice et police. Elle était menée par l'Ambassadeur Jean-Marc Boulgaris, directeur suppléant de la direction politique aux Affaires étrangères. Plusieurs organisations suisses ont également fait le voyage à Stockholm, dont la Communauté de travail contre la prostitution enfantine (Arge kipro), créée en février 1996 à Berne, à laquelle adhèrent des organisations comme Terre des Hommes Suisse, l'Association suisse de la protection de l'enfant ou encore le CIDE (Comité international pour la dignité de l'enfant). 


\section{LA LOI SUISSE DEVRA S'ADAPTER}

$L$ a loi suisse pénalisant l'exploitation et les abus sexuels envers les enfants doit être adaptée à l'internationalisation de ce genre de délits. Les spécialistes conviennent que la loi actuelle ne permet pas de pénaliser le tourisme sexuel, mais qu' elle pourrait être améliorée sur certains points. Le Conseil fédéral et le Parlement ont entamé le débat sur la question en 1993. Mais en mars 1994, le Conseil fédéral déclarait que la répression du tourisme sexuel restait à inscrire dans une problématique juridique plus large. Le 13 juin 1996, le Conseil national a néanmoins relancé le débat sur l'exploitation sexuelle des enfants, en approuvant une initiative parlementaire de Margrith von Felten. Le texte interdit la possession de matériel pornographique mettant en scène des enfants. Mais le Conseil national avait renvoyé à l'automne le débat sur la prolongation de cinq à dix ans du délai de prescription pour les abus sexuels commis sur des enfants. L'été 1996 a été marqué par des affaires de pédophilie de retentissement international ayant suscité une très grande émotion. Lors de la session d'automne 1996, sensibilisé par ces drames, le Conseil national a décidé à l'unanimité (157 voix sans opposition) de ramener le délai de prescription à dix ans pour les abus sexuels commis contre des enfants (le délai de prescription avait été raccourci à cinq ans en 1992). Lors de la session d'hiver le Conseil des Etats a à son tour approuvé l' initiative parlementaire $d u$ Conseil national par 31 voix sans opposition en $y$ ajoutant une disposition transitoire. $^{28}$

En outre, Arnold Koller a annoncé que son département travaillait à d'autres mesures pour tenir les auteurs de crimes sexuels graves à l'écart de la société.

Neuf thèmes de discussion étaient à l'ordre du jour : révision et mise en œuvre du droit, prévention et réhabilitation psychosociale, tourisme sexuel, l'exploiteur sexuel, santé, médias y compris Internet, pornographie, éducation et valeurs humaines. Ils ont donné lieu à neuf tables rondes et à une cinquantaine d'ateliers. La délégation suisse avait donné priorité à quatre groupes de travail : le tourisme sexuel, la réforme et la mise en œuvre du droit, la prévention et la réhabilitation psychosociale, enfin les médias et les valeurs humaines. La Convention des Nations Unies relative aux droits de l'enfant (1989), signée et ratifiée par 188 pays et dont le Parlement fédéral a approuvé la ratification en décembre 1996, institue une base juridique internationale, sur laquelle il est possible de s'appuyer en ce qui concerne l'exploitation sexuelle des enfants, plusieurs articles se référant à cette question.

Le Congrès a adopté à l'unanimité une Déclaration et un Programme d'action ${ }^{29}$ selon lesquels les Etats s'engagent à mobiliser leurs forces, à coordonner leurs efforts, à améliorer leur législation, à «criminaliser» davantage les activités pédophiles en étendant les clauses d'extraterritorialité (possibilité de poursuivre

${ }^{28}$ La disposition transitoire suivante a été ajoutée par le Conseil des Etats : « Art. 187, ch. 6 CP (nouveau), Art. 156, ch. 6 CPM (nouveau) : L'action pénale se prescrit également par dix ans, si le délai de prescription de l'infraction selon le chiffre 5 dans sa version du 21 juin 1991 n'est pas encore échu le... (date de l'entrée en matière de l'abrogation du chiffre 5 de l'art. 187).

${ }^{29}$ Les documents publiés lors du Congrès sont disponibles auprès de Défense des Enfants-International, case postale 88, 1211 Genève 20 ou sur Internet http ://www.childhub.ch/webpub/csechome/ 
des ressortissants ayant commis des actes sexuels illégaux à l'étranger), à développer des programmes afin de lutter contre l'exploitation sexuelle des enfants. Ils s'engagent également à établir chacun, d'ici l'an 2000, un plan national d'action à cette fin.

Les ONG se disent satisfaites des résultats du Congrès. Florence Bruce, directrice des programmes du Bureau international catholique de l'enfance (BICE) relève que le Congrès a rempli les objectifs fixés. «D'une part, il a replacé à l'ordre du jour des politiques nationales la question de la prostitution et de la pornographie enfantines, les gouvernements ayant tous accepté le plan d'action proposé. D'autre part, un maximum d'ONG et d'Etats se sont mis autour d'une table pour réfléchir sur la meilleure façon d'agir, chacun apportant ses expériences et ses spécificités. Enfin, la couverture médiatique a été excellente. ${ }^{30}$

\section{SOURCES}

Florence Bruce, Enfants et prostitution. Ne me laisser pas tomber, Genève : BICE, Genève, 1996.

Bulletin Terre des Hommes, $4^{\mathrm{e}}$ trimestre 1996, "Un congrès pas comme les autres ».

epd-Entwicklungspolitik, 18/96 (September), "Weltkongress gegen Kinderprostitution » und " Dokumentation ».

Basler Zeitung, 27. August 1996, « Prostitution von Kindern : Die Schweiz ist keine Insel ».

Le Courrier, 21 juillet 1996 " Il est grand temps de ratifier la convention des droits de l'enfant », 26 août 1996, « Les victimes se comptent par millions ", 30 août 1996 « Enfants martyrs ", 7 septembre 1996 « Les Etats ont trop longtemps ignoré l'exploitation sexuelle des gosses ».

Journal de Genève, 27 août 1996 « Le monde se mobilise contre la prostitution enfantine ".

Neue Zürcher Zeitung, 28. August 1996 « Gegen die sexuelle Ausbeutung von Kindern », 31. August 1996 " Alltäglichkeit der Pädophilie », 2. September 1996 « Das Drama sexuell missbrauchter Kinder » und « Aufruf zum Kampf gegen Sexhandel mit Kindern ", 26. September 1996 « Für eine Revision des Allgemein Teils des Strafgesetzbuches ".

Tages Anzeiger, 27. August 1996 « In Stockholm beginnt eine Konferenz über die sexuelle Ausbeutung von Kindern ", 31. August 1996 «Stockholm, positive Bilanz einer Schweizer NGO-Vertreterin ».

\section{SITE INTERNET}

http ://www.childhub.ch/webpub/csechome/

Le site du World Congress Against Commercial Sexuel Exploitation of Children offre des papiers d'informations sur les problématiques débattues lors du Congrès, ainsi que les communiqués de presse et les Déclarations adoptées.

\subsection{FAO - SOMMET MONDIAL POUR L'ALIMENTATION DANS LE MONDE 1996}

Le Sommet mondial de l'alimentation, qui s'est tenu à Rome au siège de l'Organisation des Nations Unies pour l'alimentation et l'agriculture (FAO) du 13 au 17 novembre 1996, a rassemblé près d' une centaine de Chefs d'Etat et de Gouvernement, plus de 3500 délégués, un millier de représentants des ONG et des milieux économiques, ainsi que 2000 journalistes. Le Sommet vise à renouveler, au plus haut niveau, l'engagement de supprimer la faim et la malnutrition et d'assurer de manière durable la sécurité alimentaire pour tous.

Lors de la Conférence mondiale de l'alimentation de 1974, les gouvernements ont examiné le problème de la production et de la consommation alimentaires à l'échelle planétaire et ont proclamé solennellement que « chaque homme, femme et enfant a le droit inaliénable d'être libéré de la faim et de la malnutrition afin de développer pleinement ses facultés mentales ${ }^{31}$. Or, vingt ans plus tard, l'objectif que s'est fixé la Conférence (l'élimination « en une décennie » de la faim, de l'insécurité alimentaire et de la malnutrition) n'a pas été atteint.

\footnotetext{
${ }^{30}$ Le Courrier, 7 septembre 1996, « Les Etats ont trop longtemps ignoré l'exploitation sexuelle des gosses ».

${ }^{31}$ Sommet mondial de l'alimentation, Informations générales, site Internet http ://www.fao.org
} 
A la $27^{e}$ session de la Conférence de la FAO, qui s'est tenue au niveau ministériel en novembre 1993, les Etats membres ont exprimé «leur vive préoccupation » face à la situation actuelle et aux perspectives pour l'avenir proche et ont souligné que « les grands problèmes d'alimentation, de nutrition et de durabilité à l'échelle mondiale appelaient des mesures immédiates aux niveaux international et national ». Sur proposition du Directeur général de la FAO, lors de sa 28 e session en octobre 1995, la Conférence de la FAO qui compte 175 Etats membres, a demandé la convocation, à Rome en novembre 1996, d'un Sommet mondial de l'alimentation au niveau des Chefs d'Etat et de Gouvernement. Lors de l'annonce du Sommet, le Directeur général de la FAO, Jacques Diouf a précisé qu'il ne s'agissait pas d'un Sommet d'annonce de contributions ou de créer des dispositifs financiers, des organismes ou des rouages administratifs nouveaux. ${ }^{32}$ Jacques Diouf a invité les participants au Sommet à prendre une série engagements visant l'éradication de la faim et la promotion de la sécurité alimentaire universelle en agissant sur plusieurs fronts.

De manière expresse le Directeur général a souhaité que les coûts de base entraînés par la convocation du Sommet soient minimaux et imputés sur le programme ordinaire de la FAO. Les participants ont été encouragés à ne pas organiser de réceptions ou de dîners et à faire don des sommes ainsi économisées pour financer le Programme spécial de sécurité alimentaire à l'appui des pays à faible revenu et à déficit vivrier.

\section{$\square$ Situation alimentaire au niveau mondial}

La situation alimentaire mondiale s'est nettement améliorée ces vingt-cinq dernières années. En 1970, en effet, quelque 950 millions de personnes souffraient de faim et de sous-alimentation. Aujourd'hui on estime leur nombre à 800 millions. Dans le même laps de temps, la population mondiale s'est accrue de 2,5 milliards pour atteindre 5,7 milliards d'habitants. Cette amélioration de la situation nutritionnelle mérite d'être relevée. Mais à l'aube du XXI' siècle, l'humanité est confrontée à un nouveau dilemme : la population mondiale croît toujours, tandis que les réserves en ressources naturelles se font toujours plus précaires. ${ }^{33}$ Dans les pays en développement, plus de 800 millions de personnes connaissent aujourd'hui une sous-alimentation chronique, dont environ 200 millions d'enfants de moins de cinq ans qui souffrent de carences caloriques et protéiques chroniques. Si des mesures énergiques ne sont pas prises, le nombre de personnes sous-alimentées pourrait encore atteindre 700 millions en l'an 2010 , dont plus de 260 millions en Afrique subsaharienne.

A l'heure actuelle, les nations classées dans la catégorie des pays à faible revenu et à déficit vivrier (PFRDV) sont au nombre de $82: 41$ en Afrique subsaharienne, 19 en Asie et dans le Pacifique, 9 en Europe et dans la Communauté des Etats indépendants, 7 en Amérique latine et dans les Caraïbes et 6 au Proche-Orient et en Afrique du Nord. L'augmentation des prix sur le marché international des céréales a de graves conséquences pour ces pays, qui doivent importer des céréales afin de couvrir les besoins alimentaires de leur population. Parallèle-

${ }^{32}$ Communiqué de presse de la FAO, PR 96.3, « Annonce du Directeur général de la FAO du Sommet mondial de l'alimentation », novembre 1996, Rome.

33 " L'alimentation au XXI" siècle - Politique de la FAO pour lutter contre la faim - Position de la Suisse », Anton Kohler in Annuaire Suisse-Tiers Monde 1996, IUED, 1996, p. 271. 
ment, l'ensemble de l'aide bilatérale et multilatérale accordée à l'agriculture des pays en développement est en régression : entre 1982 et 1992, les montants versés à ce titre sont en effet tombés de 10 milliards à 7,2 milliards de dollars US (en dollars constants 1985). Qui plus est, les ressources halieutiques sont surexploitées, la déforestation s'accélère et la superficie arable disponible par habitant, actuellement de 0,25 hectare, est en diminution.

D'après les estimations les plus récentes, la population mondiale passera de 5,7 milliards à 8,7 milliards de personnes d'ici l'an 2030. A mesure que la population augmente, la disponibilité en terre arable par habitant diminue, d'où la nécessité d'augmenter encore la production agricole et d'exploiter par conséquent toujours davantage des ressources naturelles qui sont loin d'être inépuisables. Si rien n'est fait pour inverser cette tendance, le nombre de personnes souffrant de sous-alimentation chronique pourrait ne pas diminuer en deçà de 730 millions d'ici l'an 2010, dont plus de 300 millions en Afrique subsaharienne.

\section{$\square$ Déclaration, Plan d'action et documents techniques}

Lors du Sommet mondial de l'alimentation les Chefs d'Etat et de Gouvernement ont adopté une Déclaration politique et un Plan d'action pour parvenir à la sécurité alimentaire. Un comité (Comité de la sécurité alimentaire mondiale - CSA) a été chargé des travaux préparatoires et de la rédaction des documents officiels. « Nous estimons intolérable que plus de 800 millions de personnes dans le monde et, plus particulièrement dans les pays en développement, n'aient pas de quoi satisfaire leurs besoins nutritionnels les plus élémentaires. Cette situation est inacceptable » affirme la Déclaration. Et de souligner "l'urgente nécessité d'agir dès aujourd'hui pour nous acquitter de nos responsabilités vis-à-vis des générations actuelles et futures en matière de sécurité alimentaire, tâche complexe qui incombe d'abord à chaque gouvernement ".

Le Plan d'action énonce sept engagements, mesures concrètes et pratiques afin d'assurer :

- des conditions économiques, sociales et politiques visant l'éradication de la pauvreté et le maintien de la paix, conditions indispensables à la sécurité alimentaire ;

- l'accès de tous à une alimentation suffisante, adéquate du point de vue nutritionnel et salubre ;

口 une production agricole, halieutique et forestière durable, permettant d'assurer un approvisionnement alimentaire adéquat et fiable au niveau des ménages ainsi qu'aux échelons national et mondial, tout en considérant le caractère multifonctionnel de l'agriculture ;

- que les politiques concernant le commerce des denrées alimentaires et agricole contribuent à renforcer la sécurité alimentaire pour tous grâce à un système commercial mondial à la fois juste et axé sur le marché ;

口 des secours d'urgence disponibles en temps utile et là où ils sont nécessaires ;

口 une allocation optimale de l'investissement public et privé dans l'agriculture et le développement rural.

Le dernier point consiste en l'engagement d'exécuter le plan d'action, d'assurer son contrôle et son suivi aux niveaux national et international. Chaque Etat membre déterminera, en toute indépendance, les moyens pour atteindre les objectifs fixés dans le Plan d'action. 
Les délibérations du Sommet mondial de l'alimentation devaient reposer sur une perception correcte des nombreuses dimensions de la sécurité alimentaire. Une série de quinze documents ont permis une analyse approfondie des événements passés, de la situation actuelle et des tendances futures. L'élaboration des documents techniques de base a été une des activités de la préparation du Sommet dans laquelle les principaux partenaires de la FAO, tels que la Banque mondiale, les banques régionales de développement, le FIDA et le PAM, ont été impliqués. La collaboration des principales agences des Nations Unies ainsi que les commentaires des ONG et du secteur privé sur les documents offrent une analyse scientifique objective sur la problématique de l'alimentation dans le monde. ${ }^{34}$

\section{$\square$ Rôle des $O N G$}

Lors du processus préparatoire du Sommet, la FAO a vivement encouragé les ONG à participer aux discussions de la Conférence. Leur participation a été envisagée comme suit : au niveau national, les ONG ont été invitées à prendre contact avec les secrétariats nationaux en charge de la préparation du Sommet ; à l'échelle régionale, cinq conférences régionales ${ }^{35}$ ont été organisées en 1996, qui ont permis des observations aussi bien sur le projet de Déclaration de politique générale et de Plan d'action que sur les documents d'analyse sur la situation de la sécurité alimentaire dans chaque région ; au niveau mondial, d'une part en participant à la consultation FAO/ONG de trois jours en septembre 1996 afin de coordonner les propositions d'amendements pour les textes officiels, d'autre part en prenant part au Forum des ONG qui s'est tenu, parallèlement au Sommet officiel, du 11 au 17 novembre 1996 à Rome. Les points clés présentés au Comité de la sécurité alimentaire mondiale (CSA) par les ONG ont concerné principalement un commerce plus juste, la reconnaissance de l'accès à la nourriture comme un droit de l'homme et la collaboration entre les gouvernements, les organisations internationales et la société civile.

La libéralisation progressive du commerce mondial résultant des accords de l'OMC modifie les règles du jeu des marchés agricoles. Le démantèlement des barrières commerciales ouvre aux pays en développement exportateurs et compétitifs de nouveaux débouchés dans l'hémisphère Nord. La menace d'une aggravation de la situation en matière de disponibilités vivrières pèse en revanche sur d'autres régions, notamment sur les pays africains les plus pauvres, en raison de l'augmentation des prix à l'importation d'aliments de première nécessité. Fortes de ce constat, les ONG ont regretté que cet impact négatif ait été passé sous silence dans les documents finaux du Sommet.

Dans leur Déclaration finale au Comité de la sécurité alimentaire mondiale, les ONG ont réitéré l'importance qu'elles attachent à la reconnaissance par les gouvernements du « droit de l'homme à la nourriture comme le plus fondamental des droits de l'homme ». Elles ont, par ailleurs, insisté sur leur désir de voir ce « droit à la nourriture traduit en termes juridiquement contraignants, sous forme d'une convention internationale avec l'interdiction d'utiliser l'alimentation, mais aussi la faim, comme une arme politique, exigeant en particulier, la fin de tous les

\footnotetext{
${ }^{34} \mathrm{La}$ Déclaration politique, le Plan d'action et les documents techniques sont disponibles sur Internet (site de la FAO : http ://www.fao.org.) ou auprès du secrétariat genevois de la FAO, av. de la Paix 8-14, 1202 Genève.

${ }^{35}$ Les réunions régionales en prévision du Sommet ont eu lieu selon le rythme habituel des réunions de la FAO. Elles ne s'apparentent pas aux PreCom qui ont précédé d'autres sommets mondiaux.
} 
embargos ». En outre et parallèlement à la rédaction d'une convention sur le " Droit à la nourriture ", un code de conduite à l'intention des gouvernements et des multinationales devraient être rédigé, qui définirait comment garantir un tel droit. Enfin, les ONG se sont opposée au processus de privatisation des ressources génétiques par un petit nombre d'entreprises transnationales et revendiquent les droits d'usage des paysans et des communautés indigènes.

\section{$\square$ Position de la Suisse}

En vue du Sommet mondial de l'alimentation, la Direction du développement et de la coopération (DDC) a présenté sa contribution à la sécurité alimentaire mondiale $^{36}$. Pour la Coopération suisse au développement « la sécurité alimentaire doit avant tout être assurée par le renforcement du secteur agricole dans l'hémisphère Sud. Une économie agricole bien organisée débouche sur la création d'emplois et contribue de manière substantielle à la préservation de l'environnement. Elle stimule la croissance économique et joue un rôle déterminant dans la lutte contre la pauvreté, dans le sens où l'accès à la nourriture est facilité. La culture ne doit toutefois plus être intensifiée au détriment de l'environnement ou des générations futures. Il s'agit au contraire d'améliorer considérablement la productivité grâce à une exploitation durable des ressources naturelles. » Dans sa contribution, la DDC insiste également sur le rôle que peut et doit jouer le commerce international : " un commerce plus juste contribuerait également à lutter contre la pauvreté et donc à assurer la sécurité alimentaire dans l'hémisphère Sud. La chute du prix de certains produits agricoles de base et des matières premières provenant des pays en développement ainsi que les restrictions douanières frappant les importations de biens manufacturés dans les pays du Tiers-Monde entravent le développement de ces régions et ont contribué à l'endettement de nombreux pays d'Afrique et d'Amérique latine. "

La délégation suisse était conduite par le président de la Confédération Jean-Pascal Delamuraz. En outre, elle comprenait Rudolph Horber, vice-directeur de l'Office fédéral de l'agriculture, Jean-François Giovannini, directeur suppléant de la DDC, Anton Kohler, chef du secrétariat suisse de la FAO et d'autres fonctionnaires du Département des affaires étrangères, d'un parlementaire (Paul Günter) et de représentants des organisations de développement, des milieux économiques et scientifiques ${ }^{37}$. Seule la Suisse avait invité des représentants d'ONG à faire partie de la délégation officielle.

Le Conseiller fédéral Jean-Pascal Delamuraz a pris part au Sommet le samedi 16 novembre 1996 et a présenté lors d'une allocution les quatre priorités de la Suisse pour arriver à la sécurité alimentaire mondiale :

๖ la nécessité d'une "good governance », c'est-à-dire une bonne gestion des affaires publiques en créant les conditions nécessaires sur les plans politique, institutionnel, économique et social et par une réforme de l'économie de marché prévoyant des mesures d'accompagnement social et écologique ;

」 une bonne politique agricole visant entre autres à stopper l'exode rural et encourager le développement des espaces ruraux, en particulier dans les régions marginales ;

\footnotetext{
${ }^{36}$ Cette position a été présentée lors d'une conférence de presse le 7 octobre 1996 à Genève et le 8 octobre 1996 à Berne Le dossier de presse, comprenant une quinzaine de fiches techniques très bien documentées, est disponible à la DDC.

${ }^{37}$ Dr. H.R.Herren, Lauréat du Prix mondial de l'Alimentation en 1995.
} 
a des méthodes de production durable (par une utilisation appropriée des ressources et une régénération des terres et par l'introduction du critère de durabilité dans les règles commerciales) ;

- la participation des personnes concernées (par un processus de développement depuis le bas - formation, vulgarisation et travail - et par une participation des hommes et des femmes sur le même pied d'égalité).

Le conseiller fédéral a également plaidé pour un renforcement des synergies entre les Etats, les ONG, les organisations internationales et les différents acteurs dans leur combat contre la faim. Il s'est aussi engagé à ce que la Suisse participe activement dans la mise en œuvre du plan d'action et du suivi.

\section{$\square$ Position des ONG suisses}

Les ONG suisses ont participé activement au processus de préparation du Sommet en faisant part de leurs commentaires et suggestions sur la Déclaration et le plan d'action à la délégation suisse lors d'une séance consultative qui s'est tenue en juin 1996 à Berne. D'autre part, elles ont rédigé une Déclaration commune publiée dans un petit journal ${ }^{38}$ qui a été diffusé à plus de 67’000 exemplaires. Les ONG demandent notamment que les programmes contre la faim tiennent compte de l'utilisation des ressources et de la surconsommation des pays industrialisés. Elles insistent sur le développement des zones rurales, sur la valorisation de la contribution des femmes. Enfin, elles plaident pour une économie de marché reposant sur des conditions d'échange équitable. Deux représentantes des ONG suisses ont été invitées dans la délégation officielle (Déclaration de Berne et Communauté de travail).

1996 L'alimentation au XXI ${ }^{\mathrm{e}}$ siècle - Politique de la FAO pour lutter contre la faim - Position de la Suisse, pp. 271-287.

\footnotetext{
SOURCES

FAO, Déclaration de Rome sur la sécurité alimentaire mondiale et Plan d'action du Sommet mondial de l'alimentation, FAO, nov. 1996, WFS 96/3.

FAO, Synthèse des documents d'information technique pour le Sommet mondial de l'alimentation, FAO, sept. 1996. Secrétariat suisse de la FAO/OFAG, Communiqué de presse, " Sommet mondial de l'alimentation à Rome 1996 " Communauté de travail, Rapports et communiqués de presse en relation avec le Sommet mondial de l'alimentation, 1996. Produire mieux pour tous, Journal du Forum romand à l'occasion du Sommet mondial de l'alimentation. Septembre 1996. Welternährungs-Zeitung, NRO-Rat für Uno-Belange, Herbst 1996.

Alternatives Economiques, octobre 1996, "Le défi alimentaire ", Dossier spécial.

Solagral, mai-juin 1996, « Agriculture et environnement ».

Le Courrier, 11 novembre 1996 «La nourriture constitue un droit fondamental pour l'humanité », 13 novembre 1996 , «La faim restera, hélas, un scandale », 18 novembre 1996 « Le Sommet de Rome s'achève sur un nouveau plan d'action », 25 janvier 1997 « Il n'y aura pas d'argent pour la sécurité alimentaire au Sud ».

Journal de Genève, 13 novembre 1996 «En finir avec la faim ?".

Neue Zürcher Zeitung, 31. Oktober 1996 « Die Bekämpfung des Hungers hat Vorrang », 1. November 1996 « Sichere Ernährung in globaler Wirtschaft ? ", 8. November 1996 « Endspurt vor dem Welternährungsgipfel ».
}

\section{SITE INTERNET}

On trouve sur le Web les principaux documents du Sommet mondial de l'alimentation.

http ://www.fao.org.wfs.aaastart.htm

Site de la FAO : http ://www.fao.org

${ }^{38}$ Produire mieux pour tous, Journal du Forum romand à l'occasion du Sommet mondial de l'alimentation. Automne 1996. Tirage de 37' 500 exemplaires pour la version française. Disponible auprès de la Déclaration de Berne, C.P. 212, 1000 Lausanne 9. Welternährungs-Zeitung, Herbst 1996. Tirage 30’000 exemplaires. Erklärung von Bern, Postfach, 8031 Zurich. 